Florida International University FIU Digital Commons

FIU Electronic Theses and Dissertations

University Graduate School

2-18-2016

\title{
Advanced Electrode Materials by Electrostatic Spray Deposition for Li-ion Batteries
}

Chunhui Chen

Florida International University, cchen012@fiu.edu

DOI: 10.25148 /etd.FIDC000789

Follow this and additional works at: https:// digitalcommons.fiu.edu/etd

Part of the Nanoscience and Nanotechnology Commons, and the Other Materials Science and Engineering Commons

\section{Recommended Citation}

Chen, Chunhui, "Advanced Electrode Materials by Electrostatic Spray Deposition for Li-ion Batteries" (2016). FIU Electronic Theses and Dissertations. 2532.

https://digitalcommons.fiu.edu/etd/2532

This work is brought to you for free and open access by the University Graduate School at FIU Digital Commons. It has been accepted for inclusion in FIU Electronic Theses and Dissertations by an authorized administrator of FIU Digital Commons. For more information, please contact dcc@fiu.edu. 


\section{FLORIDA INTERNATIONAL UNIVERSITY}

Miami, Florida

\section{ADVANCED ELECTRODE MATERIALS}

BY ELECTROSTATIC SPRAY DEPOSITION FOR LI-ION BATTERIES

A dissertation submitted in partial fulfillment of the

requirements for the degree of

DOCTOR OF PHILOSOPHY

in

MATERIALS SCIENCE AND ENGINEERING

by

Chunhui Chen

2016 
To: Interim Dean Ranu Jung

College of Engineering and Computing

This dissertation, written by Chunhui Chen, and entitled Advanced Electrode Materials by Electrostatic Spray Deposition for Li-ion Batteries, having been approved in respect to style and intellectual content, is referred to you for judgment.

We have read this dissertation and recommend that it be approved.

$\begin{array}{r}\hline \text { Norman D. H. Munroe } \\ \hline \text { Bilal El-Zahab } \\ \hline \text { Wenzhi Li } \\ \hline \text { Chunlei Wang, Major Professor }\end{array}$

Date of Defense: February 18, 2016

The dissertation of Chunhui Chen is approved.

Interim Dean Ranu Jung College of Engineering and Computing

Andrés G. Gil

Vice President for Research and Economic Development and Dean of the University Graduate School

Florida International University, 2016 
(C) Copyright 2016 by Chunhui Chen

All rights reserved. 


\section{DEDICATION}

I dedicate this dissertation to my loving parents and wife. Without their love, support, and patience, it would have been impossible to complete this research. 


\section{ACKNOWLEDGMENTS}

I would like to express my deepest appreciation to my advisor, Dr. Chunlei Wang, for her guidance, vision and support throughout the course of my $\mathrm{PhD}$ research. I appreciate her patience, understanding, inspiration and invaluable encouragement which help me to overcome lots of obstructions during my study. I also cordially appreciate her effort on reviewing my research works and providing constructive comments to improve the quality of my research.

I am grateful to all the members of my dissertation committee, Dr. Norman D.H. Munroe, Dr. Nezih Pala, Dr. Bilal El-Zahab and Dr. Wenzhi Li for their willingness to serve on my dissertation committee and for their invaluable support and encouragement. I would also like to thank Dr. Cesar Levy for his generous support and encouragement during my study.

I sincerely thank my past and present research group members: Dr. Wei Chen, Dr. Xifei Li, Dr. Yan Yu, Dr. Varun Penmatsa, Dr. Abirami Dhanabalan, Dr. Majid Beidaghi, Dr. Yin Song, Dr. Jun Wu, Dr. Jujun Yuan, Dr. Jianwen Yang, Dr. Xianke Zhang, Tae Kwon Kim, Kevin Bechtold, Richa Agrawal, Yong Hao, Wladimir Valdenegro, Michael Page, Ali Henriques and Adelowo Dotun.

This work would not have been possible without the excellent facilities provided at Advanced Materials Engineering Research Institute (AMERI) and The Center for the Study of Matter at Extreme Conditions (CeSMEC) at FIU. I also would like to appreciate all the

collaborators, Dr. Yanzhang Ma (TTU), Dr. Donald Gardner (Intel) and Dr. Sylvia Daunert (UM) for their strong support and valuable suggestions. 
I acknowledge the University Graduate School at FIU for supporting me through Dissertation Evidence Acquisition (DEA) and Dissertation Year Fellowship (DYF) awards. I also appreciate the funding from NSF, ACS and DOD to support my PhD program.

I am grateful to my parents and in-laws for their endless support and love. Finally, I would like to thank my loving wife, Feifei $\mathrm{Xu}$, for her understanding and support. She gave me strength, dedication, and encouragement especially during my low points. I also wish to thank her for taking good care of our children, Rachel, Jessica and Justin, and the whole family, which make me be able to spend all my effort and focus on this study. 


\title{
ABSTRACT OF THE DISSERTATION \\ ADVANCED ELECTRODE MATERIALS BY ELECTROSTATIC SPRAY \\ DEPOSITION FOR LI-ION BATTERIES
}

\author{
by
}

Chunhui Chen

Florida International University, 2016

Miami, Florida

\section{Professor Chunlei Wang, Major Professor}

Recent development in portable electronics and electric vehicles have increased the demand for high performance lithium ion batteries. However, it is still challenging to produce high energy and high power lithium ion batteries. The major objective of this research is to fabricate advanced electrode materials with enhanced power density and energy density. Porous $\mathrm{Li}_{4} \mathrm{Ti}_{5} \mathrm{O}_{12}$ (LTO) and its nanocomposites (with $\mathrm{Si}$ and reduced graphene oxide (rGO)) synthesized by electrostatic spray deposition (ESD) technique were mainly studied and promising electrochemical performance was achieved.

In chapter 3, porous LTO thin film electrode was synthesized by ESD to solve the low energy density and low power density issues by providing good ionic and electronic conductivities. Electrochemical test results showed that it had a large specific capacity of $357 \mathrm{mAh} \mathrm{g}^{-1}$ at $0.15 \mathrm{~A} \mathrm{~g}^{-1}$, which was even higher than its theoretical capacity. It also exhibited very high rate capability of $98 \mathrm{mAh} \mathrm{g}^{-1}$ at $6 \mathrm{~A} \mathrm{~g}^{-1}$. The improved electrochemical performance was due to the advantage of ESD generated porous structures. In order to further enhance the power density of LTO, ESD derived LTO/rGO composite electrodes were studied in chapter 4 . In chapter 5, high energy density component Si was introduced 
into LTO composite. The synergistic effect between commercial LTO and Si powder was studied. Then, ESD derived LTO/Si/rGO composite was prepared and evaluated. At 0.15 $\mathrm{A} \mathrm{g}^{-1}$, a stable capacity of $624 \mathrm{mAh} \mathrm{g}^{-1}$ was observed, which was much higher than the capacities of LTO and LTO/rGO electrodes. In addition, effect of activation process on electrochemical performance of carbon nanofibers (ACNFs) and feasibility of ion intercalation into 2D MMT montmorillonite clay (MMT) were studied and discussed in chapter 6.

In summary, we have successfully synthesized various LTO based electrodes by ESD. Both high energy and high power density were achieved as compared to commercial LTO electrode. Through electrochemical characterization and charge storage distribution analysis, origins of the high rate capability were proposed. This work demonstrates ESD as a powerful tool for fabricating high performance porous structures and nanocomposite electrode materials. 


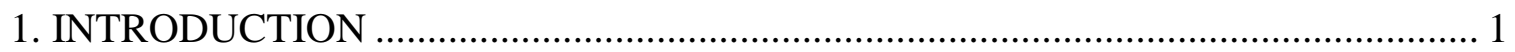

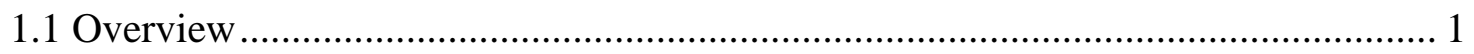

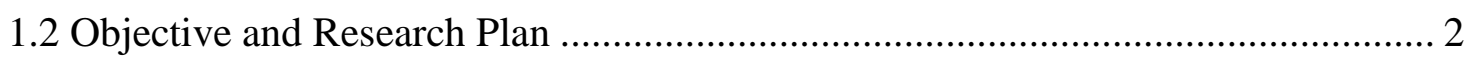

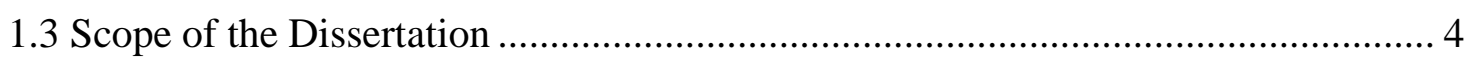

2. BACKGROUND AND LITERATURE REVIEW ………………........................ 5

2.1 Fundamental Aspects of Lithium-ion Batteries ...................................................... 6

2.2 Electrode Materials for Anodes .................................................................... 8

2.2.1 High Capacity Anode Material: Si.............................................................. 8

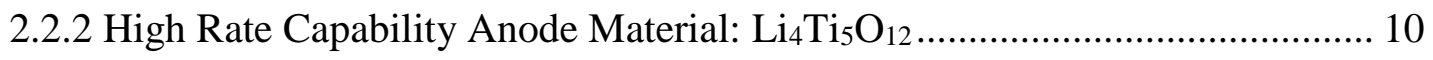

2.3 Electrostatic Spray Deposition Technique .......................................................... 16

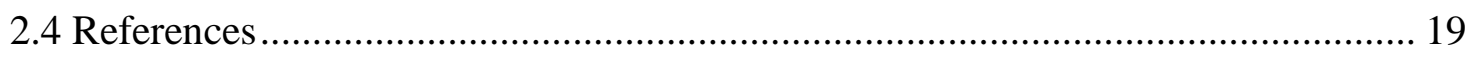

3. FABRICATION AND CHARACTERIZATION OF POROUS LTO THIN FILM

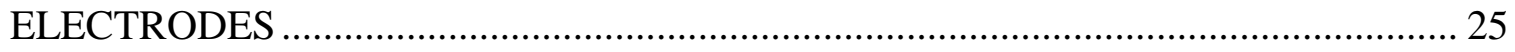

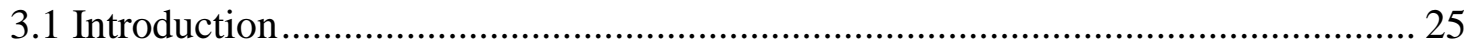

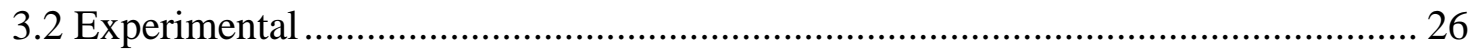

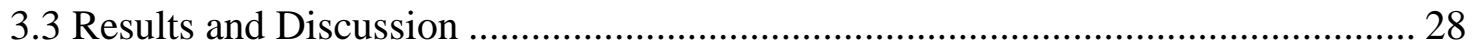

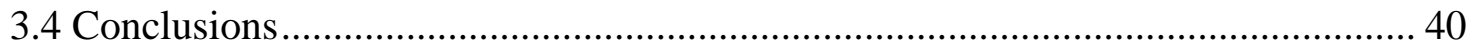

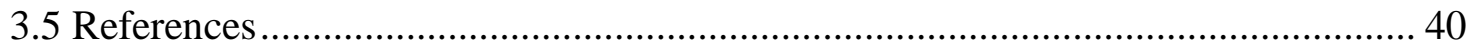

4. FABRICATION AND CHARACTERIZATION OF LTO/RGO COMPOSITE

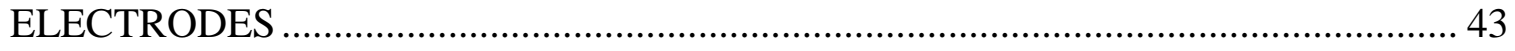

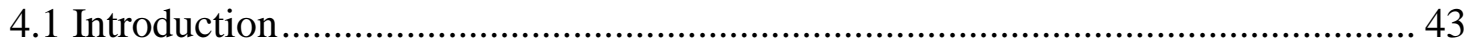

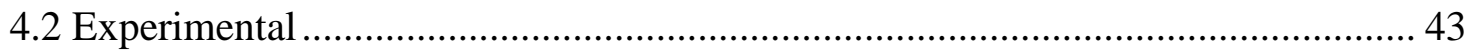

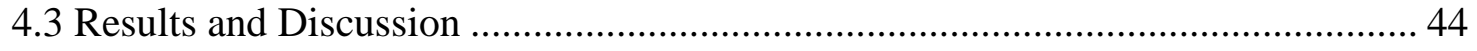

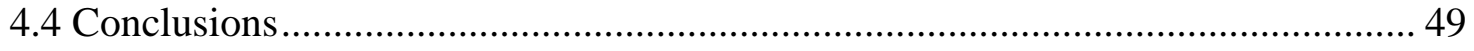

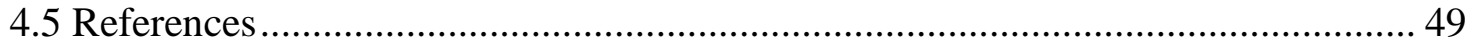

5. FABRICATION AND CHARACTERIZATION OF LTO/SILICON/RGO

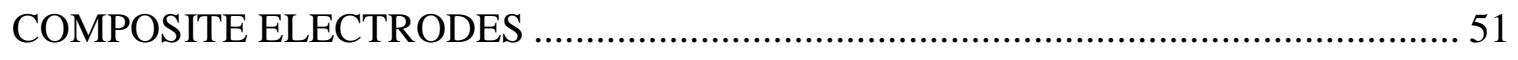

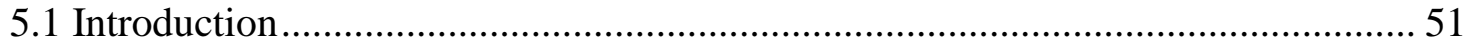




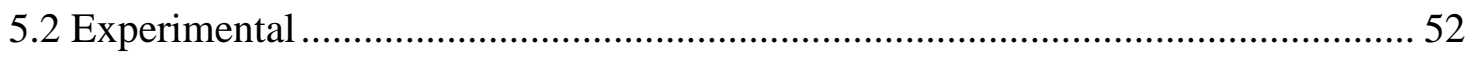

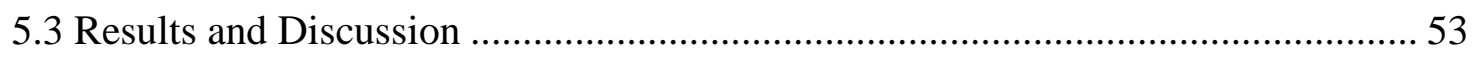

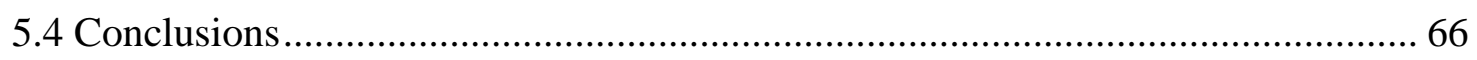

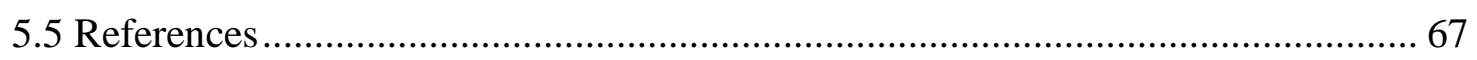

6. FABRICATION AND CHARACTERIZATION OF OTHER ELECTRODE

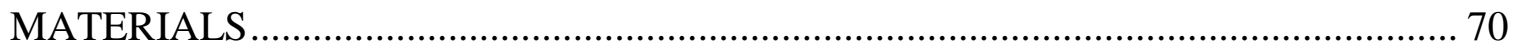

6.1 Activated Carbon Nanofiber Electrodes ………………........................................ 70

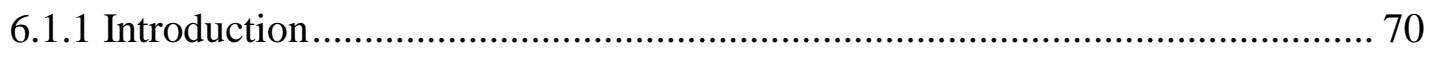

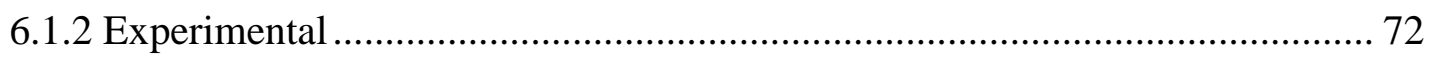

6.1.3 Results and Discussion ........................................................................ 73

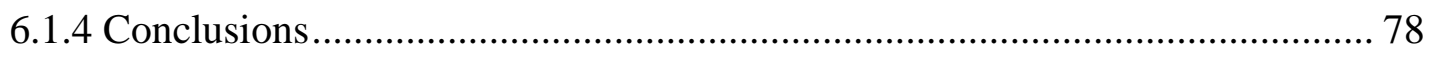

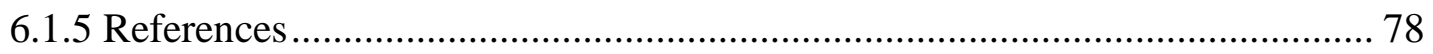

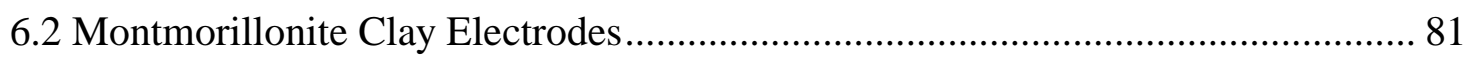

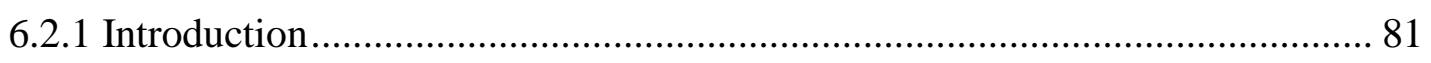

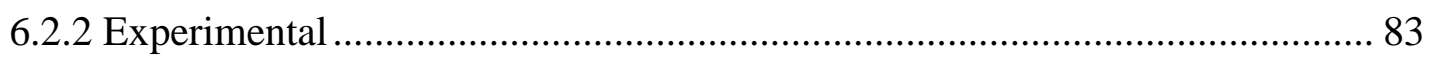

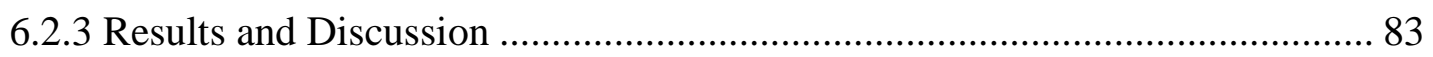

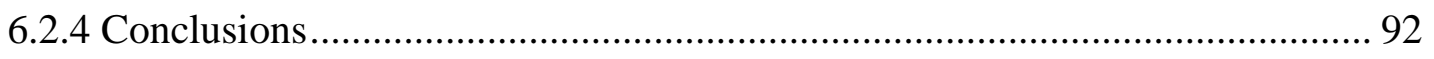

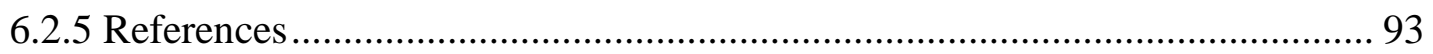

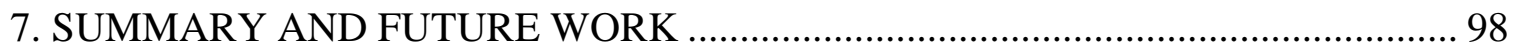

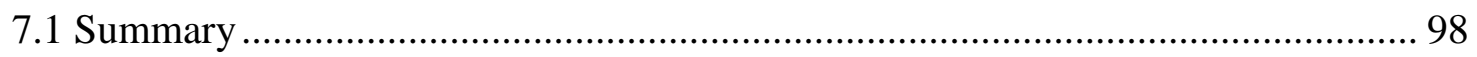

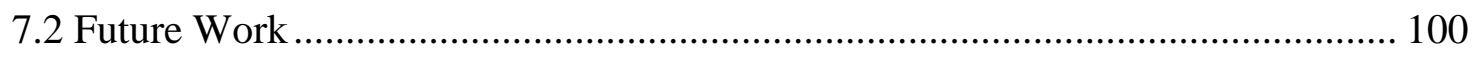

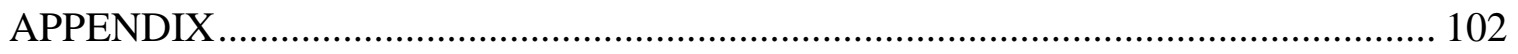

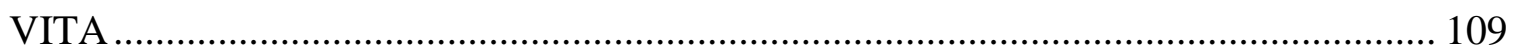




\section{LIST OF TABLES}

$\begin{array}{lll}\text { TABLE } & \text { PAGE }\end{array}$

Table 2. 1 Advantages of Li-ion batteries compared to other commonly used battery

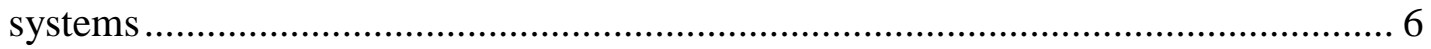

Table 2. 2 Advantages and disadvantages of spinel-LTO as anode. ............................. 11

Table 2. 3 Merits and shortcomings of various LTO synthesis methods......................... 13

Table 5. 1 Summary of sample compositions in LTO/Si composites........................... 53

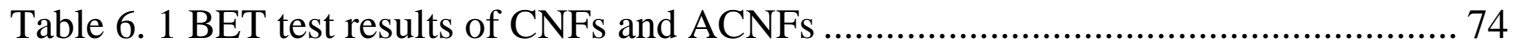

Table 6. 2 Summary of FTIR peak identification of MMT clay. ................................ 86

Table A 1 Summary of relationships between current and scan rate of various reaction

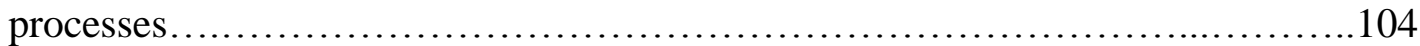




\section{LIST OF FIGURES}

FIGURE

PAGE

Figure 1.1 Flow chart of the research plan. .......................................................... 3

Figure 2. 1 Ragone plot of various electrical energy storage devices ........................... 5

Figure 2. 2 Schematic drawing of a typical lithium-ion battery …............................. 7

Figure 2. 3 (a) Schematic drawing and (b) photo image of ESD experimental set-up.

(c) Schematic drawing of film formation process and (d) zoomed in photo image of corn-type spray

Figure 3. 1 (a) XRD pattern of ESD-LTO after annealing at $750{ }^{\circ} \mathrm{C}$. (b) Nitrogen adsorption-desorption isotherm of ESD-LTO powder. (c) SEM Images (insert: at higher magnification) and (d) TEM images (insert: SAED pattern) of ESD-LTO after annealing at $750{ }^{\circ} \mathrm{C}$.

Figure 3.2 (a) CV curves of ESD-LTO electrode in the voltage window of 0.02-3 V at $0.2 \mathrm{mV} \mathrm{s}^{-1}$. (b) The $5^{\text {th }}$ cycle of $\mathrm{CV}$ curves at various scan rates ranging from 0.1 to $0.5 \mathrm{mV} \mathrm{s}^{-1}$. (c) The relationship between anodic/cathodic peak currents and scan rates in $\mathrm{CV}$ curves at the scan rates between $0.1-0.5 \mathrm{mV} \mathrm{s}^{-1}$. (d) Calculated capacitive charge storage contribution at $0.5 \mathrm{mV} \mathrm{s}^{-1}$

Figure 3. 3 (a) Cyclability and rate capability of ESD-LTO electrode. (b) Chargedischarge curves of the $1^{\text {st }}, 2^{\text {nd }}, 3^{\text {rd }}, 10^{\text {th }}$ and $20^{\text {th }}$ cycles under current density of $0.15 \mathrm{~A} \mathrm{~g}^{-1}$, respectively, and (c) Charge-discharge curves under current densities of $0.15,0.3,0.6,1.5,3$ and $6 \mathrm{~A} \mathrm{~g}^{-1}$, respectively

Figure 3. 4 Asymmetric rate capability test results of ESD-LTO electrode. Test conditions: constant charge current density: $3 \mathrm{~A} \mathrm{~g}^{-1}$, discharge current density: 3$60 \mathrm{~A} \mathrm{~g}^{-1}$; constant discharge current density: $3 \mathrm{~A} \mathrm{~g}^{-1}$, charge current densities: 3 $120 \mathrm{~A} \mathrm{~g}^{-1}$

Figure 4. 1 (a) Nitrogen adsorption-desorption isotherm and (b) XRD pattern of ESDLTO-5rGO powder

Figure 4. 2 SEM images of ESD-LTO-5rGO electrode (a-b) as-deposited and (c-d) after heat treatment

Figure 4. 3 The first 10 cycle CV curves of ESD-LTO-5rGO electrode at $0.2 \mathrm{mV} \mathrm{s}^{-1} \ldots .46$ 
Figure 4. 4 Cyclability and rate capability $\left(0.15-6 \mathrm{~A} \mathrm{~g}^{-1}\right)$ test results of ESD-LTO5 rGO electrode

Figure 4. 5 Asymmetric rate capability test results of ESD-LTO-5rGO electrode. Test conditions: constant charge current density: $3 \mathrm{~A} \mathrm{~g}^{-1}$, discharge current density: 3 $60 \mathrm{~A} \mathrm{~g}^{-1}$; constant discharge current density: $3 \mathrm{~A} \mathrm{~g}^{-1}$, charge current densities: 3 $60 \mathrm{~A} \mathrm{~g}^{-1}$

Figure 4. 6 (a) Symmetric rate capability (0.15-6 $\left.\mathrm{A} \mathrm{g}^{-1}\right)$ test results of ESD-LTO20rGO electrode. (b) Asymmetric rate capability test results of ESD-LTO-20rGO electrode Test conditions: constant charge current density: $3 \mathrm{~A} \mathrm{~g}^{-1}$, discharge current density: 3-60 $\mathrm{A} \mathrm{g}^{-1}$; constant discharge current density: $3 \mathrm{~A} \mathrm{~g}^{-1}$, charge current densities: $3-120 \mathrm{~A} \mathrm{~g}^{-1}$.

Figure 5. 1 Typical SEM images of electrodes based on (a) pure-Si; (b) pure-LTO and 50LTO20Si before the electrochemical test $(\mathrm{a}-\mathrm{c})$ and after the electrochemical test $(\mathrm{d}-\mathrm{f})$, respectively

Figure 5. 2 CV curves of electrodes based on (a) pure-Si, (b) pure-LTO and (c) $50 \mathrm{LTO} 20 \mathrm{Si}$ at scan rate of $0.2 \mathrm{mV} \mathrm{s}^{-1}$ in the range of $0.02-3 \mathrm{~V}$, respectively

Figure 5. 3 The rate performance and corresponding charge-discharge curves for electrodes based on (a,b) pure-Si, (c,d) pure-LTO, (e,f) 35LTO35Si, (g,h) 50LTO20Si and $(\mathrm{i}, \mathrm{j})$ 65LTO5Si, respectively

Figure 5. 4 Relationship between capacities and current densities of pure $\mathrm{Si}$, pure LTO, 35LTO35Si, 50LTO20Si and 65LTO5Si electrodes

Figure 5. $5 \mathrm{CV}$ curves of ESD-LTO-10Si-5rGO electrodes (a) at fixed scan rate of 0.2 $\mathrm{mV} \mathrm{s}^{-1}$; (b) at various scan rates from 0.2 to $10 \mathrm{mV} \mathrm{s}^{-1}$

Figure 5. 6 Cyclability and rate capability performance of ESD-LTO-10Si-5rGO electrode at current densities ranging from 0.15 to $150 \mathrm{~A} \mathrm{~g}^{-1}$ for over 1400 cycles. 64

Figure 5. 7 Charge-discharge curves of ESD-LTO-10Si-5rGO electrode at current densities of $0.15,0.3,0.6,1.5,3,6,9,12$ and $15 \mathrm{~A} \mathrm{~g}^{-1}$, respectively

Figure 5. 8 Asymmetric rate capability performance of ESD-LTO-10Si-5rGO electrode Test conditions: constant charge current density: $3 \mathrm{~A} \mathrm{~g}^{-1}$, discharge current density: 3-60 $\mathrm{A} \mathrm{g}^{-1}$; constant discharge current density: $3 \mathrm{~A} \mathrm{~g} \mathrm{~g}^{-1}$, charge current densities: 3-120 $\mathrm{A} \mathrm{g}^{-1}$.....

Figure 5. 9 (a) Symmetric rate capability performance comparison between ESD-LTO and its composites. (b) Asymmetric rate capability performance (constant 
discharge current density: $3 \mathrm{~A} \mathrm{~g}^{-1}$, charge current density: 3-120 $\mathrm{A} \mathrm{g}^{-1}$ )

comparison between ESD-LTO and its composites

Figure 6. 1 (a)-(b) SEM images of as-electrospun PAN fibers before and after heat treatment. (c) XRD pattern of CNFs and (d) Raman spectra of CNFs

Figure 6. $2 \mathrm{CV}$ curves of (a) CNFs and (b) ACNFs electrodes at a scan rate of $0.2 \mathrm{mV}$ $\mathrm{s}^{-1}$ in the range of 0.02-3 V. Galvanostatic charge-discharge curves of (c) CNFs and (d) ACNFs electrodes between 0.02 and $3 \mathrm{~V}$ at a current density of $100 \mathrm{~mA}$ $\mathrm{g}^{-1}$

Figure 6. 3 The cycling performance and columbic efficiency of (a) CNFs electrode and (b) ACNFs electrode, respectively.

Figure 6. 4 The rate performance of $\mathrm{CNFs}$ and $\mathrm{ACNF}$ s electrodes at various current densities ranging from $100 \mathrm{~mA} \mathrm{~g}^{-1}$ to $1000 \mathrm{~mA} \mathrm{~g}^{-1}$

Figure 6. 5 (a) Schematic drawing of HMMT structure. (b) SEM and (c) TEM images of HMMT powders.

Figure 6. 6 (a) TGA curve of HMMT powder. (b) Nitrogen adsorption-desorption isotherms, (c) FTIR spectra and (d) XRD patterns of both HMMT and DMMT powders

Figure 6. $7 \mathrm{CV}$ curves of (a) HMMT and (b) DMMT at $1 \mathrm{mV} \mathrm{s}^{-1}$, in the voltage window of $0.05-3.8 \mathrm{~V}$

Figure 6. 8 (a) Cycliability performance of both HMMT and DMMT electrodes at current density of $0.5 \mathrm{~A} \mathrm{~g}^{-1}, 0.05 \mathrm{~V}-3.8 \mathrm{~V}$. (b) Rate capability performance of both HMMT and DMMT electrodes at current density of 0.2, 0.5, 1 and $2 \mathrm{~A} \mathrm{~g}^{-1}$. Corresponding charge-discharge curves of (c) HMMT and (d) DMMT at different cycles

Figure 6. 9 (a) Nyquist plots of both HMMT and DMMT electrodes at freshly assembled state (b) Nyquist plots of HMMT electrode at different voltages

Figure A 1. Capacitive charge storage contribution of different materials at various scan rates. (a) LTO thin film $(35 \mathrm{~nm})$ electrode at $2 \mathrm{mV} \mathrm{s}^{-1}$. (b) Graphene oxide wrapped amorphous copper vanadium oxide electrode at $2 \mathrm{mV} \mathrm{s}^{-1}$. (c) $\mathrm{Na}_{2} \mathrm{Ti}_{3} \mathrm{O}_{7} @ \mathrm{CNT}$ coaxial nanocables electrode at $0.6 \mathrm{mV} \mathrm{s}^{-1}$. (d) $\mathrm{V}_{2} \mathrm{O}_{5} / \mathrm{CNT}$ electrode at $10 \mathrm{mV} \mathrm{s}^{-1}$. (e) $\mathrm{In} \mathrm{Nb}_{2} \mathrm{O}_{5} @$ Carbon core-shell nanoparticles and reduced graphene oxide nanocomposites electrode at $0.1 \mathrm{mV} \mathrm{s}^{-1}$. (f) $\mathrm{Nb}_{2} \mathrm{O}_{5} @ \mathrm{C}$ electrode at $0.1 \mathrm{mV} \mathrm{s}^{-1}$. (g) Mesoporous $\mathrm{MoS}_{2}$ electrode at $1 \mathrm{mV} \mathrm{s}^{-1}$. (h) $\mathrm{VOPO}_{4}$ nanosheets electrode at $1 \mathrm{mV} \mathrm{s}^{-1}$ 


\section{INTRODUCTION}

\subsection{Overview}

Rechargeable lithium-ion battery (LIB) is one of the most important energy storage systems used in a wide range of applications, ranging from portable electronics to electric vehicles. The global market of LIB is expanding dramatically mainly because of its high energy density, high power density and long cycle life. Three major application areas for the LIB are: (i) portable electronics, (ii) power tools and electric vehicles (such as pure electric vehicles, hybrid electric vehicles and plug-in hybrid electric vehicles), and (iii) stationary electrical energy storage for renewable energies (wind and solar power). LIB technology has revolutionized the portable electronics market in the past two decades.

The overall performance of LIBs is related to the properties and characteristics of the various components in the cell, such as: anodes, cathodes, and electrolytes materials. Much effort has been focused on replacing the currently commercialized graphite anode by other materials. LTO recently has attracted great interests because of its excellent cyclability, good rate capability, structure stability and solid electrolyte interphase (SEI) free nature. However, it has low energy density due to low theoretical capacity of $175 \mathrm{mAh}$ $\mathrm{g}^{-1}$ (when cutoff voltage $\left.=1 \mathrm{~V}\right)$ and high working voltage of $1.55 \mathrm{~V}$. Lots of research efforts have been put to resolve this issue. On the one hand, different nanostructured (mesoporous, hierarchical, core-shell, 1D nanofiber/nanotube, 2D nanosheets) LTO electrodes have been synthesized because of their attractive properties, such as higher surface area and shorter $\mathrm{Li}^{+}$diffusion length which could improve reaction kinetics and enable high rate performance. On the other hand, many kinds of LTO based composites have been prepared taking advantages of higher specific capacities of the compositing components. Great 
electrochemical performance enhancement of LTO based electrodes have been observed due to these research efforts.

\subsection{Objective and Research Plan}

The objective of this dissertation is to develop high energy and high power electrode materials for LIBs. LTO and its nanocomposites were mainly studied in order to enhance its electrochemical performance.

In order to improve the energy and power density of $\mathrm{Li}_{4} \mathrm{Ti}_{5} \mathrm{O}_{12}$ (LTO) electrode, porous binder free thin film structured electrode is fabricated. Electrostatic spray deposition (ESD) is utilized in developing LTO electrode with the proposed structures. One of the promising aspects of ESD is that various structures and morphologies can be formed by controlling deposition conditions. The resulting porous structures enable higher surface area and shorter $\mathrm{Li}^{+}$diffusion length which may improve reaction kinetics and enable the enhanced high rate performance. In addition, the LTO electrode will be discharged to $0 \mathrm{~V}$, which not only can increase the specific capacity of LTO, but also can decrease the average working voltage, which is beneficial for high energy performance.

In order to improve the energy density and power density of LTO electrode, various types of LTO based nanocomposites are developed. Reduced graphene oxide (rGO) and silicon are selected to make composite with LTO, as a rate capability enhancement component and a capacity enhancement component, respectively. The positive synergic effect between LTO and $\mathrm{Si}$ in the composite is expected since LTO can alleviate the stresses from volumetric changes of Si upon cycling, while Si can add to the capacity of the composite. 
In addition, other types of electrode materials, such as activated CNFs and MMT clay are studied. For CNF electrode, chemical activation by $\mathrm{KOH}$ is applied to create porous structures on CNFs in order to increase its specific capacity and rate capability. For MMT clay electrode, since this is the first time to utilize MMT as electrode material for LIB, we focus on evaluating the feasibility of lithium ions to reversibly intercalate/deintercalate into its 2D layered structures. Figure 1.1 presents the flow chart of this thesis research.

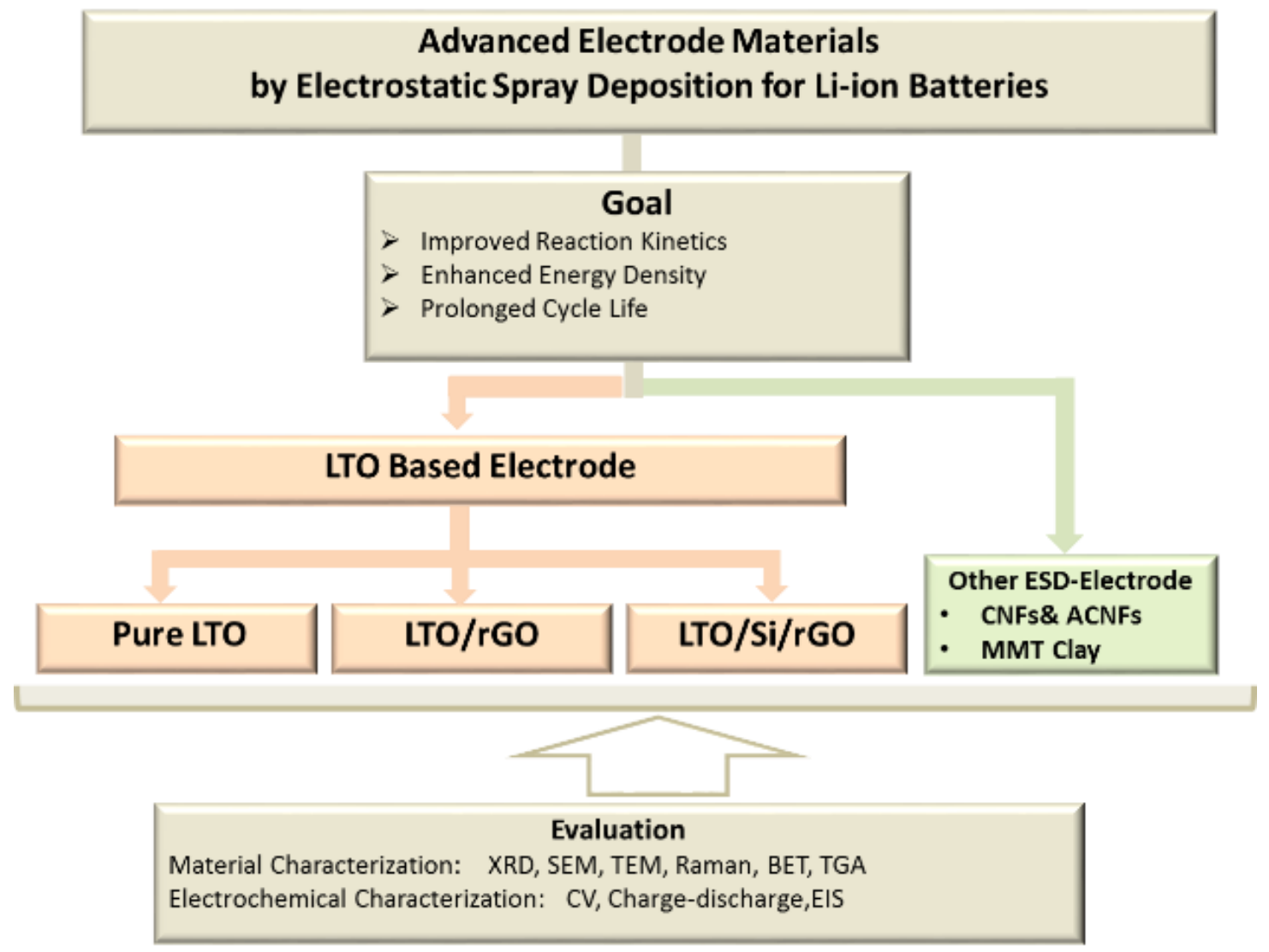

Figure 1.1 Flow chart of the research plan. 


\subsection{Scope of the Dissertation}

Chapter 2 provides a general review on LIBs and electrode materials for the system. In order to provide new insight for further investigations of electrode materials for LIBs, a background of batteries and two types of anode materials are discussed. In addition, chapter 2 describes the experimental techniques used in this study. The fabrication process and evaluation of porous LTO thin film electrode are presented in chapter 3. Studies on electrochemical performance of resulting LTO are focused on various aspects including: origin of the extra capacity, reason for extreme fast reaction kinetics and capacitive charge contribution, etc. Chapter 4 describes the advantages of adding rGO to enhance the electrochemical performance of LTO/rGO composites. The fabrication and evaluation of $\mathrm{LTO} / \mathrm{Si} / \mathrm{rGO}$ composite are presented in chapter $5 . \mathrm{Si}$ and $\mathrm{rGO}$ were used as capacity enhancement and rate capability improvement components in the study. In chapter 6 , the study of other electrode materials including activated CNFs based electrodes and montmorillonite clay based electrodes are described. Chapter 7 gives a summary of the dissertation and proposes future works.

In this dissertation, the physical properties and structures of the electrode materials were characterized through various techniques, such as X-ray diffraction, scanning electron microscopy, transmission electron microscopy, Brunauer Emmett Teller adsorption/desorption measurement, thermogravimetric analysis and Raman spectroscopy measurement. The electrodes were prepared through traditional casting methods and ESD process. The electrochemical performance of resulting electrodes were tested in half-cells and characterized by different tests, such as galvanostatic charge-discharge test, cyclic voltammetry test and electrochemical impedance spectroscopy. 


\section{BACKGROUND AND LITERATURE REVIEW}

Rechargeable LIB is one of the most important and widely used energy storage devices. The global market of LIB is growing dramatically which is mainly due to its high energy density and high power density as well as long cycle life compared to other primary and secondary batteries, such as: lead acid batteries, Ni-Cd batteries and Ni-MH batteries. Figure 2.1 shows the Ragone plot of various currently available electrical energy storage devices [1].

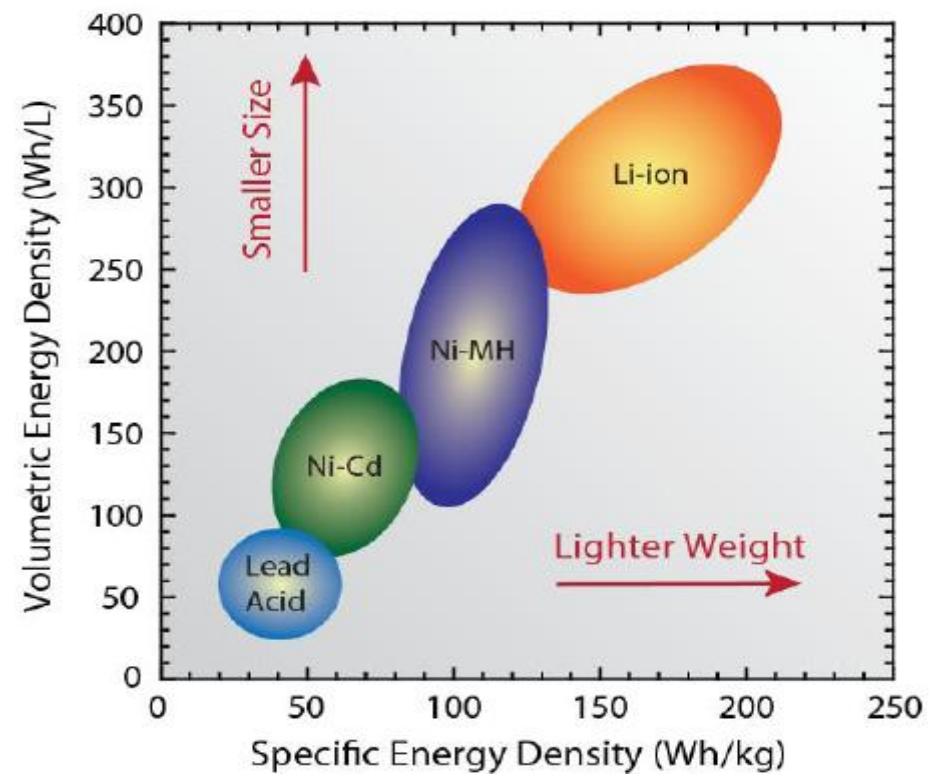

Figure 2. 1 Ragone plot of various electrical energy storage devices [1].

The specified advantages of LIB include high working voltage $(\sim 3.6 \mathrm{~V})$, high energy density $\left(\sim 160 \mathrm{Wh} \mathrm{kg}^{-1}\right)$, high power density $\left(\sim 440 \mathrm{~W} \mathrm{~kg}^{-1}\right)$, long cycling life (> 1000 cycles), eco-friendliness and no memory effect, etc., as listed in Table 2.1 [2]. Since the commercialization of first LIB by SONY, great improvement has been realized due to better cell design, reduced amount of inactive materials, and optimized electrode materials. 
Table 2. 1 Advantages of Li-ion batteries compared to other commonly used battery systems [2].

\begin{tabular}{lllll}
\hline Battery type & Pb-Acid & Ni-Cd & Ni-MH & Li-ion \\
\hline Voltage/ V & 2 & 1.25 & 1.25 & 3.6 \\
Specific energy density/ Wh/g & $30 \sim 50$ & $45 \sim 80$ & $60 \sim 20$ & $110 \sim 160$ \\
Specific energy density/ Wh/l & 70 & 100 & 245 & 440 \\
Peak load current & $5 \mathrm{C}$ & $20 \mathrm{C}$ & $5 \mathrm{C}$ & $>30 \mathrm{C}$ \\
Cycle life & $200-300$ & 1500 & 500 & 1000 \\
Self-discharge time/ months & 5 & 20 & 30 & 10 \\
Operation Temperature $/{ }^{\circ} \mathrm{C}$ & $-20 \sim 60$ & $-40 \sim 60$ & $-20 \sim 60$ & $-40 \sim 70$
\end{tabular}

\subsection{Fundamental Aspects of Lithium-ion Batteries}

In LIBs, electrical energy is stored in the form of chemical energy in the anode and cathode. A typical LIB inside package consists of a positive electrode (cathode), a negative electrode (anode), separator and an electrolyte. The electrolyte can be liquid, gel, or solid. Most of the lithium-ion batteries use liquid electrolyte which contains lithium salts (such as $\mathrm{LiPF}_{6}, \mathrm{LiBF}_{4}, \mathrm{LiClO}_{4}$, etc), dissolved in an organic alkyl carbonate solvents mixture. Solid electrolytes can physically isolated anode and cathode. However, when liquid electrolytes are used, porous membranes must be used as separator between two electrodes to prevent electrical contact and at the same time allow the lithium ions containing electrolyte to penetrate. The electrolyte is electronically insulating and ionically conducting which enables the shuttling of lithium ions between two electrodes [3-6]. A schematic drawing of a traditional lithium-ion battery with graphite as anode and $\mathrm{LiCoO}_{2}$ as cathode is shown in Figure 2.2. 


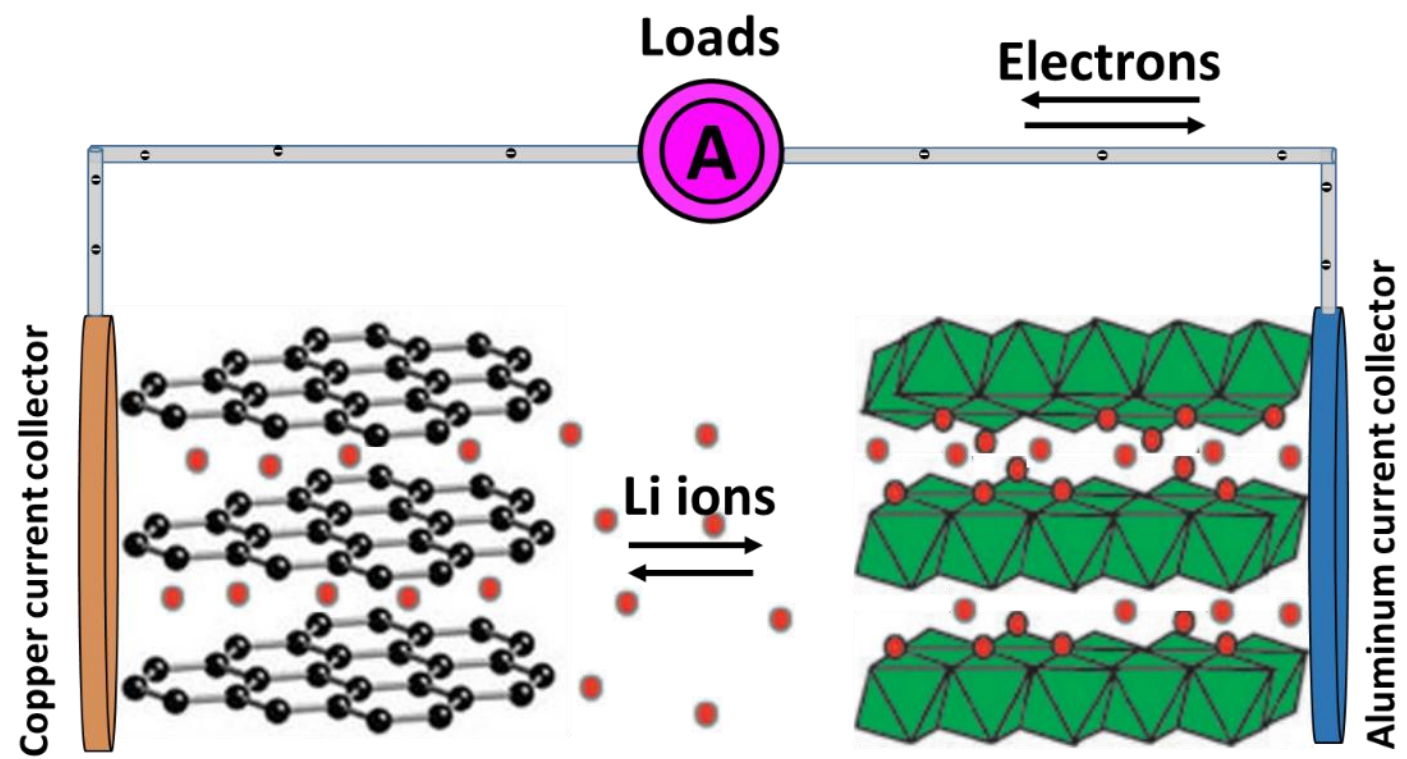

Anode Electrolyte Cathode

Figure 2. 2 Schematic drawing of a typical lithium-ion battery.

Typically, a lithium-ion battery is assembled in discharged state in which cathode is in lithiated state and anode is in a state that can accommodate lithium ions. In charging process, lithium ions move from cathode side and intercalate into graphite anode through electrolyte. Electrons move from cathode to anode through the external circuit. During discharge, both lithium ions and electrons reverse their moving directions as in the charging process. The reactions that happened in anode, cathode as well as full cell are shown in Equations (2.1)-(2.3). During cycling, $\mathrm{Li}^{+}$repeatedly shuttles between cathode and anode, which is why LIB is called the "rocking-chair" battery [7-11].

Anode: $\mathrm{Li}_{\mathrm{x}} \mathrm{C}_{6} \leftrightarrow \mathrm{xLi}^{+}+\mathrm{xe}^{-}+\mathrm{C}_{6}(\mathrm{x}<1)$

Cathode: $\mathrm{Li}_{1-\mathrm{x}} \mathrm{CoO}_{2}+\mathrm{xLi}^{+}+\mathrm{xe}^{-} \leftrightarrow \mathrm{Li}_{1-\mathrm{x}} \mathrm{CoO}_{2}(\mathrm{x}<0.5)$

Full cell: $\mathrm{LiC}_{6}+\mathrm{CoO}_{2} \leftrightarrow \mathrm{C}_{6}+\mathrm{LiCoO}_{2}$ 


\subsection{Electrode Materials for Anodes}

Currently, the anode and cathode materials in commercial LIBs are graphite and lithium metal oxides $\left(\left(\mathrm{LiCoO}_{2}\right)\right.$ or $\left.\left(\mathrm{LiFePO}_{4}\right)\right)$. The theoretical capacity of graphite is 372 $\mathrm{mAh} \mathrm{g}^{-1}$ [12-14]. Developing alternative anode materials with much higher energy capacities is one of the challenges in improving the performance of LIBs. The development and current state-of-arts of Si and LTO anode materials are reviewed below.

\subsubsection{High Capacity Anode Material: Si}

In the early 70s, Dey demonstrated that Li metal can electrochemically alloy with other metallic or semi-metallic elements at room temperature in a non-aqueous based electrolyte. Since then, alloying based anode materials have been widely investigated in the past few decades. Among various Li alloy elements, $\mathrm{Si}$ is considered as one of the most attractive candidates owing to its highest gravimetric and volumetric capacities. For example, Si has a theoretical capacity of $4200 \mathrm{mAh} \mathrm{g}^{-1}$, which is about 10 times higher than that of commercial graphite [15-16]. In addition, the discharge potential for Si is around $0.2 \mathrm{~V}\left(\mathrm{vs} . \mathrm{Li} / \mathrm{Li}^{+}\right.$), which is lower than most of other anode materials and enables a very high energy density in a Si containing full cell. Besides, its high theoretical performance, low cost, abundance as well as environmentally benign, make Si more promising to be applied in commercial LIBs [15-16]. However, the use of Si anode still remains challenging because of large volume expansion $(>400 \%)$ during cycling. Such huge volume change will induce large stresses within $\mathrm{Si}$ and the whole electrode leading to active material pulverization and peeling off from current collector, which is the main reason for the capacity fading and even electrode failure [17]. Another challenge of Si anode is the continuous solid-electrolyte interphase (SEI) growth [18]. The organic 
electrolyte will decompose at electrode surface when potential is below $\sim 1 \mathrm{~V}$ and form an ionically conducting and electronically insulating layer which can prevent further SEI formation. For most of the anode materials, major SEI formation process happens in the first several cycles. However, the large volume change of Si makes it very challenging to achieve a stable SEI. Breakage of SEI layer due to volume expansion-contraction cycles and re-formation on new Si surface lead to a very thick SEI layer which can hinder further electrochemical reaction. This effect is more detrimental for a full cell which has limited amount of $\mathrm{Li}^{+}$in the system, since increasing amount of $\mathrm{Li}^{+}$will be trapped in the SEI layer. Moreover, the electrochemical reaction kinetics between $\mathrm{Si}$ and $\mathrm{Li}^{+}$are hindered by relatively low $\left(\approx 10^{-3} \mathrm{~S} \mathrm{~cm}^{-1}\right)$ electronic conductivity and slow (diffusion coefficient between $10^{-14} \sim 10^{-13} \mathrm{~cm}^{2} \mathrm{~s}^{-1}$ ) lithium diffusion in $\mathrm{Si}$, which limit the full utilization of the active material and also the rate capability [19].

In order to resolve these issues, various methods have been applied, including carbon or metal coating, utilizing electrochemical active/inactive buffering materials, formation of nanostructured/porous Si electrodes and use of new binders. Significant breakthroughs have been achieved in terms of extended cycle life and enhanced rate performance. For example, carbon coating from various organic precursors is a common way to improve the electronic conductivity of Si [20-21]. Carbon also serves as a buffer media to alleviate the stress from volume change of Si phase. Besides carbon, many other materials have been used as the matrix to reduce the volume change effect. However, there is a drawback of this approach that the presence of other low capacity components could lower the specific capacity of the composites. In addition, utilization of porous and/or nanosized silicon (0D nanoparticles [22], 1D nanowires [23] and nanotubes [24] and 2D thin films [25]) based 
materials have shown significant enhanced electrochemical performance. Compared to bulk $\mathrm{Si}$, engineered porous/nanosized silicon not only can effectively accommodate the volume through dramatically improved damage tolerance, but also enable fast (de)lithiation process due to reduced diffusion distance and large contact area with electrolyte. The main shortcoming for this approach is the low tap density which causes limited volumetric capacity. In order to tolerate the large volume change, besides active materials, binder also plays a critical role. Other than traditional binder, Poly(vinylidene fluoride) (PVDF) [26], various other binders, such as sodium carboxymethyl cellulose (NaCMC) [27], poly(acrylic acid) (PAA) [28], alginate (nature polysaccharide extracted from brown algae) [29] have been investigated for Si based anode materials. The enhanced electrochemical performance have been observed by selecting these novel binders. It could be due to one or several of the following reasons: a) less interaction between binder and electrolyte; b) better $\mathrm{Li}^{+}$accessibility; c) higher elastic modulus; d) higher electronic conductivity. Although great progress has been achieved via above approaches, further improvement on buffering volume change, controlling SEI growth, enhancing reaction kinetics etc. could be expected to make Si more suitable for LIBs.

\subsubsection{High Rate Capability Anode Material: $\mathrm{Li}_{4} \mathrm{Ti}_{5} \mathrm{O}_{12}$}

As an alternative anode material to graphite, lithium titanate $\left(\mathrm{Li}_{4} \mathrm{Ti}_{5} \mathrm{O}_{12}\right)$, also written as $\left.\mathrm{Li}\left(\mathrm{Li}_{1 / 3} \mathrm{Ti}_{2 / 3}\right) \mathrm{O}_{4}\right)$ has been extensively studied especially for high power and large scale Li-ion storage applications. LTO has a lot of advantages when cutoff voltage is $1 \mathrm{~V}$, which include: i) a very flat and stable charge/discharge platform at $\sim 1.55 \mathrm{~V}$; ii) high redox potential which restrains the SEI formation; iii) negligible volume change (also called "zero strain") during Li insertion/extraction; iv) excellent cycling reversibility and 
cycle life; v) inexpensive and environmental friendly material [30] . However, untreated coarse LTO exhibits poor electrochemical performance, especially under high current densities, mainly due to its inherent low electronic conductivity $\left(<10^{-13} \mathrm{~S} \mathrm{~cm}^{-1}\right)$ and sluggish $\mathrm{Li}^{+}$diffusivity $\left(<10^{-6} \mathrm{~cm}^{2} \mathrm{~s}^{-1}\right)[30]$. Table 2.2 summarized the advantages and disadvantages of LTO as anode for LIBs.

Table 2. 2 Advantages and disadvantages of spinel-LTO as anode.

\begin{tabular}{|c|c|}
\hline Advantages & $\begin{array}{ll}\text { - } & \text { Excellent } \mathrm{Li}^{+} \text {insertion/extraction reversibility } \\
\text { - } & \text { Negligible volume/structure change } \\
\text { - } & \text { Long cycle life (over } 1000 \text { cycles }) \\
\text { - } & \text { Excellent safety characteristics } \\
\text { - } & \text { Flat discharge profile } \\
\text { - } & \text { Solid electrolyte interphase }(\mathrm{SEI}) \text { free }(\text { cutoff voltage }=1 \mathrm{~V}) \\
\text { - } & \text { Better high temperature performance }\left(<60^{\circ} \mathrm{C}\right) \\
\text { - } & \text { High rate performance }(90 \% \text { capacity retention at } 10 \mathrm{C})\end{array}$ \\
\hline Disadvantages & $\begin{array}{l}\text { - Low electronic conductivity }\left(10^{-13} \mathrm{~S} \mathrm{~cm}^{-1}\right) \\
\text { - } \quad \text { Low theoretical specific capacity }\left(175 \mathrm{mAh} \mathrm{g}^{-1} @ 1 \mathrm{~V} \text { cutoff voltage }\right) \\
\text { - High reaction voltage }(1.55 \mathrm{~V})\end{array}$ \\
\hline
\end{tabular}

In order to overcome the disadvantages of LTO, lots of efforts have been devoted in various aspects including: i) applying different synthesis methods (solid state reaction, sol-gel method, hydro/Solve-thermal method, spray pyrolysis method, etc.); ii) structure and morphology modifications (nanoparticle, nanoplate, nanofiber, nanotube, porous, etc.); iii) surface and material modifications (carbon coating, doping); iv) forming composite materials (LTO/carbon, $\mathrm{LTO} / \mathrm{TiO}_{2}$, $\mathrm{LTO} /$ other anode materials). LTO has been used in some commercial applications, such as hybrid/plug-in electrical vehicles and large scale energy storage for renewable energy generations.

From structure point of view, LTO has a defective spinel structure with a space group of $F d \overline{3} m$, in which all tetrahedral 8a sites are occupied by lithium, 32e positions are 
occupied by oxygen and the octahedral $16 \mathrm{~d}$ sites are shared by lithium and titanium in a ratio of $1: 5$ [31]. So $\mathrm{Li}_{4} \mathrm{Ti}_{5} \mathrm{O}_{12}$ can also be write as $\left[\mathrm{Li}_{3}\right]^{8 \mathrm{a}}[]^{16 \mathrm{c}}\left[\mathrm{Li}_{1} \mathrm{Ti}_{5}\right]^{16 \mathrm{~d}}\left[\mathrm{O}_{12}\right]^{32 \mathrm{e}}$. During lithium intercalation process, three $\mathrm{Li}$ ions at $8 \mathrm{a}$ sites move towards $16 c$ sites and three more Li ions intercalate into $16 c$ sites causing fully filled $16 c$ sites and emptied $8 a$ sites, resulting in $\mathrm{Li}_{7} \mathrm{Ti}_{5} \mathrm{O}_{12},[]^{8 \mathrm{a}}\left[\mathrm{Li}_{6}\right]^{16 \mathrm{c}}\left[\mathrm{Li}_{1} \mathrm{Ti}_{5}\right]^{16 \mathrm{~d}}\left[\mathrm{O}_{12}\right]^{32 \mathrm{e}}$. The process can be expressed as in Equation 2.4 [31]. In the atomic structure of $\mathrm{Li}_{7} \mathrm{Ti}_{5} \mathrm{O}_{12}, 8 a$ sites are still empty and could provide more spaces for further lithium ions storage. According to $a b$ initial calculation, additional $1.5 \mathrm{Li}$ ions can be stored at $8 a$ sites when cut off voltage is $0 \mathrm{~V}$, resulting in $\left[\mathrm{Li}_{1.5}\right]^{8 \mathrm{a}}\left[\mathrm{Li}_{6}\right]^{16 \mathrm{c}}\left[\mathrm{Li}_{1} \mathrm{Ti}_{5}\right]^{16 \mathrm{~d}}\left[\mathrm{O}_{12}\right]^{32 \mathrm{e}}\left(\mathrm{Li}_{8.5} \mathrm{Ti}_{5} \mathrm{O}_{12}\right)$. The process can be expressed as in Equation 2.5. Through this process, the theoriterical capacity of LTO increased to $263 \mathrm{mAh} \mathrm{g}^{-1}, 1.5$ times higher than that of when cutoff voltage is $1 \mathrm{~V}$. From structure point of view, $\mathrm{Li}_{8.5} \mathrm{Ti}_{5} \mathrm{O}_{12}$ still has half of the $8 a$ sites empty which can be further used to store Li ions. The possible reaction can be expressed as in Equation 2.6. The ending member will be $\mathrm{Li}_{10.5} \mathrm{Ti}_{5} \mathrm{O}_{12}$ when all $8 \mathrm{a}$ and $16 \mathrm{c}$ sites are occupied, corresponding to a capacity of 350 $\mathrm{mAh} \mathrm{g}^{-1}$. However, this reaction will not happen because a negative voltage is required which is not possible for the Li half cell [32-33].

$$
\begin{aligned}
& {\left[\mathrm{Li}_{3}\right]^{8 \mathrm{a}}[]^{16 \mathrm{c}}\left[\mathrm{Li}_{1} \mathrm{Ti}_{5}\right]^{16 \mathrm{~d}}\left[\mathrm{O}_{12}\right]^{32 \mathrm{e}}+3 \mathrm{e}^{-}+3 \mathrm{Li}^{+} \leftrightarrow[]^{8 \mathrm{a}}[\mathrm{Li}]^{16 \mathrm{c}}\left[\mathrm{Li}_{1} \mathrm{Ti}_{5}\right]^{16 \mathrm{~d}}\left[\mathrm{O}_{12}\right]^{32 \mathrm{e}}} \\
& {[]^{8 \mathrm{a}}\left[\mathrm{Li}_{6}\right]^{16 \mathrm{c}}\left[\mathrm{Li}_{1} \mathrm{Ti}_{5}\right]^{16 \mathrm{~d}}\left[\mathrm{O}_{12}\right]^{32 \mathrm{e}}+1.5 \mathrm{e}^{-}+1.5 \mathrm{Li}^{+} \leftrightarrow\left[\mathrm{Li}_{1.5}\right]^{8 \mathrm{a}}\left[\mathrm{Li}_{6}\right]^{16 \mathrm{c}}\left[\mathrm{Li}_{1} \mathrm{Ti}_{5}\right]^{16 \mathrm{~d}}\left[\mathrm{O}_{12}\right]^{32 \mathrm{e}}} \\
& {\left[\mathrm{Li}_{1.5}\right]^{8 \mathrm{a}}\left[\mathrm{Li}_{6}\right]^{16 \mathrm{c}}\left[\mathrm{Li}_{1} \mathrm{Ti}_{5}\right]^{16 \mathrm{~d}}\left[\mathrm{O}_{12}\right]^{32 \mathrm{e}}+1.5 \mathrm{e}^{-}+1.5 \mathrm{Li}^{+} \leftrightarrow\left[\mathrm{Li}_{3}\right]^{8 \mathrm{a}}\left[\mathrm{Li}_{6}\right]^{16 \mathrm{c}}\left[\mathrm{Li}_{1} \mathrm{Ti}_{5}\right]^{16 \mathrm{~d}}\left[\mathrm{O}_{12}\right]^{32 \mathrm{e}}}
\end{aligned}
$$

Spinel $\mathrm{Li}_{4} \mathrm{Ti}_{5} \mathrm{O}_{12}$ can be synthesized via various methods, such as solid-state reaction [34], sol-gel method [35], hydro-thermal/solve-thermal method [36], spray pyrolysis method [37], electrospinning method [38] and so on. The properties of LTO such as morphology, particle size and distribution, phase purity, surface area, crystallinity, are 
greatly affected by the synthesis methods/processes and conditions. As a result, the electrochemical performance is highly dependent on the synthesis method. The merits and shortcomings for various LTO synthesis methods are summarized in Table 2.3.

Table 2. 3 Merits and shortcomings of various LTO synthesis methods.

\begin{tabular}{|c|c|c|c|}
\hline $\begin{array}{l}\text { Synthesis } \\
\text { method }\end{array}$ & Synthesis Process & Merits & Shortcomings \\
\hline $\begin{array}{l}\text { Solid-state } \\
\text { reaction }^{[34]}\end{array}$ & $\begin{array}{l}\text { Stoichiometric amount of } \mathrm{Li}_{2} \mathrm{CO}_{3} \\
\text { and } \mathrm{TiO}_{2} \text { are mixed evenly first, } \\
\text { then heat-treated at } 700-1000{ }^{\circ} \mathrm{C} \\
\text { for } 1-20 \mathrm{~h}\end{array}$ & $\begin{array}{l}\text { Simple and easy } \\
\text { process; } \\
\text { low cost; } \\
\text { potential commercial } \\
\text { application }\end{array}$ & $\begin{array}{l}\text { low homogeneity; } \\
\text { irregular morphology; } \\
\text { significant } \\
\text { agglomeration; } \\
\text { coarse particle size; } \\
\text { long calcination time }\end{array}$ \\
\hline Sol-gel ${ }^{[35]}$ & $\begin{array}{l}\text { Stoichiometric } \mathrm{Li} \text { and } \mathrm{Ti} \text { sources } \\
\text { are dissolved and form a gel } \\
\text { which will be dried to obtain the } \\
\text { organic precursors. Then heat } \\
\text { treatment at } 500-800^{\circ} \mathrm{C} \text { is } \\
\text { performed to obtain LTO }\end{array}$ & $\begin{array}{l}\text { High purity; } \\
\text { sub-micron size } \\
\text { particles; } \\
\text { homogeneous size } \\
\text { distribution; } \\
\text { low synthesis } \\
\text { temperature; } \\
\text { short calcination time }\end{array}$ & $\begin{array}{l}\text { High material cost; } \\
\text { Complex synthetic } \\
\text { route }\end{array}$ \\
\hline $\begin{array}{l}\text { Hydro/Solve } \\
\text {-thermal }\end{array}$ & $\begin{array}{l}\text { First } \mathrm{Li} \text { and } \mathrm{Ti} \text { sources are } \\
\text { dissolved in solvent then react in } \\
\text { autoclave at } 100-200{ }^{\circ} \mathrm{C} \text { followed } \\
\text { by low temperature calcination. }\end{array}$ & $\begin{array}{l}\text { Fast reaction; } \\
\text { High purity; } \\
\text { Small particle size; } \\
\text { Homogenous } \\
\text { distribution; } \\
\text { Low calcination } \\
\text { temperature; } \\
\text { Scale up easily }\end{array}$ & $\begin{array}{l}\text { Expensive precursor; } \\
\text { Require autoclave as } \\
\text { reactor; } \\
\text { Need washing process }\end{array}$ \\
\hline $\begin{array}{l}\text { Spray } \\
\text { Pyrolysis }^{[37]}\end{array}$ & $\begin{array}{l}\text { Precursor solutions are prepared } \\
\text { and feed as atomized phase into a } \\
\text { heated chamber for } \\
\text { decomposition }\end{array}$ & $\begin{array}{l}\text { High productivity; } \\
\text { Easy control of size; } \\
\text { Homogenous particles; }\end{array}$ & Micrometer range size \\
\hline
\end{tabular}

It is well known that particle size and morphology have great influence on electrochemical performance of electrode materials due to modified surface area, surface chemistry, surface energy, ion diffusion distance, etc [39]. Reduced particle sizes could enable large contact area between electrode and electrolyte and also reduced diffusion length for lithium ions and electrons. As a result, fast reaction kinetics could be achieved 
which leads to enhanced high rate performance. In addition, defects in nanomaterials may also act as $\mathrm{Li}^{+}$storage sites that can increase the total charge storage capacity. For example, porous LTO consisting ultra-small interconnected nanoparticles $(3-4 \mathrm{~nm})$ was synthesized through solve-thermal method. The resulting LTO showed a capacity of $175 \mathrm{mAh} \mathrm{g}^{-1}$ at 50 $\mathrm{C}$ and furthermore, $74 \%$ of the initial capacity can be maintained at an extreme high rate of $800 \mathrm{C}$ for over a thousand cycles. The drastically enhanced reaction kinetics is mainly because of the nanoscale building blocks with enhanced charge transfer and reduced ion/electron diffusion length [40]. However, there are some drawbacks with nanosizing, such as: low tap density, more side reactions, difficulty in controlling the synthesis reactions and procedures, etc. Considering the low tap density issue, $\mathrm{Lu}$ et al. fabricated mesoporous LTO ( $4.5 \mathrm{~nm}$ pore size) consisting large sphere particles $(660 \mathrm{~nm})$ and small primary particles (20-100 nm) with high tap density of $1.62 \mathrm{~g} \mathrm{~cm}^{-3}$ [41]. The increased tap density made it more suitable for practical applications. The nanosized pores and primary particles still maintained the advantage of improved reaction kinetics. A high charge capacity of $179 \mathrm{mAh} \mathrm{g}^{-1}$ was obtained at $0.5 \mathrm{C}$ with high first cycle coulombic efficiency of $93.5 \%$. The charge capacity decreased to $109 \mathrm{~mA} \mathrm{~h} \mathrm{~g}^{-1}$ when charge rate increased to $10 \mathrm{C}$ and the capacity retention for over 100 cycles was $97.8 \%$. Such nano/microcombined structure with high tap density is desirable towards practical applications [41].

Besides creating nanostructures, surface modification is another commonly used method to improve the electrochemical performance of LTO. Among all surface modification methods, surface coating is generally employed and proved to be effective towards performance enhancement. Various types of carbons [42-45] and metals (such as $\mathrm{Ag}$ [46], $\mathrm{Au}$ [47]), metal oxides (such as $\mathrm{TiO}_{2}$ [48], $\mathrm{Cu}_{\mathrm{x}} \mathrm{O}$ [49], $\mathrm{ZnO}$ [50]) and other 
conductive species are frequently selected as coating materials for LTO. Carbon is one of the most widely used coating materials due to its unique chemical and physical properties and the feasibility of conducting coating process. The insulating nature of LTO can be easily altered by carbon coating. High rate performance has been remarkably improved due to enhanced electronic conductivity. The level of the electrochemical performance improvement is strongly dependent on the properties of carbon coating, such as thickness, uniformity, degree of graphitization, defects and vacancies, which are mainly decided by the carbon sources, coating processes and post treatments [42-45].

In addition to the surface modification, various types of LTO based composites have also been studied. One type of composite is carbon based LTO composite formed by adding carbon nanotubes (CNTs) [51] or graphene [52] into LTO, which will provide even higher electronic conductivity than graphic carbon coating. Furthermore, the high specific surface areas of these materials enable good contact between electrode and electrolyte and shorten the ion diffusion length. Since the capacity enhancement of composite electrode is closely related to the capacity of another component in the composite, in order to further increase the specific capacity of LTO based composites, high capacity anode materials are preferred. Unfortunately, the operational voltages for some anode materials that can be used to make composites with LTO are less than $1 \mathrm{~V}$, which makes cutting off voltage below $1 \mathrm{~V}$ a prerequisite to utilize all components as active materials. This brings us back the SEI formation issue. Energy density enhancement through this method comes with trading off important advantage of SEI free for LTO. However, SEI formation could be alleviated by surface coating technology, such as $\mathrm{ALD}$ based $\mathrm{Al}_{2} \mathrm{O}_{3}$ coating. Till now, there are scattered efforts regarding the development of composites between LTO and high 
capacity anode materials, such as: $\mathrm{Sn}$ [53], $\mathrm{SnO}_{2}$ [54], $\mathrm{CuO}$ [55], $\mathrm{Fe}_{2} \mathrm{O}_{3}$ [56] and $\mathrm{Si}$ [57].

Silicon is an excellent choice due to its highest theoretical capacity (4200 $\left.\mathrm{mAh} \mathrm{g}^{-1}\right)$. However, one of the problems of using silicon alone is the $\sim 400 \%$ volumetric change during cycling, which results in peeling and pulverization of the electrode and eventual capacity loss. We believe LTO/Si based composite could reduce the negative effect introduced by Si phase.

\subsection{Electrostatic Spray Deposition Technique}

Electrostatic spray deposition (ESD) is a unique thin film fabrication method initially developed by Schoonman et al. at Delft University of Technology [58]. Due to the advantages of simple and low-cost setup, non-vacuum, low deposition temperature, high deposition efficiency, as well as good control of the composition and morphology, ESD technique shows some promising aspects as compared to other film formation processes, such as sputtering, chemical/physical vapor deposition, sol-gel and so on. Till now, various thin film electrodes with different morphologies have been synthesized through ESD for LIBs. The resulting electrodes could be dense, sponge-line porous, fractal-like porous etc. which can be controlled by varying deposition conditions [59]. It is belived that controling structures of electrodes is an effective way to optmize electrochemical performance regarding volume change buffering, decreasing ion diffusion passway and increasing contact areas between electrode and electrolyte. For example, the 3D sponge-like films with high surface area and high porosity are beneficial for buffering the large volume changes of anode materials during charge/discharge process and improving reaction kinetics with reduced diffusion length for lithium ions [60]. In addition, it is convenient to prepare uniform multi-component composites through ESD by varying the type and 
concentration of precursor solutions. Clearly, ESD-derived thin films are favorable for application in lithium-ion batteries.

Figure 2.3a and $\mathrm{b}$ show schematic drawing and photo image of experimental set-up for ESD, respectively. The major components in the ESD set-up contain a nozzle connected with a syringe that supplies the precursor solution through a syringe pump, a substrate heated up at high temperature, and a DC high voltage power supply between nozzle and substrate. During deposition. A high DC voltage is used to generate a high electrostatic force and accelerate atomized liquid droplets at the tip of a nozzle; the charged droplets formed aerosol is sequentially deposited on a heated substrate to construct the designed thin film. The structures and morphologies of the resulting film can be controlled by varying: applied voltage, flow rate, deposition time, substrate temperature, needle to substrate distance, precursor concentration, mixture of solvents, selection of substrate, deposition atmosphere, etc. In general, the deposition process can be divided to five steps [61]: (i) Spray formation: A precursor solution is atomized into charged droplets at the tip of the nozzle by the electro-hydrodynamic force. (ii) Droplet transport, evaporation, and disruption: under the electric force, charged droplets move towards the substrate with the solvent evaporation. A charged droplet may be disrupted into a few smaller droplets after reaching a maximum attainable charge density. (iii) Preferential landing: The charged droplet will be attracted more towards these more curved areas due to the stronger electric field. Roughness of the substrate influences the morphology of thin film. (iv) Discharge and droplet spreading: The interfacial tensions determine the spreading rate of droplets: $\mathrm{S}$ $=\gamma_{\mathrm{sv}}-\gamma_{\mathrm{sl}}-\gamma_{\mathrm{lv}}$, where $\gamma_{\mathrm{sv}}, \gamma_{\mathrm{sl}}$ and $\gamma_{\mathrm{lv}}$ are interfacial tensions between substrate and ambient gas, substrate and liquid, and liquid and ambient gas, respectively. If $\mathrm{S}<0$, only partial wetting 
occurs with equilibrium reached at a finite contact area. If $S \geq 0$, the drop spreads until it completely covers the surface. (v) Decomposition and drying of the precursor salt: the decomposition and reaction (either partial or complete) of the solute may have occurred before the droplets reach the substrate. Rearrangement of these dry particles on the substrate surface by surface diffusion is not expected at moderate deposition temperatures less than $500{ }^{\circ} \mathrm{C}$ and a porous-like structure is expected to be formed instead of a very dense morphology. The schematic drawing of film formation process and photo image of corn-type spray are shown in Figure 2.3 (c) and (d), respectively. In our group, ESD has been demonstrated as a promising method for the formation of various porous structured and composite electrodes [62-65].

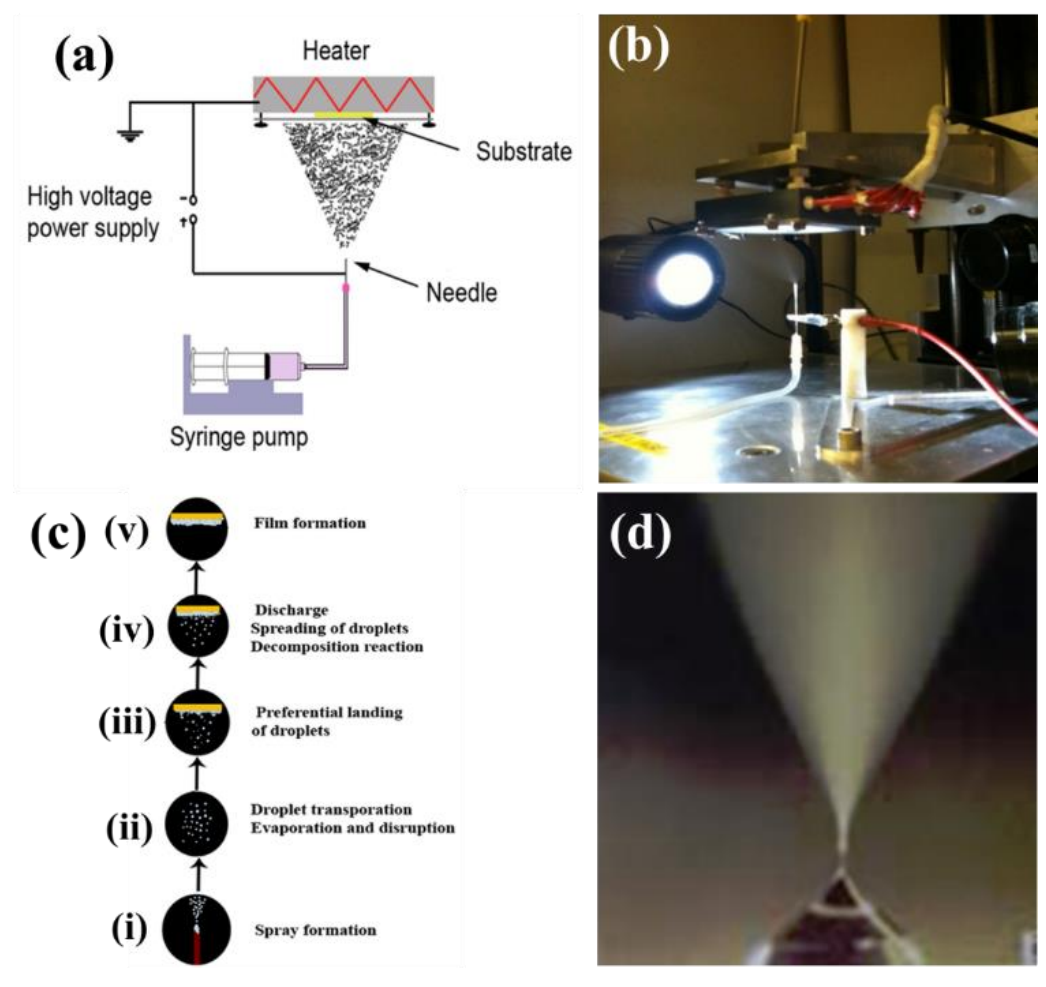

Figure 2. 3 (a) Schematic drawing and (b) photo image of ESD experimental set-up. (c) Schematic drawing of film formation process and (d) zoomed in photo image of corn-type spray. 


\subsection{References}

1. Simon, P. and Gogotsi, Y., 2008. Materials for electrochemical capacitors. Nature materials, 7(11), pp.845-854.

2. Linden, D. Handbook of Batteries; McGraw Hill: New York, $3^{\text {rd }}$. ed.; 2002.

3. Thackeray, M.M., Wolverton, C. and Isaacs, E.D., 2012. Electrical energy storage for transportation-approaching the limits of, and going beyond, lithium-ion batteries. Energy \& Environmental Science, 5(7), pp.7854-7863.

4. Julien, C., Mauger, A., Vijh, A., \& Zaghib, K. (2015). Lithium Batteries: Science and Technology. Springer.

5. Yang, Z., Zhang, J., Kintner-Meyer, M.C., Lu, X., Choi, D., Lemmon, J.P. and Liu, J., 2011. Electrochemical energy storage for green grid. Chemical reviews, 111(5), pp.3577-3613.

6. Whittingham, M.S., 1976. The role of ternary phases in cathode reactions. Journal of The Electrochemical Society, 123(3), pp.315-320.

\section{Sony Corporation, US4959281, 1990}

8. S. Basu, US patent 4304825,1981

9. Yazami, R. and Touzain, P., 1983. A reversible graphite-lithium negative electrode for electrochemical generators. Journal of Power Sources, 9(3), pp.365-371.

10. Padhi, A._.K., Nanjundaswamy, K.S. and Goodenough, J.B.D., 1997. Phospho-olivines as positive-electrode materials for rechargeable lithium batteries. Journal of the electrochemical society, 144(4), pp.1188-1194.

11. Kim, T.H., Park, J.S., Chang, S.K., Choi, S., Ryu, J.H. and Song, H.K., 2012. The current move of lithium ion batteries towards the next phase. Advanced Energy Materials, 2(7), pp.860-872.

12. Goodenough, J.B., 2012. Rechargeable batteries: challenges old and new. Journal of Solid State Electrochemistry, 16(6), pp.2019-2029.

13. Zu, C.X. and Li, H., 2011. Thermodynamic analysis on energy densities of batteries. Energy \& Environmental Science, 4(8), pp.2614-2624.

14. Goodenough, J.B., 2012. Rechargeable batteries: challenges old and new. Journal of Solid State Electrochemistry, 16(6), pp.2019-2029. 
15. Obrovac, M.N. and Chevrier, V.L., 2014. Alloy negative electrodes for Li-ion batteries. Chemical reviews, 114(23), pp.11444-11502.

16. Wu, H. and Cui, Y., 2012. Designing nanostructured Si anodes for high energy lithium ion batteries. Nano Today, 7(5), pp.414-429.

17. Chan, C.K., Peng, H., Liu, G., McIlwrath, K., Zhang, X.F., Huggins, R.A. and Cui, Y., 2008. High-performance lithium battery anodes using silicon nanowires. Nature nanotechnology, 3(1), pp.31-35.

18. Su, X., Wu, Q., Li, J., Xiao, X., Lott, A., Lu, W., Sheldon, B.W. and Wu, J., 2014. Silicon-based nanomaterials for lithium-ion batteries: a review. Advanced Energy Materials, 4(1).

19. Cui, L.F., Hu, L., Choi, J.W. and Cui, Y., 2010. Light-weight free-standing carbon nanotube-silicon films for anodes of lithium ion batteries. Acs Nano, 4(7), pp.36713678.

20. Cui, L.F., Yang, Y., Hsu, C.M. and Cui, Y., 2009. Carbon- silicon core- shell nanowires as high capacity electrode for lithium ion batteries. Nano letters, 9(9), pp.3370-3374.

21. Dimov, N., Kugino, S. and Yoshio, M., 2003. Carbon-coated silicon as anode material for lithium ion batteries: advantages and limitations. Electrochimica Acta, 48(11), pp.1579-1587.

22. Kim, H., Seo, M., Park, M.H. and Cho, J., 2010. A Critical Size of Silicon Nano-Anodes for Lithium Rechargeable Batteries. Angewandte Chemie International Edition, 49(12), pp.2146-2149.

23. Peng, K., Jie, J., Zhang, W. and Lee, S.T., 2008. Silicon nanowires for rechargeable lithium-ion battery anodes. Applied Physics Letters, 93(3), p.033105.

24. Wu, H., Chan, G., Choi, J.W., Yao, Y., McDowell, M.T., Lee, S.W., Jackson, A., Yang, Y., Hu, L. and Cui, Y., 2012. Stable cycling of double-walled silicon nanotube battery anodes through solid-electrolyte interphase control. Nature nanotechnology, 7(5), pp.310-315.

25. Maranchi, J.P., Hepp, A.F. and Kumta, P.N., 2003. High capacity, reversible silicon thin-film anodes for lithium-ion batteries. Electrochemical and solid-state letters, 6(9), pp.A198-A201.

26. Komaba, S., Shimomura, K., Yabuuchi, N., Ozeki, T., Yui, H. and Konno, K., 2011. Study on polymer binders for high-capacity $\mathrm{SiO}$ negative electrode of Li-ion batteries. The Journal of Physical Chemistry C, 115(27), pp.13487-13495. 
27. Li, J., Lewis, R.B. and Dahn, J.R., 2007. Sodium carboxymethyl cellulose a potential binder for Si negative electrodes for Li-ion batteries. Electrochemical and Solid-State Letters, 10(2), pp.A17-A20.

28. Magasinski, A., Zdyrko, B., Kovalenko, I., Hertzberg, B., Burtovyy, R., Huebner, C.F., Fuller, T.F., Luzinov, I. and Yushin, G., 2010. Toward efficient binders for Li-ion battery Si-based anodes: polyacrylic acid. ACS applied materials \& interfaces, 2(11), pp.3004-3010.

29. Kovalenko, I., Zdyrko, B., Magasinski, A., Hertzberg, B., Milicev, Z., Burtovyy, R., Luzinov, I. and Yushin, G., 2011. A major constituent of brown algae for use in highcapacity Li-ion batteries. Science, 334(6052), pp.75-79.

30. Zhao, B., Ran, R., Liu, M. and Shao, Z., 2015. A comprehensive review of $\mathrm{Li}_{4} \mathrm{Ti}_{5} \mathrm{O}_{12}-$ based electrodes for lithium-ion batteries: The latest advancements and future perspectives. Materials Science and Engineering: R: Reports, 98, pp.1-71.

31. Yi, T.F., Yang, S.Y. and Xie, Y., 2015. Recent advances of $\mathrm{Li}_{4} \mathrm{Ti}_{5} \mathrm{O}_{12}$ as a promising next generation anode material for high power lithium-ion batteries. Journal of Materials Chemistry A, 3(11), pp.5750-5777.

32. Yi, T.F., Liu, H., Zhu, Y.R., Jiang, L.J., Xie, Y. and Zhu, R.S., 2012. Improving the high rate performance of $\mathrm{Li}_{4} \mathrm{Ti}_{5} \mathrm{O}_{12}$ through divalent zinc substitution. Journal of Power Sources, 215, pp.258-265.

33. Yi, T.F., Shu, J., Zhu, Y.R., Zhu, X.D., Yue, C.B., Zhou, A.N. and Zhu, R.S., 2009. High-performance $\mathrm{Li}_{4} \mathrm{Ti}_{5-\mathrm{x}} \mathrm{V}_{\mathrm{x}} \mathrm{O}_{12}(0 \leq \mathrm{x} \leq 0.3)$ as an anode material for secondary lithiumion battery. Electrochimica Acta, 54(28), pp.7464-7470.

34. Hong, C.H., Noviyanto, A., Ryu, J.H., Kim, J. and Yoon, D.H., 2012. Effects of the starting materials and mechanochemical activation on the properties of solid-state reacted $\mathrm{Li}_{4} \mathrm{Ti}_{5} \mathrm{O}_{12}$ for lithium ion batteries. Ceramics International, 38(1), pp.301-310.

35. Wang, D., Ding, N., Song, X.H. and Chen, C.H., 2009. A simple gel route to synthesize nano- $\mathrm{Li}_{4} \mathrm{Ti}_{5} \mathrm{O}_{12}$ as a high-performance anode material for Li-ion batteries. Journal of materials science, 44(1), pp.198-203.

36. Shen, L., Uchaker, E., Zhang, X. and Cao, G., 2012. Hydrogenated $\mathrm{Li}_{4} \mathrm{Ti}_{5} \mathrm{O}_{12}$ nanowire arrays for high rate lithium ion batteries. Advanced Materials, 24(48), pp.6502-6506.

37. Ju, S.H. and Kang, Y.C., 2009. Characteristics of spherical-shaped $\mathrm{Li}_{4} \mathrm{Ti}_{5} \mathrm{O}_{12}$ anode powders prepared by spray pyrolysis. Journal of Physics and Chemistry of Solids, 70(1), pp.40-44. 
38. Guo, B., Li, Y., Yao, Y., Lin, Z., Ji, L., Xu, G., Liang, Y., Shi, Q. and Zhang, X., 2011. Electrospun $\mathrm{Li}_{4} \mathrm{Ti}_{5} \mathrm{O}_{12} / \mathrm{C}$ composites for lithium-ion batteries with high rate performance. Solid State Ionics, 204, pp.61-65.

39. Bresser, D., Paillard, E., Copley, M., Bishop, P., Winter, M. and Passerini, S., 2012. The importance of "going nano" for high power battery materials. Journal of Power Sources, 219, pp.217-222.

40. Feckl, J.M., Fominykh, K., Döblinger, M., Fattakhova-Rohlfing, D. and Bein, T., 2012. Nanoscale porous framework of lithium titanate for ultrafast lithium insertion. Angewandte Chemie International Edition, 51(30), pp.7459-7463.

41. Lin, C., Fan, X., Xin, Y., Cheng, F., Lai, M.O., Zhou, H. and Lu, L., 2014. Monodispersed mesoporous $\mathrm{Li}_{4} \mathrm{Ti}_{5} \mathrm{O}_{12}$ submicrospheres as anode materials for lithiumion batteries: morphology and electrochemical performances. Nanoscale, 6(12), pp.6651-6660.

42. Kang, E., Jung, Y.S., Kim, G.H., Chun, J., Wiesner, U., Dillon, A.C., Kim, J.K. and Lee, J., 2011. Highly Improved Rate Capability for a Lithium-Ion Battery Nano- $\mathrm{Li}_{4} \mathrm{Ti}_{5} \mathrm{O}_{12}$ Negative Electrode via Carbon-Coated Mesoporous Uniform Pores with a Simple SelfAssembly Method. Advanced Functional Materials, 21(22), pp.4349-4357.

43. Guo, X., Xiang, H.F., Zhou, T.P., Ju, X.K. and Wu, Y.C., 2014. Morphologies and structures of carbon coated on $\mathrm{Li}_{4} \mathrm{Ti}_{5} \mathrm{O}_{12}$ and their effects on lithium storage performance. Electrochimica Acta, 130, pp.470-476.

44. Zhu, G.N., Wang, C.X. and Xia, Y.Y., 2011. A comprehensive study of effects of carbon coating on Li4Ti5O12 anode material for lithium-ion batteries. Journal of the Electrochemical Society, 158(2), pp.A102-A109.

45. Wang, J., Liu, X.M., Yang, H. and Shen, X.D., 2011. Characterization and electrochemical properties of carbon-coated $\mathrm{Li}_{4} \mathrm{Ti}_{5} \mathrm{O}_{12}$ prepared by a citric acid sol-gel method. Journal of Alloys and Compounds, 509(3), pp.712-718.

46. Ge, H., Chen, L., Lin, S., Shi, X. and Song, X.M., 2014. Advanced electrochemical performances of Li4Ti5O12/Ag prepared by a facile synthesis route. Ionics, 20(8), pp.1189-1192.

47. Li, C.C., Li, Q.H., Chen, L.B. and Wang, T.H., 2012. A facile titanium glycolate precursor route to mesoporous $\mathrm{Au} / \mathrm{Li}_{4} \mathrm{Ti}_{5} \mathrm{O}_{12}$ spheres for high-rate lithium-ion batteries. ACS applied materials \& interfaces, 4(3), pp.1233-1238.

48. Rahman, M.D., Wang, J.Z., Hassan, M.F., Wexler, D. and Liu, H.K., 2011. Amorphous Carbon Coated High Grain Boundary Density Dual Phase $\mathrm{Li}_{4} \mathrm{Ti}_{5} \mathrm{O}_{12}-\mathrm{TiO}_{2}$ : A 
Nanocomposite Anode Material for Li-Ion Batteries. Advanced Energy Materials, 1(2), pp.212-220.

49. Hu, M., Jiang, Y. and Yan, M., 2014. High rate $\mathrm{Li}_{4} \mathrm{Ti}_{5} \mathrm{O}_{12}-\mathrm{Fe}_{2} \mathrm{O}_{3}$ and $\mathrm{Li}_{4} \mathrm{Ti}_{5} \mathrm{O}_{12}-\mathrm{CuO}$ composite anodes for advanced lithium ion batteries. Journal of Alloys and Compounds, 603, pp.202-206.

50. Han, C., He, Y.B., Li, H., Li, B., Du, H., Qin, X. and Kang, F., 2015. Suppression of interfacial reactions between $\mathrm{Li}_{4} \mathrm{Ti}_{5} \mathrm{O}_{12}$ electrode and electrolyte solution via zinc oxide coating. Electrochimica Acta, 157, pp.266-273.

51. Shu, J., Hou, L., Ma, R., Shui, M., Shao, L., Wang, D., Ren, Y. and Zheng, W., 2012. In situ fabrication of $\mathrm{Li}_{4} \mathrm{Ti}_{5} \mathrm{O}_{12} @ \mathrm{CNT}$ composites and their superior lithium storage properties. RSC Advances, 2(27), pp.10306-10309.

52. Pang, S., Zhao, Y., Zhang, C., Zhang, Q., Gu, L., Zhou, X., Li, G. and Cui, G., 2013. Electrostatic assembly of mesoporous $\mathrm{Li}_{4} \mathrm{Ti}_{5} \mathrm{O}_{12} /$ graphene hybrid as high-rate anode materials. Scripta Materialia, 69(2), pp.171-174.

53. Sivashanmugam, A., Gopukumar, S., Thirunakaran, R., Nithya, C. and Prema, S., 2011. Novel $\mathrm{Li}_{4} \mathrm{Ti}_{5} \mathrm{O}_{12} / \mathrm{Sn}$ nano-composites as anode material for lithium ion batteries. Materials Research Bulletin, 46(4), pp.492-500.

54. Wang, Y.Y., Hao, Y.J., Lai, Q.Y., Lu, J.Z., Chen, Y.D. and Ji, X.Y., 2008. A new composite material $\mathrm{Li}_{4} \mathrm{Ti}_{5} \mathrm{O}_{12}-\mathrm{SnO}_{2}$ for lithium-ion batteries. Ionics, 14(1), pp.85-88.

55. Zhu, J.P., Yang, G., Zhao, J.J., Wang, Q.S. and Yang, H.W., 2011, September. Synthesis and electrochemical properties of $\mathrm{Li}_{4} \mathrm{Ti}_{5} \mathrm{O}_{12} / \mathrm{CuO}$ anode material for $\mathrm{Li}$-ion batteries. In Advanced Materials Research (Vol. 279, pp. 77-82).

56. Chen, M., Li, W., Shen, X. and Diao, G., 2014. Fabrication of core-shell $\alpha-\mathrm{Fe}_{2} \mathrm{O}_{3} @$ $\mathrm{Li}_{4} \mathrm{Ti}_{5} \mathrm{O}_{12}$ composite and its application in the lithium ion batteries. ACS applied materials \& interfaces, 6(6), pp.4514-4523.

57. Yu, Y., Gu, L., Dhanabalan, A., Chen, C.H. and Wang, C., 2009. Three-dimensional porous amorphous $\mathrm{SnO}_{2}$ thin films as anodes for $\mathrm{Li}$-ion batteries. Electrochimica Acta, 54(28), pp.7227-7230.

58. Van Zomeren, A.A., Kelder, E.M., Marijnissen, J.C.M. and Schoonman, J., 1994. The production of thin films of $\mathrm{LiMn}_{2} \mathrm{O}_{4}$ by electrospraying. Journal of aerosol science, 25(6), pp.1229-1235.

59. Shui, J.L., Yu, Y. and Chen, C.H., 2006. Deposition conditions in tailoring the morphology of highly porous reticular films prepared by electrostatic spray deposition (ESD) technique. Applied Surface Science, 253(5), pp.2379-2385. 
60. Chen, C.H., Kelder, E.M. and Schoonman, J., 1997. Effect of layer morphology on the lithium-ion diffusion in thin $\mathrm{Li}_{x} \mathrm{CoO}_{2}$ films. Journal of materials science letters, 16(24), pp.1967-1969.

61. Jiang, Y., Yu, Y., Sun, W., Chen, C., Meng, G. and Gao, J., 2007. Electrostatic Spray Assembly of Nanostructured $\mathrm{La}_{0.7} \mathrm{Ca}_{0.3} \mathrm{CrO}_{3-\delta}$ Films. Journal of The Electrochemical Society, 154(8), pp.E107-E111.

62. Li, X., Dhanabalan, A., Gu, L. and Wang, C., 2012. Three-Dimensional Porous CoreShell Sn@Carbon Composite Anodes for High-Performance Lithium-Ion Battery Applications. Advanced Energy Materials, 2(2), pp.238-244.

63. Yu, Y., Chen, C.H. and Shi, Y., 2007. A Tin-Based Amorphous Oxide Composite with a Porous, Spherical, Multideck-Cage Morphology as a Highly Reversible Anode Material for Lithium-Ion Batteries. Advanced Materials, 19(7), pp.993-997.

64. Li, X., Dhanabalan, A. and Wang, C., 2011. Enhanced electrochemical performance of porous $\mathrm{NiO}-\mathrm{Ni}$ nanocomposite anode for lithium ion batteries. Journal of Power Sources, 196(22), pp.9625-9630.

65. Chen, C., Agrawal, R., Kim, T.K., Li, X., Chen, W., Yu, Y., Beidaghi, M., Penmatsa, V. and Wang, C., 2014. Nanostructured Electrodes via Electrostatic Spray Deposition for Energy Storage System. ECS Transactions, 61(27), pp.155-163. 


\section{FABRICATION AND CHARACTERIZATION OF POROUS LTO THIN FILM ELECTRODES}

\subsection{Introduction}

Lithium titanate $\left(\mathrm{Li}_{4} \mathrm{Ti}_{5} \mathrm{O}_{12}, \mathrm{LTO}\right)$ is one of the candidate anode materials, which has attracted great attention due to its intrinsic properties. Usually its lower cutoff voltage is setting as $1 \mathrm{~V}$ since the main reactions for $\mathrm{LTO}$ happen at $\sim 1.55 \mathrm{~V} \mathrm{vs} \mathrm{Li}^{\prime} / \mathrm{Li}^{+}$, exhibiting very flat charge-discharge plateaus. This makes it safer to use because it avoids the formations of solid electrolyte interphase (SEI) and lithium dendrite. Also, as a zero-strain insertion material, LTO is able to intercalate three lithium ions per molecule with negligible volumetric change giving rise to its excellent cycling performance [1-6]. These features make it promising for some applications, such as large scale and long cycle-life stationary batteries. However, one of the main issues for LTO is its low theoretical capacity, which

is only $175 \mathrm{mAh} \mathrm{g}^{-1}$ corresponding to a structural transition from spinel $\left(\mathrm{Li}_{4} \mathrm{Ti}_{5} \mathrm{O}_{12}\right)$ to rock salt $\left(\mathrm{Li}_{7} \mathrm{Ti}_{5} \mathrm{O}_{12}\right)$. Both high working voltage and low theoretical capacity hinder its potential use in high energy density applications.

In order to improve the energy density of LTO, two strategies have been employed, including increasing the specific capacity and reducing the average working voltage. $\mathrm{Ab}$ initio calculations corroborated that it is possible to discharge LTO to $0 \mathrm{~V}$ to obtain a theoretical composition of $\mathrm{Li}_{8.5} \mathrm{Ti}_{5} \mathrm{O}_{12}$, corresponding to a capacity of $262 \mathrm{mAh} \mathrm{g}^{-1}$ [7]. In addition, fabricating composite materials with other high capacity anode materials may also enhance the energy capacity [8-12]. In order to utilize all of the components in the composite as active materials, it's better to set the lower cutoff voltage to $\sim 0 \mathrm{~V}$ since the operating voltages for some of anode materials are less than $1 \mathrm{~V}$, such as Si and Sn. 
In this dissertation, our goal is to enhance the energy density of LTO by synthesizing LTO/Si/rGO nanocomposite electrode. Due to the low working voltages of $\mathrm{Si}$ and $\mathrm{rGO}$, the resulting composite need to be discharged to $\sim 0 \mathrm{~V}$ to make them active. In this chapter, we focus on the electrochemical performance evaluation of LTO when cutoff voltage is $\sim 0 \mathrm{~V}$. The porous LTO thin film electrode was synthesized by electrostatic spray deposition (ESD) process. The porous structure provides a large contact area between electrode and electrolyte which reduces the $\mathrm{Li}^{+}$diffusion path and improves the high rate performance. Physical characterization showed that phase-pure LTO with a surface area of $76.51 \mathrm{~m}^{2} \mathrm{~g}^{-1}$ can be obtained under optimized conditions. Electrochemical testing showed that the resulting LTO had a large specific capacity of $357 \mathrm{mAh} \mathrm{g}^{-1}$ at a current density of $0.15 \mathrm{~A} \mathrm{~g}^{-1}$ and high rate capability of $98 \mathrm{mAh} \mathrm{g}^{-1}$ at $6 \mathrm{~A} \mathrm{~g}^{-1}$ (actual discharge time $=60 \mathrm{~s}$ ). In addition, asymmetric rate behavior was observed with a faster charging but slower discharging process. When discharge current density was set as $3 \mathrm{~A} \mathrm{~g}^{-1}$, charge capacities at 3,30 , and $120 \mathrm{~A} \mathrm{~g}^{-1}$ were 162,85 and $16 \mathrm{mAh} \mathrm{g}^{-1}$, respectively. Compared to commercial LTO powders, our superior electrochemical performance can be attributed to its ESD derived porous structures.

\subsection{Experimental}

Porous LTO thin film was prepared by an electrostatic spray deposition (ESD) setup. The precursor solution was prepared by adding Titanium (IV) butoxide $(0.34032 \mathrm{~g})$ and Lithium acetate $(0.0528 \mathrm{~g})$ into a solvent mixture of ethanol and butyl carbitol (4:1 volume ratio, $20 \mathrm{ml}$ ). The resulting solution was used as the precursor solution for ESD process. The flow rate of the precursor solution was set at $2 \mathrm{~mL} \mathrm{~h}^{-1}$ and controlled by a syringe pump. Porous nickel foam was used as the deposition substrate. The nozzle-to-substrate 
distance was kept at $5 \mathrm{~cm}$. A high voltage of $6-8 \mathrm{kV}$ was applied between the nozzle and the substrate. The deposition temperature was $250{ }^{\circ} \mathrm{C}$. ESD-derived films were next heated in a tube furnace at $750{ }^{\circ} \mathrm{C}$ for 2 hours in an argon gas environment.

The morphology of the ESD-LTO electrode was investigated using a field emissionscanning electron microscopy (JEOL 6335FE-SEM) and transmission electron microscopy (Philips CM200 FEG TEM). Selected area electron diffraction (SAED) was performed and the resulting diffraction patterns were analyzed by "Digital Micrograph" software. $\mathrm{N}_{2}$ adsorption-desorption isotherms were collected by a Micromeritics instrument at $77 \mathrm{~K}$. Xray diffraction (XRD) patterns were recorded using a D-5000 diffractometer with $\mathrm{Cu} \mathrm{K} \alpha$ radiation $(\lambda=0.154056 \mathrm{~nm}),(40 \mathrm{kV} / 25 \mathrm{~mA})$ at the scan rate of $1^{\circ} \mathrm{min}^{-1}$ from $10^{\circ}$ to $90^{\circ}$. The patterns were identified by the program "search-match" using databases "Joint Committee on Powder Diffraction Standards - International Center for Diffraction Data (JCPDS ICDD)".

Electrochemical test cells (2032 coin cells) were assembled in an argon filled glove box. The ESD derived electrode was used as the working electrode while lithium foil was used as the counter and reference electrodes. Celgard 2400 microporous polypropylene was used as the separator. The electrolyte used was $1 \mathrm{M}$ lithium bis(perfluoroethylsulfonyl)imide dissolved in ethylene carbonate (EC): diethyl carbonate (DEC): ethyl methyl carbonate (EMC) in the volume ratio of 1:1:1. Cleaned Ni foam was used during cell assembly acting as a spacer to adjust the thickness of all components to ensure a good electric contact. Cyclic voltammetry (CV) was performed at a scan rate of $0.2 \mathrm{mV} \mathrm{s}^{-1}$ within voltage range from 0.02 to $3 \mathrm{~V}$ by using a Bio-logic versatile multichannel potentiostat (VMP3, Bio logic). The data points will be recorded every $5 \mathrm{mV}$ 
or every $60 \mathrm{~s}$, whichever comes first. All electrochemical cells were galvanostatically cycled at room temperature using a NEWARE BTS-610 Battery Test System. EIS were performed using Bio-logic versatile multichannel potentiostat (VMP3, Bio logic). The EIS was potentiostatically measured with an $\mathrm{AC}$ oscillation of $10 \mathrm{mV}$ amplitude over the frequencies ranging from $100 \mathrm{kHz}$ to $0.01 \mathrm{~Hz}$ at various voltage stages. The voltage stage was achieved by charging the cell at a constant current density and stabilizing for 2 hours before EIS tests. The EIS data were fitted using Z-fit function in EC-Lab (V10.40) software.

\subsection{Results and Discussion}

The porous LTO thin film electrode was prepared via ESD followed by a high temperature annealing process. Physical properties and structures were examined and the results are shown in Figure 3.1. The LTO powder was scratched off from Ni foam substrate for X-ray diffraction (XRD) and Brunauere-Emmette-Teller (BET) tests. The XRD pattern can be indexed as spinel LTO, according to the JCPDS card no. 49-0207 (Figure 3.1a) [13]. The BET surface area and the total pore volume of LTO powder are $76.51 \mathrm{~m}^{2} \mathrm{~g}^{-1}$ and 0.17 $\mathrm{m}^{3} \mathrm{~g}^{-1}$, respectively, according to the nitrogen adsorption/desorption isotherms in Figure 3.2b. There is an obvious $\mathrm{H} 2$ type adsorption-desorption hysteresis loop which is attributed to the pore connectivity effect from relatively uniform channel-like pores [14]. The average pore width is calculated to be about $8 \mathrm{~nm}$ based on the Barrett-Joyner-Halenda (BJH) adsorption. SEM images in Figure 3.1c exhibit uniform deposition of LTO on 3D inter connected porous $\mathrm{Ni}$ foam. The porous structure observed is typical for materials deposited via the ESD process due to the solvent evaporation and the decomposition of organic salts. The selected area electron diffraction (SAED) pattern exhibits the poly- 
crystalline property of LTO. From the above characterization it can be seen that porous polycrystalline LTO was formed through ESD and post annealing process.

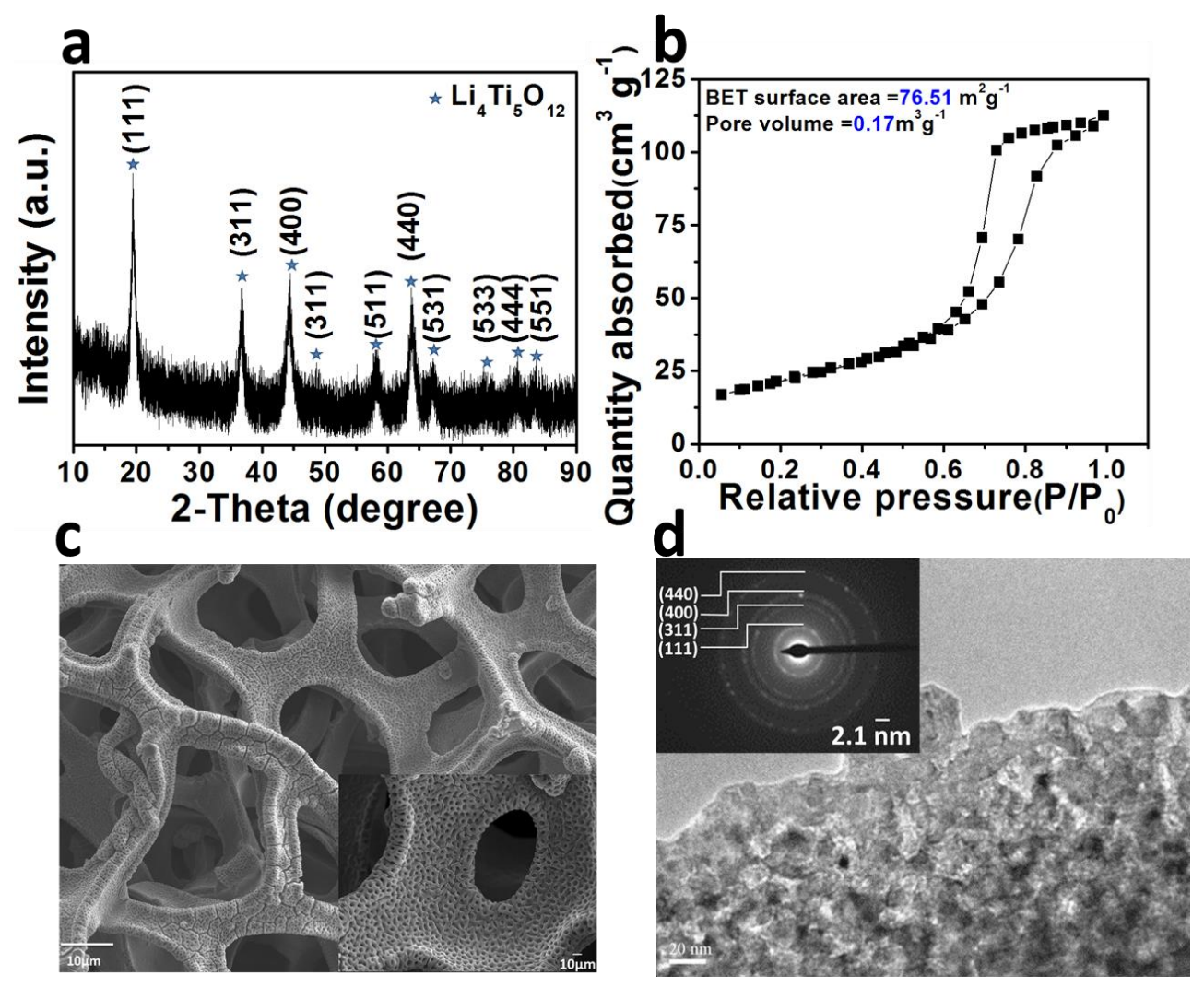

Figure 3. 1 (a) XRD pattern of ESD-LTO after annealing at $750{ }^{\circ} \mathrm{C}$. (b) Nitrogen adsorption-desorption isotherm of ESD-LTO powder. (c) SEM Images (insert: at higher magnification) and (d) TEM images (insert: SAED pattern) of ESD-LTO after annealing at $750{ }^{\circ} \mathrm{C}$.

To investigate the electrochemical behavior of lithium intercalation into the LTO electrode, typical cyclic voltammetry $(\mathrm{CV})$ was first measured at a scan rate of $0.2 \mathrm{mV} \mathrm{s}^{-1}$ in the voltage range from 0.02 to $3 \mathrm{~V}$ for 10 cycles, as shown in Figure 3.2a. In the first cycle, a pair of redox peaks appears at $1.47 \mathrm{~V}$ (reduction) and $1.68 \mathrm{~V}$ (oxidation) corresponding to the $\mathrm{Li}^{+}$insertion and extraction process of LTO, as expressed in Equation 2.4 , which is in good agreement with literature [15-16]. There is a $0.21 \mathrm{~V}$ voltage separation in the first cycle between the anodic and cathodic peaks which is most likely because of 
the polarization resulting from the sluggish lithium diffusion and relatively low electrical conductivity [16]. In the following cycles, the positions for this pair of peaks slightly shifted far away, resulting in a gradually increased polarization, which may be due to the resistance increase caused by SEI layer. Other than this pair of redox peaks, there is broad band below $1.45 \mathrm{~V}$ in the first cathodic cycle which may be due to two possible reasons. The first reason is because of the formation of a solid electrolyte interface (SEI) layer and the second reason could be due to the further intercalation of $\mathrm{Li}^{+}$into $\mathrm{Li}_{7} \mathrm{Ti}_{5} \mathrm{O}_{12}$ structure [15-16]. The broad peak disappeared in the following cycles indicating the SEI formation was almost complete.
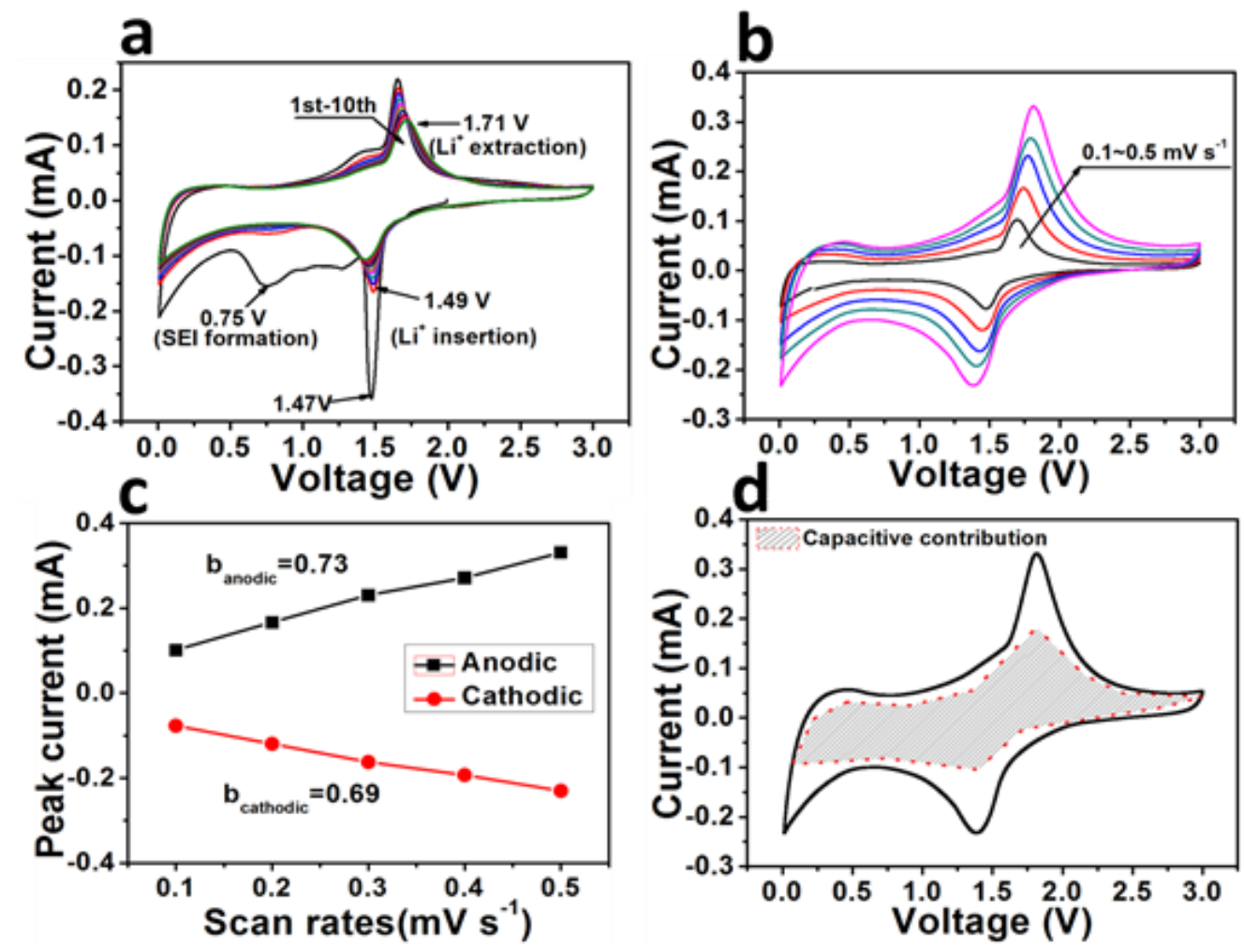

Figure 3. 2 (a) CV curves of ESD-LTO electrode in the voltage window of 0.02-3 V at 0.2 $\mathrm{mV} \mathrm{s}^{-1}$. (b) The $5^{\text {th }}$ cycle of $\mathrm{CV}$ curves at various scan rates ranging from 0.1 to $0.5 \mathrm{mV} \mathrm{s}^{-}$ ${ }^{1}$. (c) The relationship between anodic/cathodic peak currents and scan rates in CV curves at the scan rates between $0.1-0.5 \mathrm{mV} \mathrm{s}^{-1}$. (d) Calculated capacitive charge storage contribution at $0.5 \mathrm{mV} \mathrm{s}^{-1}$. 
$\mathrm{CV}$ at various scan rates were also performed to investigate the kinetic responses of the system, which also can provide quantitative information about diffusion controlled and non-diffusion controlled (capacitive) charge storage processes (See detailed introduction of this method in appendix). CV curves at low scan rates from 0.1 to $0.5 \mathrm{mV} \mathrm{s}^{-1}$ are shown in Figure 3.2b. The relationships between peak currents and scan rates have been plotted in Figure 4.2c. Based on equation ${ }^{i=a v^{b}}$, in which $a$ and $b$ are adjustable parameters that may vary at different voltages, $v$ is the applied scan rate, $i$ is the current at any point on $\mathrm{CV}$ curve, the corresponding $b$ values were calculated for both the anodic and cathodic peaks [17-18]. There are two well-defined conditions: $b=0.5$ (diffusion controlled charge storage contribution) and $b=1.0$ (non-diffusion controlled charge storage contribution). It is apparent that the anodic process has more capacitve charge storage than cathodic process due to larger $b$ value. To quantitatively determine the contributions from these two different charge storage mechanisms, equation $i(V)=k_{1} v+k_{2} v^{1 / 2}$ was used, where $k_{1}$ and $k_{2}$ are variables that will change at different voltages, $k_{l} v$ represents the non-diffusion controlled charge storage and $k_{2} v^{1 / 2}$ represents the diffusion controlled charge storage [17-18]. The capacitive charge contribution at $0.5 \mathrm{mV} \mathrm{s}^{-1}$ was calculated and shown in Figure $3.2 \mathrm{~d}$. It can be seen that the the capacitive charge storage resigned in the whole voltage range and takes $\sim 60 \%$ of the total charge storage. Though through the above mentioned method we can calculate the distribution of diffusion controlled and capacitive charge storages, it has some limitations from both (a) theoretical aspects and (b) data collection/calculation aspects, which make the obtained value a rough estimation. The detailed discussions from these two aspects are provided as below [20-25]. 
(a) Limitations from theoretical aspects.

The limitations coming from theoretical aspects will be discussed in detail from three points. (i) The two parts in the equation may not represent all the electrochemical reactions that happening in LIB, which are complicate processes. For some of the reactions, we know the reaction process and can express it mathematically in the equation, such as lithium insertion/extraction process of LTO. For some of the reactions, we know they may be happening during charge/discharge, but the mathematic expressions of the reactions are still unknown, such as SEI formation and decomposition process. Furthermore, there may be existing more reactions that haven't been discovered yet. In addition, it's very hard to separate the diffusion controlled process with pseudocapacitance, especially for nanomaterials. Since for diffusion controlled process, it always will encounter certain nondiffusion controlled process first then start the diffusion controlled reactions. The amount of non-diffusion controlled process depends on the properties of the material, such as particle size, electronic and ionic conductivities. However, the above used equation simplified the situation under the assumption that all the reactions are either diffusion controlled processes or non-diffusion controlled (capacitive) processes. So for the electrochemical processes that are closer to this assumption, more accurate results can be obtained. (ii) Not all equations follows exact rule that current is proportional to scan rate $(v)$ or square root of scan rate $\left(v^{\frac{1}{2}}\right)$. For example, the current does not exactly proportional to the square root of the scan rate for quasi-reversible system. However, in the calculation equation, it still treat the quasi-reversible reaction that current is proportional to square root of scan rate. In a battery, only in the situation that the reaction kinetics are very fast or sluggish, the reaction can be treated as reversible or totally irreversible. In the appendix, 
we discussed how to distinguish these processes theoretically and experimentally. If the diffusion controlled reaction belongs to a quasi-reversible system, some error can be introduced by the equation. (iii) The actual reaction conditions may not meet the conditions under which the equations were developed. The appendix shows the important assumptions and conditions of the equations for both diffusion controlled and non-diffusion controlled processes. In addition, the boundary conditions applied during equation development may not be met in real test environment. For example, in order to apply Fick's diffusion law to Nernst equation, the boundary conditions that the initial reactant is uniformly distributed throughout the solution at a bulk concentration at the start of the experiment. However, this cannot always be achieved. In our battery, after lithium insertion and extraction, not all LTO can be recovered to LTO, which leaves the unsatisfied boundary conditions for the next cycle. This also introduces in errors during calculation. In addition, during equation development, the planner diffusion process is applied which is not always true, especially for our porous electrode. This may also cause some errors during estimation.

(b) Limitations from data collection/calculation aspects.

The limitations coming from data collection/calculation aspects will be discussed in detail from three points. (i) $\mathrm{CV}$ data collection process: There are lots of parameters that have influence on CV testing, such as scan rate, voltage window, cycle number, electrolyte concentration, position of working and reference electrodes, morphology of electrode etc. In our test, the cell was first stabilized under $\mathrm{CV}$ test at $0.2 \mathrm{mV} \mathrm{s}^{-1}$, then various scan rates from $0.1 \sim 0.5 \mathrm{mV} \mathrm{s}^{-1}$ were applied. Though the same cell and same voltage window were used for all scans, it was still possible that the initial status of the battery at each scan rates were different. The curve change due to such difference was considered as the change 
caused by the scan rate change which may introduce errors in data collection process. (ii) Scan rates selection process: For the reversible and total irreversible reactions, peak current is propositional to the square root of scan rate and peak position is independent with the scan rate. However, in real case, cathodic peak and anodic peak will shift to lower and higher voltage, respectively, as the scan rate increase. Such shift is considered as one of the reason for the inaccurate calculation, as discussed in appendix in detail. In order to minimize the peak shift, low scan rates ranging from $0.1 \sim 0.5 \mathrm{mV} \mathrm{s}^{-1}$ were used in our experiment. In another aspect, the calculation of capacity distribution only need two set of $\mathrm{CV}$ data at different scan rates. For example, $\mathrm{CV}$ data at 0.1 and $0.2 \mathrm{mV} \mathrm{s}^{-1}$ can be used to calculate the capacity distribution at both scan rates. But the obtained $k_{1}$ and $k_{2}$ can only be used at these two scan rates, not applicable to other scan rates. To make the $k_{1}$ and $k_{2}$ values more universal, in another words, can be applied for a larger scan rate range, five scan rates were used in our experiment. The obtained $k_{1}$ and $k_{2}$ can not only be used at $0.1 \mathrm{mV} \mathrm{s}^{-1}$, but also at $0.5 \mathrm{mV} \mathrm{s}^{-1}$. We applied the "solve" function in excel to estimate the best $k_{1}$ and $k_{2}$ values which give the smallest variance. In our calculation, the variances at different voltages were in the range between $10^{-8} \sim 10^{-10}$, which is acceptable for the actual current values in the test. (iii) Data points selection: There are lots of data points in a CV curve which make it hard for us to calculate the capacity contribution at each point. So only limited amount of data points will be calculated and used to plot the capacitive charge storage contribution within the original CV curves, as what had been done in Figure 3.2d. In our calculation, we selected data points every $0.25 \mathrm{~V}$ in both anodic and cathodic processes and the obtained curve is relatively smooth. But we admit that selection of more data points is good for getting a more accurate estimation. According to the above 
mentioned limitations for such calculation, we can treat the obtained results as a rough estimation instead of accurate calculation. However, such estimation is still useful especially when it is used in combination with other analytical methods to give insight of the electrochemical reactions.

To test the rate capability and cycle life of LTO electrodes, charge-discharge measurements were carried out under various current densities ranging from 0.15 to $6 \mathrm{Ag}^{-}$ ${ }^{1}$ followed by another 100 cycle cyclability test at $0.6 \mathrm{~A} \mathrm{~g}^{-1}$. The results are shown in Figure 3.3a. The major trend for the rate capability test in the first 120 cycles is that as the current density increases, the capacity decreases. After that, the cell experiences a gradual capacity increase in the following 100 cycle test at $0.6 \mathrm{~A} \mathrm{~g} \mathrm{~g}^{-1}$. The discharge and charge capacities for the first cycle are $714 \mathrm{mAh} \mathrm{g}^{-1}$ and $384 \mathrm{mAh} \mathrm{g}^{-1}$, respectively, resulting in a coulombic efficiency of $53.8 \%$. Then the coulombic efficiency rapidly increases to about $98 \%$ in the second cycle and remains nearly $100 \%$ thereafter. The capacity loss in the first cycle may be attributed to SEI layer formation below $0.75 \mathrm{~V}$. Future effort is required to improve the Columbic efficiency to make it more suitable for the use in commercial LIBs. For rate capability test, the discharge capacities are $357,307,270,207,153$ and $98 \mathrm{mAh} \mathrm{g}^{-1}$ at 0.15 , $0.3,0.6,1.5,3$, and $6 \mathrm{~A} \mathrm{~g}^{-1}$, respectively. Notably, the actual charge-discharge time for 98 $\mathrm{mAh} \mathrm{g} \mathrm{g}^{-1}$ capacity at $6 \mathrm{~A} \mathrm{~g}^{-1}$ is only $60 \mathrm{~s}$. In chapter 5 we have provided the rate capability test results of LTO electrode casted with commercial LTO power. It exhibits much lower capacity than ESD derived porous electrode. For example, the discharge capacity are 118, 86, 50 and $10 \mathrm{mAh} \mathrm{g}^{-1}$ at $0.3,0.6,1.5$, and $3 \mathrm{~A} \mathrm{~g}^{-1}$, respectively. Moreover, for ESD-LTO electrode, even after cycling at such a high rate $\left(6 \mathrm{~A} \mathrm{~g}^{-1}\right)$, the capacity can reach $299 \mathrm{mAh}$ $\mathrm{g}^{-1}$, when the current density is set back to $0.6 \mathrm{~A} \mathrm{~g}^{-1}$. Since a significant amount of capacity 
is still available when testing at $6 \mathrm{~A} \mathrm{~g}^{-1}$, even higher rate capability tests were performed at $6,15,30$ and $45 \mathrm{~A} \mathrm{~g}^{-1}$, pushing the charge-discharge time to within 1 minute. The capacity drops a lot when the current density reaches $30 \mathrm{~A} \mathrm{~g}^{-1}$. Under $45 \mathrm{~A} \mathrm{~g}^{-1}$, almost no capacity can be detected. Thus, it indicates that a current density of $45 \mathrm{~A} \mathrm{~g}^{-1}$ is the charge/discharge limit for LTO electrode. After this harsh condition test, it is noteworthy that the cell is still functioning, delivering a capacity of $181 \mathrm{mAh} \mathrm{g}^{-1}$ at $3 \mathrm{~A} \mathrm{~g}^{-1}$ for 500 cycles, which is even higher than that of previous round $3 \mathrm{~A} \mathrm{~g} \mathrm{~g}^{-1}$ test. Additionally, the cell has been cycled for over 1100 cycles and thus far there is no sign of cell failure. From above cyclability test it can be seen the electrochemical performance of ESD derived LTO electrode is stable even after high current density tests. Furthermore, setting the cutoff voltage as low as $0 \mathrm{~V}$ is proved to be beneficial for the enhancement of capacity.

To get a better understanding of the electrochemical reaction of LTO, the chargedischarge curves for different cycles at various current densities are plotted, as shown in Figure 3.3b. In the first discharge process, the plateau near $1.55 \mathrm{~V}$ stands for the typical two phase reaction. The discharge curve below $1.50 \mathrm{~V}$ could be divided to two continuous slope parts with different slopes. These two parts deliver a total capacity of $540 \mathrm{mAh} \mathrm{g}^{-1}$, $76 \%$ of the $1^{\text {st }}$ cycle discharge capacity. However, after the first cycle, the capacity delivered in the slope region below $1.50 \mathrm{~V}$ decreased significantly. This could be caused by severe SEI formation in the first cycle. From the second cycle to the $20^{\text {th }}$ cycle, the discharge curves have no significant changes, indicating a stable electrochemical performance. For the charging curve from the $1^{\text {st }}$ cycle to the $20^{\text {th }}$ cycle, the charging capacities decreased slightly without major curve changes. In Figure $3.3 \mathrm{c}$, at the $20^{\text {th }}$ cycle of $0.15 \mathrm{~A} \mathrm{~g}^{-1}$ test, a stable capacity of $357 \mathrm{mAh} \mathrm{g}^{-1}$ is obtained with approximately $100 \%$ 
coulombic efficiency. From figure $4.4 \mathrm{c}$ it can be seen that the plateaus are obvious at 0.15 , 0.3 and $0.6 \mathrm{~A} \mathrm{~g} \mathrm{~g}^{-1}$ but gradually disappear as the current density increased to $6 \mathrm{~A} \mathrm{~g}^{-1}$. The polarization between the charge-discharge plateaus are $0.06 \mathrm{~V}, 0.10 \mathrm{~V}$ and $0.14 \mathrm{~V}$ for 0.15 , 0.3 and $0.6 \mathrm{~A} \mathrm{~g} \mathrm{~g}^{-1}$, respectively. They are relatively low and indicating good kinetics at low current densities.
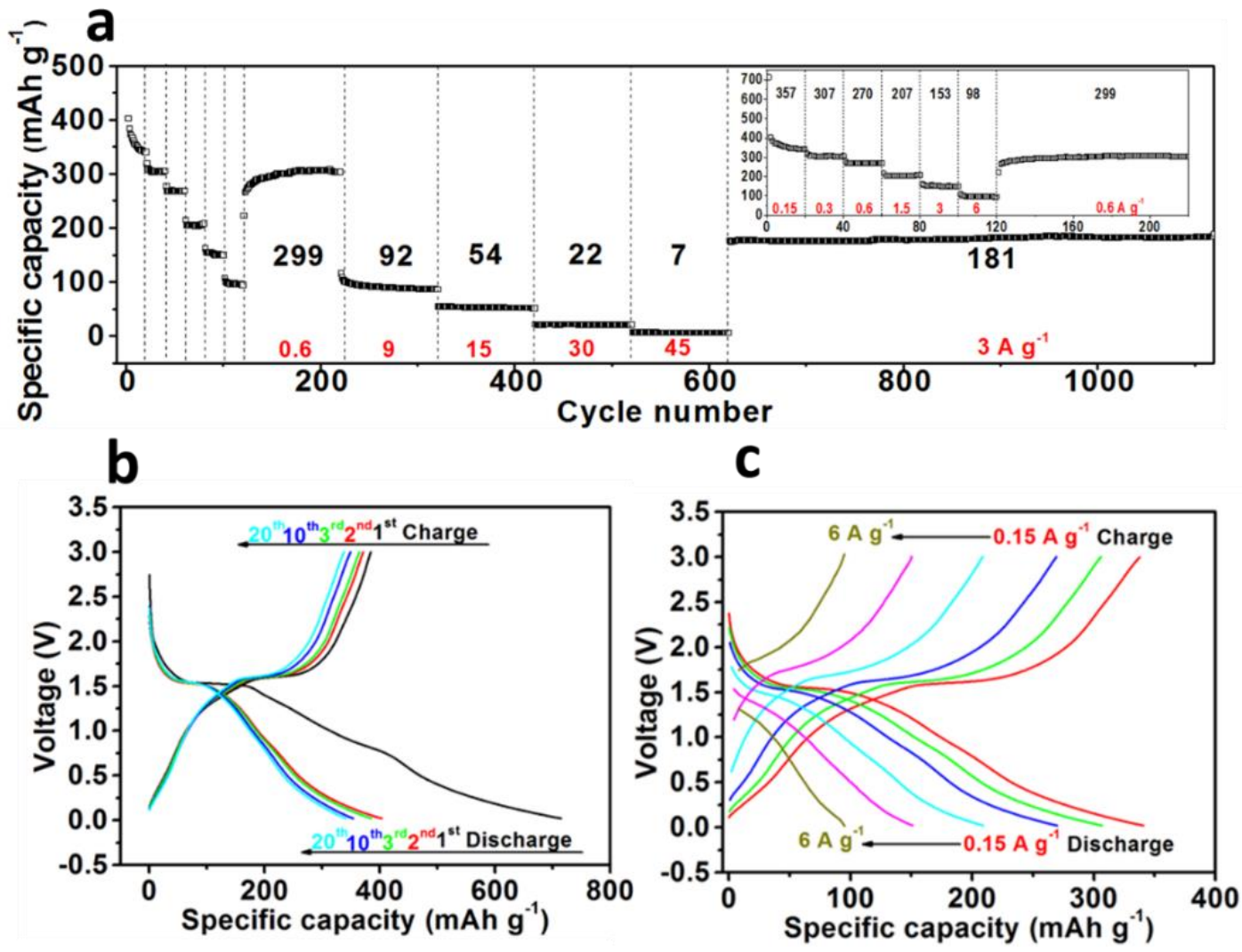

Figure 3.3 (a) Cyclability and rate capability of ESD-LTO electrode. (b) Charge-discharge curves of the $1^{\text {st }}, 2^{\text {nd }}, 3^{\text {rd }}, 10^{\text {th }}$ and $20^{\text {th }}$ cycles under current density of $0.15 \mathrm{~A} \mathrm{~g}^{-1}$, respectively, and (c) Charge-discharge curves under current densities of $0.15,0.3,0.6,1.5$, 3 and $6 \mathrm{~A} \mathrm{~g}^{-1}$, respectively.

From the rate capability test it can be seen that the ESD derived LTO thin film electrode exhibited excellent high rate performance. Here we have given some possible reasons for such high rate performance: 1) Continuous conductive pathways. Though no 
conductive additives were used, the insulating character of pristine LTO is not a bottleneck for high rate performance. During the early stages of lithium intercalation, even a small amount of lithium ions can cause a dramatic improvement in conductivity, which makes conductive additives unnecessary [5]. Furthermore, under high rates the charged or discharged products will not be the end members predicted in the reaction, which means that there will be very little $\mathrm{Li}_{4} \mathrm{Ti}_{5} \mathrm{O}_{12}$ in the electrode during cycling. 2) Short diffusion length. The porous structure facilitates $\mathrm{Li}^{+}$diffusion and electron transportation and provides a larger contact area between the electrode and the electrolyte for reaction, ensuring fast reaction kinetics and enhanced rate performance. 3) Enriched grain boundaries. Nanosized particles generate more grain boundaries which enhance the $\mathrm{Li}^{+}$ diffusion by its migration through grain boundaries [26]. 4) Pseudocapacitive charge storage. There is a large contribution from pseudocapacitive charge storage in the total charge and such a charge storage is barely influenced by the charge/discharge rates. Therefore, the capacity contribution from capacitive charge will not decrease much as it would be in bulk electrodes.

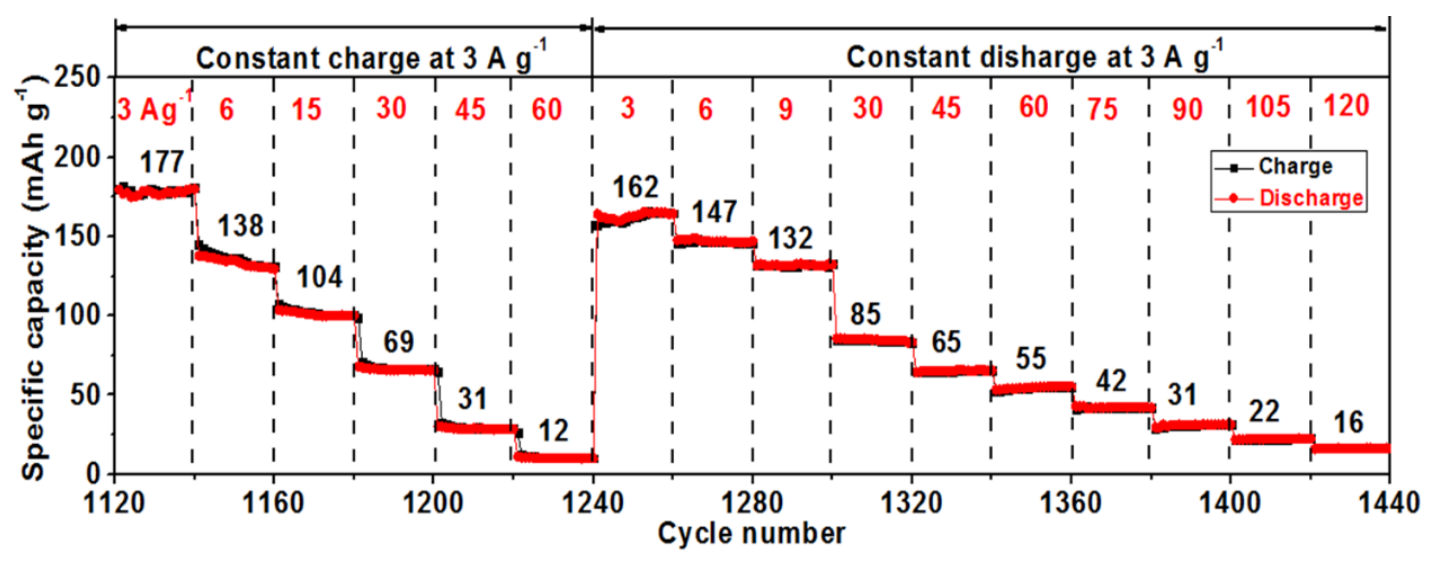

Figure 3. 4 Asymmetric rate capability test results of ESD-LTO electrode. Test conditions: constant charge current density: $3 \mathrm{~A} \mathrm{~g}^{-1}$, discharge current density: 3-60 $\mathrm{A} \mathrm{g}^{-1}$; constant discharge current density: $3 \mathrm{~A} \mathrm{~g}^{-1}$, charge current densities: 3-120 $\mathrm{A} \mathrm{g}^{-1}$. 
The rate capability of a battery is mainly determined by the kinetics of the electrochemical reactions, which rely on electronic conductivity, ionic diffusivity, charge transfer speed, etc. In most cases, the rate capability tests are performed by applying identical current to both charge and discharge processes. However, the kinetics in charge and discharge process are not necessarily the same [27]. So the capacity decrease under high current densities could be partially due to the slow cathodic or anodic process. To examine this scenario, asymmetric rate capability tests were performed, as shown in Figure 3.4. The cell which was tested for cyclability and symmetric rate capability was subsequently used in this test as well. Charging at a constant current density of $3 \mathrm{~A} \mathrm{~g} \mathrm{~g}^{-1}$ and discharging at various current densities ranging from 0.3 to $60 \mathrm{~A} \mathrm{~g}^{-1}$ was first performed, followed by discharging at a constant current density of $3 \mathrm{~A} \mathrm{~g}^{-1}$ and charging at various current densities ranging from 0.3 to $120 \mathrm{~A} \mathrm{~g}^{-1}$. It can be observed that the performance of asymmetric rate tests are all better than symmetric rate tests. In addition, the capacities in the constant discharge process are always higher than that from the constant charge process under the same rates which indicates that the discharge process has slower reactions and is one of the reasons for the drop in capacity in symmetric rate tests. Since very high rates were tested, the time scale for charging or discharging was pushed to several seconds, making it more like a capacitor. Most likely, this is due to capacitively stored Li ions at the surface. The simultaneous $8 \mathrm{a}$ and $16 \mathrm{c}$ occupation at the surface will hinder further $\mathrm{Li}^{+}$ insertion, leading to large polarization below the open cell potential. In discharge process, $\mathrm{Li}^{+}$first occupy $8 \mathrm{a}$ and $16 \mathrm{c}$ sites on the surface and hinder the further $\mathrm{Li}^{+}$insertion. But in charge process, the $\mathrm{Li}$ ions occupying the surface will move first, making the remaining $\mathrm{Li}$ ions in the bulk able to diffuse more readily [5]. 


\subsection{Conclusions}

The electrochemical performance of ESD derived porous LTO electrode was evaluated when the lower cutoff voltage was $\sim 0 \mathrm{~V}$. Without adding any binder and conductive additive, ESD-LTO demonstrated both high power density and high energy density. The porous and thin film structures provide good ionic and electronic conductivities which enable high power performance. Electrochemical studies showed that it can deliver $357 \mathrm{mAh} \mathrm{g}^{-1}$ capacity at current density of $0.15 \mathrm{~A} \mathrm{~g}^{-1}$, which is much higher than the theoretical capacity of LTO when the lower cutoff voltage is $1 \mathrm{~V}$. At a high current density of $6 \mathrm{~A} \mathrm{~g}^{-1}$, which corresponds to an actual charge/discharge time of $60 \mathrm{~s}$, a capacity of $98 \mathrm{mAh} \mathrm{g}^{-1}$ was still achievable. In addition, asymmetric rate tests were performed and revealed that the charging process was much faster than the discharging process. Furthermore, the cell lasted for more than 1400 cycles even after harsh condition tests. This study proves that ESD derived LTO electrode is capable to deliver high capacity when lower cutoff voltage is $\sim 0 \mathrm{~V}$ and it can be used to make composites and discharge to $\sim 0$ V.

\subsection{References}

1. Tarascon, J.M. and Armand, M., 2001. Issues and challenges facing rechargeable lithium batteries. Nature, 414(6861), pp.359-367.

2. Goodenough, J.B. and Kim, Y., 2009. Challenges for rechargeable Li batteries. Chemistry of Materials, 22(3), pp.587-603.

3. Winter, M., Besenhard, J.O., Spahr, M.E. and Novak, P., 1998. Insertion electrode materials for rechargeable lithium batteries. Advanced materials, 10(10), pp.725-763.

4. Yi, T.F., Yang, S.Y. and Xie, Y., 2015. Recent advances of $\mathrm{Li}_{4} \mathrm{Ti}_{5} \mathrm{O}_{12}$ as a promising next generation anode material for high power lithium-ion batteries. Journal of Materials Chemistry A, 3(11), pp.5750-5777. 
5. Zhao, B., Ran, R., Liu, M. and Shao, Z., 2015. A comprehensive review of $\mathrm{Li}_{4} \mathrm{Ti}_{5} \mathrm{O}_{12-}$ based electrodes for lithium-ion batteries: The latest advancements and future perspectives. Materials Science and Engineering: R: Reports, 98, pp.1-71.

6. Zhu, G.N., Wang, Y.G. and Xia, Y.Y., 2012. Ti-based compounds as anode materials for Li-ion batteries. Energy \& Environmental Science, 5(5), pp.6652-6667.

7. Ge, H., Li, N., Li, D., Dai, C. and Wang, D., 2009. Study on the theoretical capacity of spinel lithium titanate induced by low-potential intercalation. The Journal of Physical Chemistry C, 113(16), pp.6324-6326.

8. Wang, Y.Y., Hao, Y.J., Lai, Q.Y., Lu, J.Z., Chen, Y.D. and Ji, X.Y., 2008. A new composite material $\mathrm{Li}_{4} \mathrm{Ti}_{5} \mathrm{O}_{12}-\mathrm{SnO}_{2}$ for lithium-ion batteries. Ionics, 14(1), pp.85-88.

9. Zhu, J.P., Yang, G., Zhao, J.J., Wang, Q.S. and Yang, H.W., 2011, September. Synthesis and electrochemical properties of $\mathrm{Li}_{4} \mathrm{Ti}_{5} \mathrm{O}_{12} / \mathrm{CuO}$ anode material for $\mathrm{Li}$-ion batteries. In Advanced Materials Research (Vol. 279, pp. 77-82).

10. Chen, M., Li, W., Shen, X. and Diao, G., 2014. Fabrication of core-shell $\alpha-\mathrm{Fe}_{2} \mathrm{O}_{3} @$ $\mathrm{Li}_{4} \mathrm{Ti}_{5} \mathrm{O}_{12}$ composite and its application in the lithium ion batteries. ACS applied materials \& interfaces, 6(6), pp.4514-4523.

11. Ge, H., Chen, L., Lin, S., Shi, X. and Song, X.M., 2014. Advanced electrochemical performances of $\mathrm{Li}_{4} \mathrm{Ti}_{5} \mathrm{O}_{12} / \mathrm{Ag}$ prepared by a facile synthesis route. Ionics, 20(8), pp.1189-1192.

12. Chen, C., Agrawal, R. and Wang, C., 2015. High performance $\mathrm{Li}_{4} \mathrm{Ti}_{5} \mathrm{O}_{12} / \mathrm{Si}$ composite anodes for Li-ion batteries. Nanomaterials, 5(3), pp.1469-1480.

13. Yu, Y., Gu, L., Dhanabalan, A., Chen, C.H. and Wang, C., 2009. Three-dimensional porous amorphous $\mathrm{SnO}_{2}$ thin films as anodes for Li-ion batteries. Electrochimica Acta, 54(28), pp.7227-7230.

14. Kruk, M. and Jaroniec, M., 2001. Gas adsorption characterization of ordered organicinorganic nanocomposite materials. Chemistry of Materials, 13(10), pp.3169-3183.

15. Zhu, Y.R., Yin, L.C., Yi, T.F., Liu, H., Xie, Y. and Zhu, R.S., 2013. Electrochemical performance and lithium-ion intercalation kinetics of submicron-sized $\mathrm{Li}_{4} \mathrm{Ti}_{5} \mathrm{O}_{12}$ anode material. Journal of Alloys and Compounds, 547, pp.107-112.

16. Liu, J., Li, X., Yang, J., Geng, D., Li, Y., Wang, D., Li, R., Sun, X., Cai, M. and Verbrugge, M.W., 2012. Microwave-assisted hydrothermal synthesis of nanostructured spinel $\mathrm{Li}_{4} \mathrm{Ti}_{5} \mathrm{O}_{12}$ as anode materials for lithium ion batteries. Electrochimica Acta, 63, pp.100-104. 
17. Wang, J., Polleux, J., Lim, J. and Dunn, B., 2007. Pseudocapacitive contributions to electrochemical energy storage in $\mathrm{TiO}_{2}$ (anatase) nanoparticles. The Journal of Physical Chemistry C, 111(40), pp.14925-14931.

18. Conway, B.E., Birss, V. and Wojtowicz, J., 1997. The role and utilization of pseudocapacitance for energy storage by supercapacitors. Journal of Power Sources, 66(1), pp.1-14.

19. Shi, H., 1996. Activated carbons and double layer capacitance. Electrochimica Acta, 41(10), pp.1633-1639.

20. Opitz, M., Yue, J., Wallauer, J., Smarsly, B. and Roling, B., 2015. Mechanisms of Charge Storage in Nanoparticulate $\mathrm{TiO}_{2}$ and $\mathrm{Li}_{4} \mathrm{Ti}_{5} \mathrm{O}_{12}$ Anodes: New Insights from Scan rate-dependent Cyclic Voltammetry. Electrochimica Acta, 168, pp.125-132.

21. Bandaru, P.R., Yamada, H., Narayanan, R. and Hoefer, M., 2015. Charge transfer and storage in nanostructures. Materials Science and Engineering: R: Reports, 96, pp.1-69.

22. Bard, A.J., Faulkner, L.R., 2001. Electrochemical Methods: Fundamentals and Applications, second edition. John Wiley \& Sons.

23. Conway, B.E., 2013. Electrochemical supercapacitors: scientific fundamentals and technological applications. Springer Science \& Business Media.

24. Augustyn, V., Simon, P. and Dunn, B., 2014. Pseudocapacitive oxide materials for highrate electrochemical energy storage. Energy \& Environmental Science, 7(5), pp.15971614.

25. Zhukovskii, Y.F., Balaya, P., Kotomin, E.A. and Maier, J., 2006. Evidence for interfacial-storage anomaly in nanocomposites for lithium batteries from first-principles simulations. Physical review letters, 96(5), p.058302.

26. Wu, Q., Xu, J., Yang, X., Lu, F., He, S., Yang, J., Fan, H.J. and Wu, M., 2015. Ultrathin Anatase $\mathrm{TiO}_{2}$ Nanosheets Embedded with $\mathrm{TiO}_{2}-\mathrm{B}$ Nanodomains for Lithium-Ion Storage: Capacity Enhancement by Phase Boundaries. Advanced Energy Materials, 5(7).

27. Li, J., Dudney, N.J., Xiao, X., Cheng, Y.T., Liang, C. and Verbrugge, M.W., 2015. Asymmetric Rate Behavior of Si Anodes for Lithium-Ion Batteries: Ultrafast DeLithiation versus Sluggish Lithiation at High Current Densities. Advanced Energy Materials, 5(6). 


\section{FABRICATION AND CHARACTERIZATION OF LTO/RGO COMPOSITE ELECTRODES}

\subsection{Introduction}

The electrochemical performance of porous LTO prepared by ESD has been described in chapter 3, which exhibit enhanced energy density by discharging below $1 \mathrm{~V}$. Further electrochemical performance improvements could be achieved by addition of rate capability enhancement elements, such as conductive additives. Graphene is one of the most appealing additives for electrode materials due to its high surface area and high electronic conductivity. However, it is more convenient to use graphene oxide (GO) instead. GO offers advantages in its ease of reduction by thermal or chemical treatment to recover conductivity, as well as good solution processability. Though the conductivity for rGO is not comparable to graphene, it is sufficient in electrode application [1-3]. For example, Chen et al. reported that small amount of rGO (1.2 wt \%) had great effect on electrochemical performance of resulting composite [3]. Some of other researcher also applied higher rGO loadings in the composites and obvious high rate performance enhancement had been achieved. This chapter describes the results of electrochemical performance of $\mathrm{LTO} / \mathrm{rGO}$ composite electrodes as compared to bare ESD-LTO.

\subsection{Experimental}

The LTO/rGO composite electrodes were prepared by the method similar to the process as for pure LTO with additional $5 \mathrm{wt} . \%$ and $20 \mathrm{wt} . \% \mathrm{GO}$ in the precursor solutions for ESD-LTO-5rGO and ESD-LTO-20rGO, respectively. The electrochemical cell assembling and test conditions were the same as for ESD-LTO electrode. 


\subsection{Results and Discussion}

The LTO/rGO composite electrodes were synthesized through ESD process with the same deposition parameters as for ESD-LTO electrode, as described in chapter 3. The resulting LTO-5rGO composite powders were scratched off from $\mathrm{Ni}$ foam substrate for physical property tests. As shown in Figure 4.1a, the Brunauere-Emmette-Teller (BET) surface area is $67.32 \mathrm{~m}^{2} \mathrm{~g}^{-1}$ which is similar as for pure ESD-LTO powder. It also has an obvious $\mathrm{H} 2$ type adsorption-desorption hysteresis loop which is attributed to the pore connectivity effect from relatively uniform channel-like pores [6]. The XRD pattern can be indexed to spinel LTO and no obvious influence is observed from additional rGO phase.
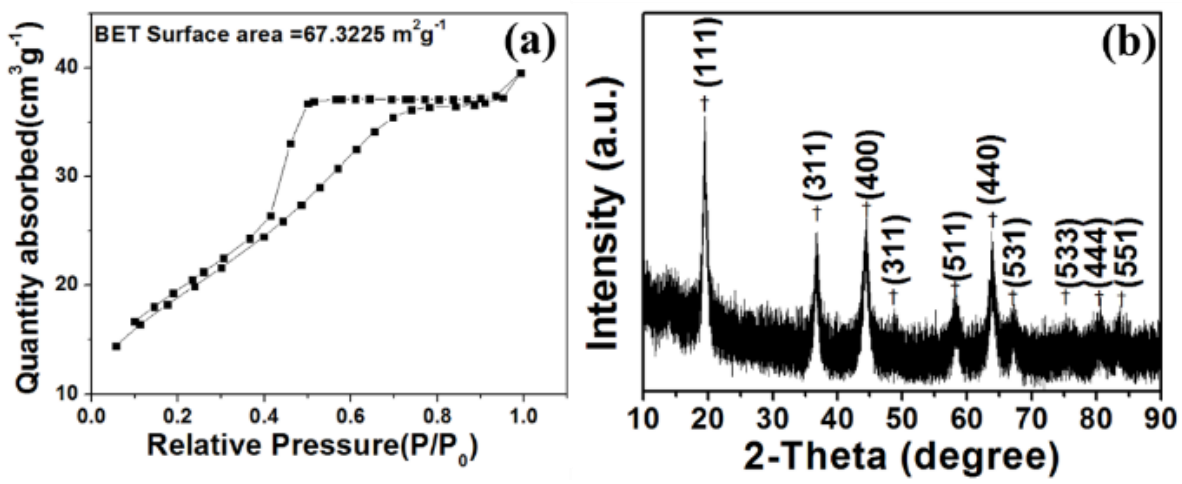

Figure 4. 1 (a) Nitrogen adsorption-desorption isotherm and (b) XRD pattern of ESD-LTO5 rGO powder.

The morphologies of as-deposited and after heat treatment electrodes were examined and the SEM images are shown in Figure 4.2. From low magnification of asdeposited electrode in Figure 4.2a it can be seen that the composites were uniformly deposited on 3D inter connected porous $\mathrm{Ni}$ form. The porous structure can be seen in the magnified image in Figure 4.2b.The porous structure is typical for ESD process due to the solvent evaporation and the decomposition of organic salts. After heat treatment, the deposited film shrinked and generated larger cracks within the film, as shown in Figure 
4.2c. In Figure 4.2d, small particles were separate out and uniformly distributed in the film. These small particles could be LTO particles which grow during heat treatment.
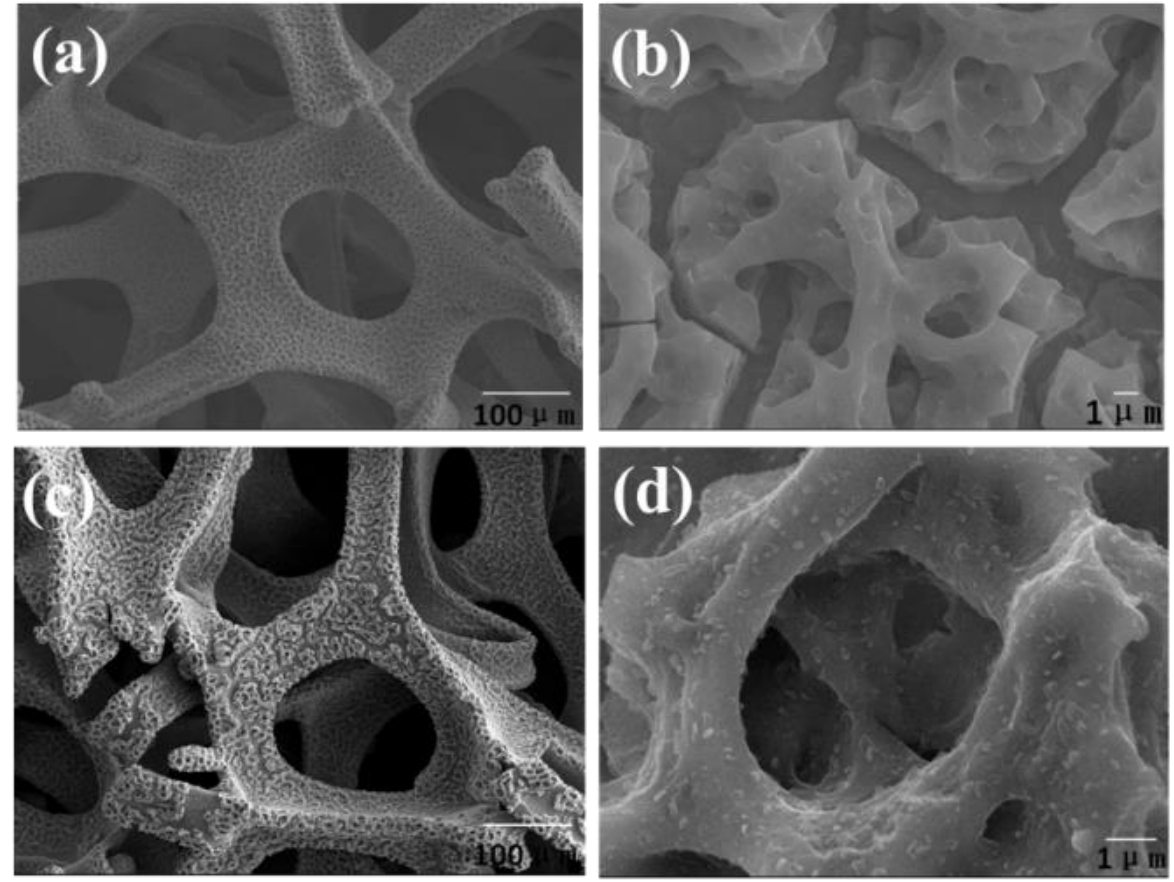

Figure 4. 2 SEM images of ESD-LTO-5rGO electrode (a-b) as-deposited and (c-d) after heat treatment.

To investigate the electrochemical behavior of lithium intercalation into the LTO5rGO composite electrode, typical cyclic voltammetry $(\mathrm{CV})$ was measured at a scan rate of $0.2 \mathrm{mV} \mathrm{s}^{-1}$ in the voltage range from 0.02 to $3 \mathrm{~V}$ for 10 cycles, as shown in Figure 4.3. The major peaks at $1.48 \mathrm{~V}$ in cathodic branch and $1.64 \mathrm{~V}$ in anodic branch correspond to the $\mathrm{Li}^{+}$insertion and extraction process of LTO. The peak separation at $10^{\text {th }}$ cycle is 0.16 $\mathrm{V}$, which is smaller than what was observed in pure LTO electrode $\left(0.21 \mathrm{~V}\right.$ at $10^{\text {th }}$ cycle). This can be ascribed to the enhanced electronic conductivity by the incorporation of rGO. There also exists a broad peak at $0.75 \mathrm{~V}$ which is due to the SEI formation process and further $\mathrm{Li}^{+}$intercalation into $\mathrm{Li}_{7} \mathrm{Ti}_{5} \mathrm{O}_{12}$. 


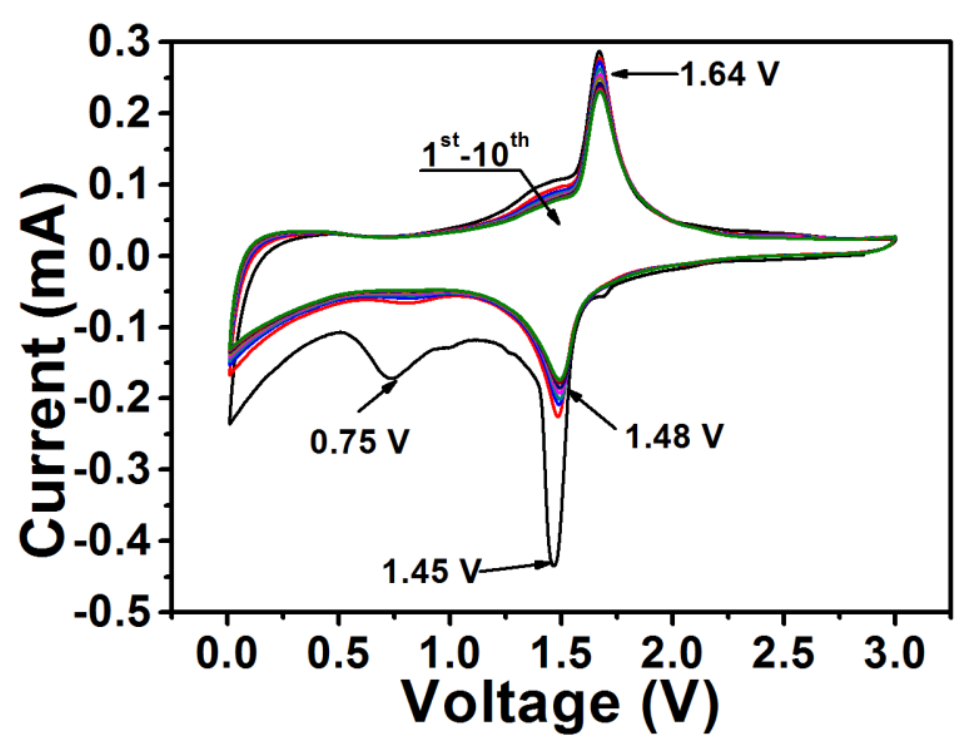

Figure 4. 3 The first 10 cycle CV curves of ESD-LTO-5rGO electrode at $0.2 \mathrm{mV} \mathrm{s}^{-1}$.

To test the rate capability and cycle life of the ESD-LTO-5rGO electrodes, chargedischarge measurements under various current densities ranging from 0.15 to $60 \mathrm{~A} \mathrm{~g} \mathrm{~g}^{-1}$ were carried out. The results are shown in Figure 4.4. The major trend for the rate capability test in the first 120 cycles is the capacity decreases as the current density increase. But even at current density of $6 \mathrm{~A} \mathrm{~g}^{-1}$, a discharge capacity of $106 \mathrm{mAh} \mathrm{g}^{-1}$ is still available, corresponding to a charge/discharge time of $60 \mathrm{~s}$. Further, the cell experience a gradual capacity increase in the following 100 cycle test at $0.6 \mathrm{~A} \mathrm{~g} \mathrm{~g}^{-1}$. The cell was also tested at extreme high rate conditions. Highest current density was pushed to $60 \mathrm{~A} \mathrm{~g}^{-1}$. Although only trace of capacity was observed under such high current density, the cell was not damaged and still showed stable performance at $6 \mathrm{~A} \mathrm{~g}^{-1}$ with a discharge capacity of 100 $\mathrm{mAh} \mathrm{g}^{-1}$. A total cycle number of over 1400 cycles was tested without signs of cell failure. As compared with pure LTO electrode, only slight capacity difference was observed for the composite with $5 \mathrm{wt} \%$ rGO. 


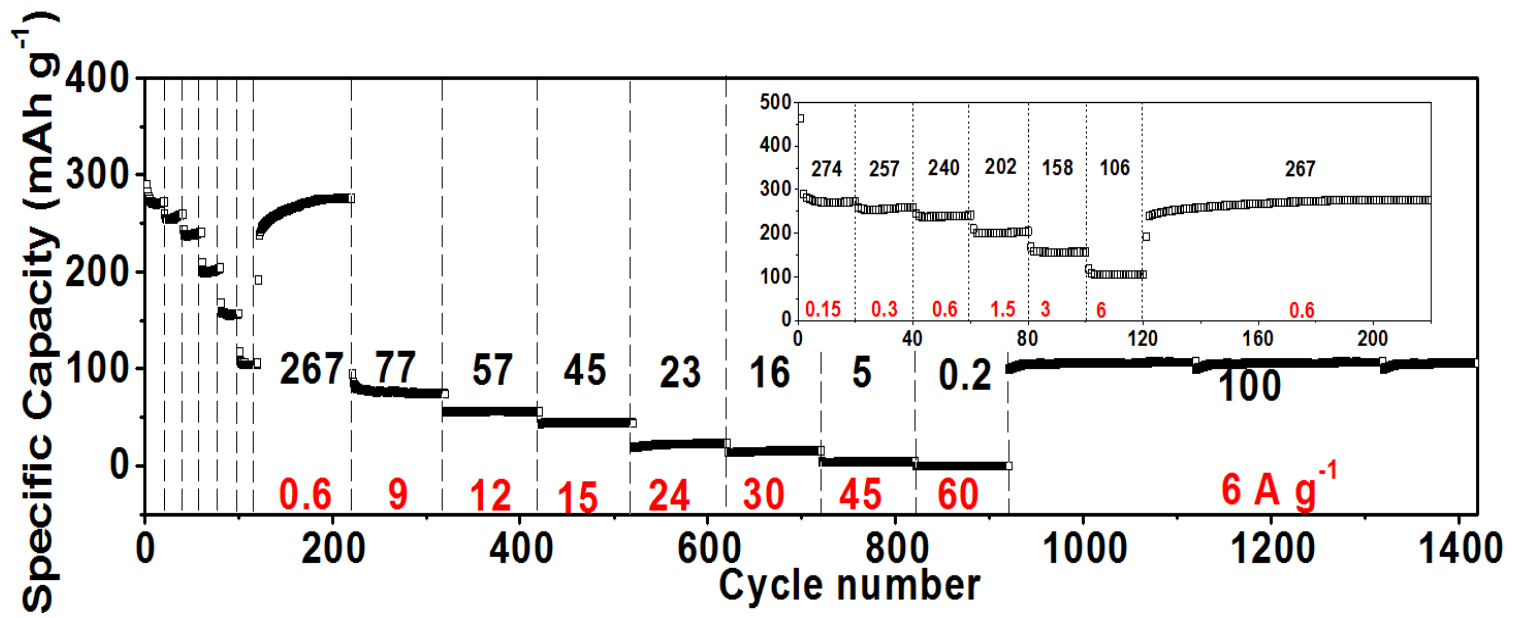

Figure 4. 4 Cyclability and rate capability $\left(0.15-6 \mathrm{~A} \mathrm{~g}^{-1}\right)$ test results of ESD-LTO-5rGO electrode.

The asymmetric rate capability test was performed for LTO-5rGO electrode after symmetric rate capability test, as shown in Figure 4.5. It is observed that charging is relatively faster than discharging. For example, when charged at $3 \mathrm{~A} \mathrm{~g}^{-1}$ and discharged at $30 \mathrm{~A} \mathrm{~g}^{-1}$, a capacity of $30 \mathrm{mAh} \mathrm{g}^{-1}$ was obtained, which was higher than symmetric test at $30 \mathrm{~A} \mathrm{~g}^{-1}\left(16 \mathrm{mAh} \mathrm{g}^{-1}\right)$. However, when charged at $30 \mathrm{~A} \mathrm{~g}^{-1}$ and discharged at $3 \mathrm{~A} \mathrm{~g}^{-1}$, a higher capacity of $65 \mathrm{mAh} \mathrm{g}^{-1}$ was observed. Such trend is similar to the results obtained for pure ESD-LTO electrode.

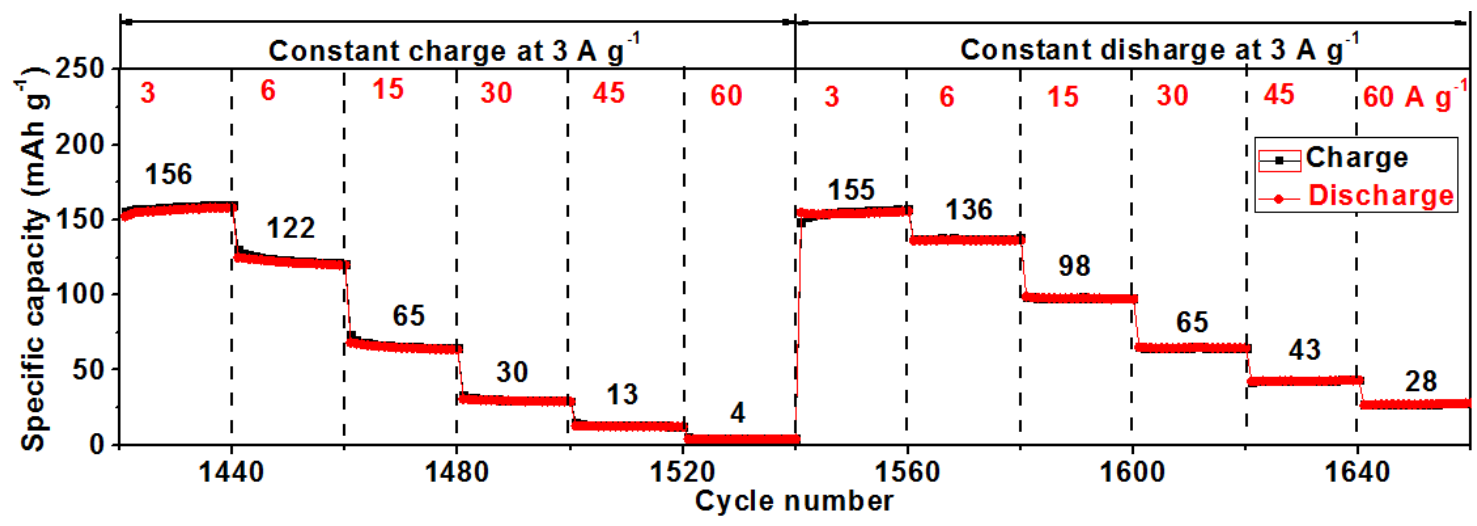

Figure 4. 5 Asymmetric rate capability test results of ESD-LTO-5rGO electrode. Test conditions: constant charge current density: $3 \mathrm{~A} \mathrm{~g}^{-1}$, discharge current density: 3-60 $\mathrm{A} \mathrm{g}^{-1}$; constant discharge current density: $3 \mathrm{~A} \mathrm{~g}^{-1}$, charge current densities: 3-60 $\mathrm{A} \mathrm{g}^{-1}$. 
In order to study the effect of rGO content on the electrochemical performance of LTO/rGO composite, another type of samples with $20 \mathrm{wt} \% \mathrm{rGO}$ in the LTO/rGO composite were synthesized and tested. The symmetric and asymmetric rate capability tests are shown in Figure 4.6a and b, respectively. For the symmetric rate capability test at low current density $\left(<3 \mathrm{~A} \mathrm{~g}^{-1}\right)$, more $\mathrm{rGO}$ in the composite enables higher specific capacities. One of the reason for the higher capacity is because rGO as anode material exhibits higher capacity than LTO at low current density [3]. In addition, more rGO in the composite may lead to even faster reaction kinetics which is beneficial for obtaining the higher capacity. However, at higher current densities, the capacities decrease significantly with values similar to composite with low rGO content. For the asymmetric rate test, higher rGO content shows better performance especially in constant discharge mode. For example, LTO-20rGO delivers a capacity of $88 \mathrm{mAh} \mathrm{g}^{-1}$ at $60 \mathrm{~A} \mathrm{~g}^{-1}$ charge and $3 \mathrm{~A} \mathrm{~g}^{-1}$ discharge current density. While the value for LTO-5rGO is only $28 \mathrm{mAh} \mathrm{g}^{-1}$.
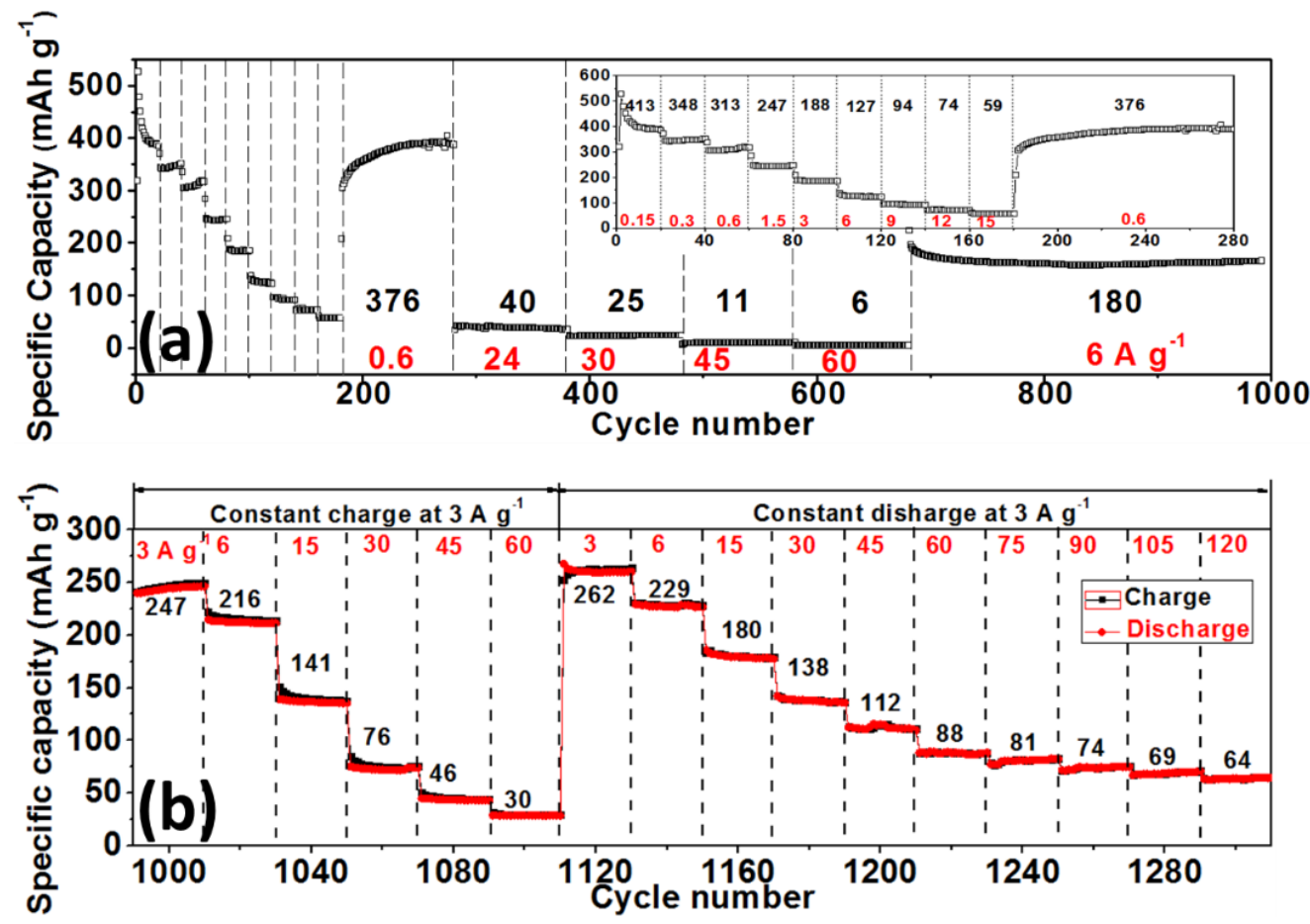
Figure 4. 6 (a) Symmetric rate capability (0.15-6 $\mathrm{A} \mathrm{g}^{-1}$ ) test results of ESD-LTO-20rGO electrode. (b) Asymmetric rate capability test results of ESD-LTO-20rGO electrode Test conditions: constant charge current density: $3 \mathrm{~A} \mathrm{~g}^{-1}$, discharge current density: 3-60 $\mathrm{A} \mathrm{g}^{-1}$; constant discharge current density: $3 \mathrm{~A} \mathrm{~g} \mathrm{~g}^{-1}$, charge current densities: 3-120 $\mathrm{A} \mathrm{g}^{-1}$.

4.4 Conclusions

LTO/rGO composite thin film electrodes with different amount of rGO contents were fabricated through ESD process. As compared to ESD-LTO, additional rGO decreased the polarization as observed in CV curves. The ESD-LTO-5rGO composite electrode showed similar electrochemical performance as ESD-LTO electrode. A discharge capacity of $106 \mathrm{mAh} \mathrm{g}^{-1}$ was still available at current density of $6 \mathrm{~A} \mathrm{~g}^{-1}$ for LTO5rGO electrode, corresponding to a charge-discharge time of 60 s. Similar to ESD- LTO, asymmetric charge-discharge character was also observed for LTO/rGO composite. Higher rGO content in ESD-LTO-20rGO composite results in much higher specific capacities as compared to ESD-LTO and ESD-LTO-5rGO electrodes which is due to the great enhancement of reaction kinetics by large involvement of high surface area and high electron conductivity component rGO.

\subsection{References}

1. Ni, H., Song, W.L. and Fan, L.Z., 2014. A strategy for scalable synthesis of $\mathrm{Li}_{4} \mathrm{Ti}_{5} \mathrm{O}_{12} /$ reduced graphene oxide toward high rate lithium-ion batteries. Electrochemistry Communications, 40, pp.1-4.

2. Chen, W., Jiang, H., Hu, Y., Dai, Y. and Li, C., 2014. Mesoporous single crystals $\mathrm{Li}_{4} \mathrm{Ti}_{5} \mathrm{O}_{12}$ grown on $\mathrm{rGO}$ as high-rate anode materials for lithium-ion batteries. Chemical Communications, 50(64), pp.8856-8859.

3. Chen, C., Huang, Y., Zhang, H., Wang, X., Li, G., Wang, Y., Jiao, L. and Yuan, H., 2015. Small amount of reduce graphene oxide modified $\mathrm{Li}_{4} \mathrm{Ti}_{5} \mathrm{O}_{12}$ nanoparticles for ultrafast high-power lithium ion battery. Journal of Power Sources, 278, pp.693-702.

4. Chen, W., Jiang, H., Hu, Y., Dai, Y. and Li, C., 2014. Mesoporous single crystals $\mathrm{Li}_{4} \mathrm{Ti}_{5} \mathrm{O}_{12}$ grown on $\mathrm{rGO}$ as high-rate anode materials for lithium-ion batteries. Chemical Communications, 50(64), pp.8856-8859. 
5. Ni, H., Song, W.L. and Fan, L.Z., 2014. A strategy for scalable synthesis of $\mathrm{Li}_{4} \mathrm{Ti}_{5} \mathrm{O}_{12} /$ reduced graphene oxide toward high rate lithium-ion batteries. Electrochemistry Communications, 40, pp.1-4.

6. Kruk, M. and Jaroniec, M., 2001. Gas adsorption characterization of ordered organicinorganic nanocomposite materials. Chemistry of Materials, 13(10), pp.3169-3183. 


\section{FABRICATION AND CHARACTERIZATION OF LTO/SILICON/RGO COMPOSITE ELECTRODES}

\subsection{Introduction}

In the previous chapters we have successfully synthesized LTO and LTO/rGO composites and evaluated their electrochemical performance when lower cutoff voltage was set as $\sim 0 \mathrm{~V}$. Further energy density enhancement could be achieved by introducing other high capacity anode materials into the composites [1-8]. Since the enhancement in capacity is a direct result of the other composite components, silicon makes an excellent choice given its theoretical capacity (4200 $\mathrm{mAh} \mathrm{g}^{-1}$ ), which is about 13 times higher than that of LTO (even when it is discharged to $0 \mathrm{~V}$ ) [9]. In addition, considering the structure stability of LTO, it is expected that LTO can also alleviate some of the volumetric expansion from silicon during the cycling process by acting as a buffer. Until now, only a few studies have been reported on the use of LTO/Si composite electrodes. Lin et al. [10] deposited a thin coating of amorphous silicon on the surface of LTO electrode by thermal evaporation aiming to improve the cycling performance of LTO at elevated temperatures. However, there is a lack of systematic study on LTO/Si composites for LIB electrodes.

In this chapter, our first goal is to investigate if LTO/Si composites hold potential as high-performance Li-ion battery anodes. We have evaluated the electrochemical performance of LTO/Si composites based on commercial battery grade electrode materials using conventional battery fabrication procedures. The synergism between LTO and Si was investigated by studying the influence of different weight ratios of LTO and Si on the rate capability and cyclability of the composites. Our results show that the LTO/Si composites exhibit both improved energy capacity and high rate capability. It is believed that the 
energy density of LTO/Si composite electrode will be further improved by replacing microsized LTO particles with ESD derived porous LTO. So the second goal of this study is to synthesize LTO/Si based nanocomposite by ESD to further increase its energy density. As demonstrated in chapter 4 that reduced graphene oxide $(\mathrm{rGO})$ has positive effect in LTO/rGO composite due to its superior electronic conductivity, structural flexibility, large surface area as well as chemical stability. It was also added into LTO/Si composite to form ESD-LTO/Si/rGO nanocomposite. In such hybrid structure, rGO not only works as templates for dispersing nanoparticles but also acts as conductive matrix enabling fast electron conduction. Furthermore, it also can buffer the stress and accommodate the volumetric changes during cycling. Therefore, we designed and synthesized LTO/Si/rGO nanocomposite electrode by ESD and its electrochemical performance will be discussed in this chapter.

\subsection{Experimental}

Fabrication of LTO-Si Composite Electrode: Silicon powder $(<100 \mathrm{~nm})$ and $\mathrm{Li}_{4} \mathrm{Ti}_{5} \mathrm{O}_{12}(\mathrm{D} 10=1.09 \mu \mathrm{m})$ powders were used as received, without any further treatment. The composite electrodes were prepared by casting a slurry on copper foil. The slurry was prepared by mixing different amounts of $\mathrm{Li}_{4} \mathrm{Ti}_{5} \mathrm{O}_{12}$ powder, silicon powder, poly (acrylic acid) (PAA) and Super $\mathrm{P} \mathrm{Li}^{\circledR}$ in ethanol, as summarized in Table 5.1. In this work, the current densities at different $\mathrm{C}$-rates were calculated based on their theoretical values as well as the weight ratios of LTO and Si components. Poly (acrylic acid) (PAA) and super $\mathrm{P} \mathrm{Li}^{\circledR}$ were used as binder and conducting additive, respectively.

Synthesis of LTO-10Si-5rGO Electrode: Nanosized Si particle (<100 nm, $10 \mathrm{wt} \%)$ and $\mathrm{GO}(5 \mathrm{wt} \%)$ were added to LTO precursor to form the new precursor for LTO/Si/rGO 
composite. In order to get a stable precursor suspension, 1,2-propanediol (in 50 volume \%) was added into LTO precursor. Other synthesis conditions are the same as what were used for LTO. The deposition was carried out in Ar atmosphere.

Table 5. 1 Summary of sample compositions in LTO/Si composites.

\begin{tabular}{cccccc}
\hline \multirow{2}{*}{ Sample } & \multicolumn{4}{c}{ Composition (wt \%) } & 1 C Current Density a $^{\text {a }}$ \\
\cline { 2 - 5 } & $\mathrm{Si}$ & LTO & PAA & Super P Li $^{\circledR}$ & $\mathrm{mA} \mathrm{g}^{-1}$ \\
\hline pure-LTO & 0 & 70 & 15 & 15 & 298 \\
65LTO5Si & 5 & 65 & 15 & 15 & 577 \\
50LTO20Si & 20 & 50 & 15 & 15 & 1413 \\
35LTO35Si & 35 & 35 & 15 & 15 & 2249 \\
pure-Si & 70 & 0 & 15 & 15 & 4200 \\
\hline
\end{tabular}

\subsection{Results and Discussion}

The morphologies of typical as-casted LTO/Si composite electrodes are shown in Figure 5.1a-c. For pure Si in Figure 5.1a, it can be seen that the average size of silicon particles was around $100 \mathrm{~nm}$ and the particles were relatively uniformly mixed with other additives, which includes carbon black and polymer binder. From the pure LTO in Figure $5.1 \mathrm{~b}$, it can be observed that the LTO particles were relatively large with particle size ranging from 0.2 to $1 \mu \mathrm{m}$. The large size and irregular shape of LTO particles results in relatively low-density composites. Figure 5.1c shows the morphology of 50LTO20Si composite electrode. No obvious cracks were observed in the as-deposited electrodes. However, the particle size of LTO in 50LTO20Si is smaller than that in pure-LTO electrode, which may be due to the grounding effect of Si nanoparticles in the sample preparation process. Morphologies of the respective electrodes after electrochemical tests are shown in Figure 5.1d-f and will be discussed later. 


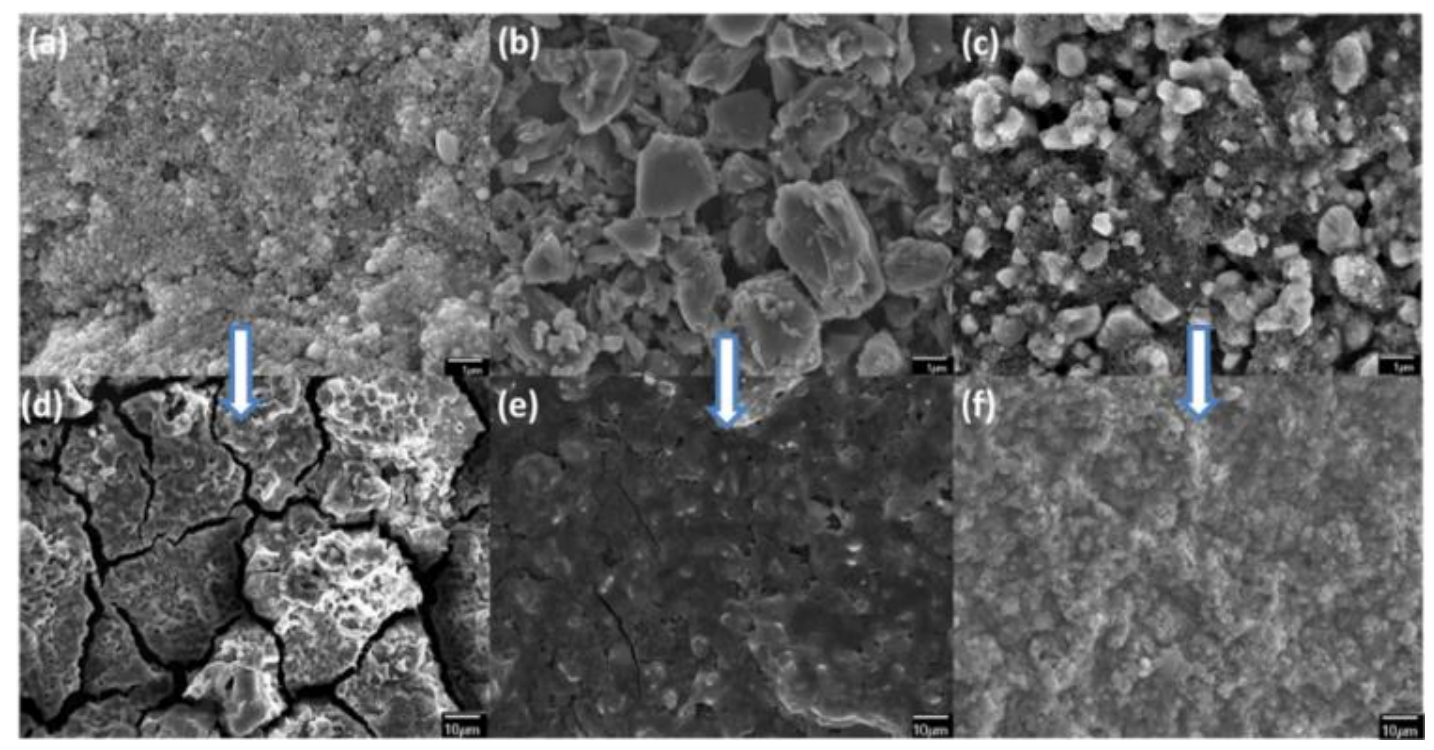

Figure 5. 1 Typical SEM images of electrodes based on (a) pure-Si; (b) pure-LTO and 50LTO20Si before the electrochemical test $(\mathrm{a}-\mathrm{c})$ and after the electrochemical test $(\mathrm{d}-\mathrm{f})$, respectively.

Figure 5.2a exhibits the CV curves for the pure-Si electrode. A broad peak can be seen at around $0.4-0.95 \mathrm{~V}$ in the cathodic branch of first and second cycles. However, this broad peak disappears in the third cycle. No obvious oxidation peaks corresponding to this reduction process is observed in the anodic branch, which indicates that this peak corresponds to the solid electrolyte interphase (SEI) formation [11-12]. There is a distinctive reduction peak which starts at $0.3 \mathrm{~V}$ and becomes quite sharp below $0.1 \mathrm{~V}$. This peak is attributed to the lithiation of silicon [13-14]. During charging, two well defined peaks centered at 0.34 and $0.51 \mathrm{~V}$ are observed and are ascribed to the formation of intermediate $\mathrm{Li}_{x} \mathrm{Si}$ and amorphous silicon, respectively [13-14]. The magnitude of current at these two anodic peaks increases from 0.05 to $0.12 \mathrm{~mA}$ from the first to the fifth cycle due to activation process from Si phase [15-16]. However, the peak current stays almost the same at the 10th cycle, implying that the activation process of $\mathrm{Si}$ is almost completed at the end of 10th cycle. The observed CV curves and the activation process are in good 
agreement with previous report of porous silicon [12-16]. The reconstruction of crystal structure near silicon surface is explained as the reason for the activation phenomenon.
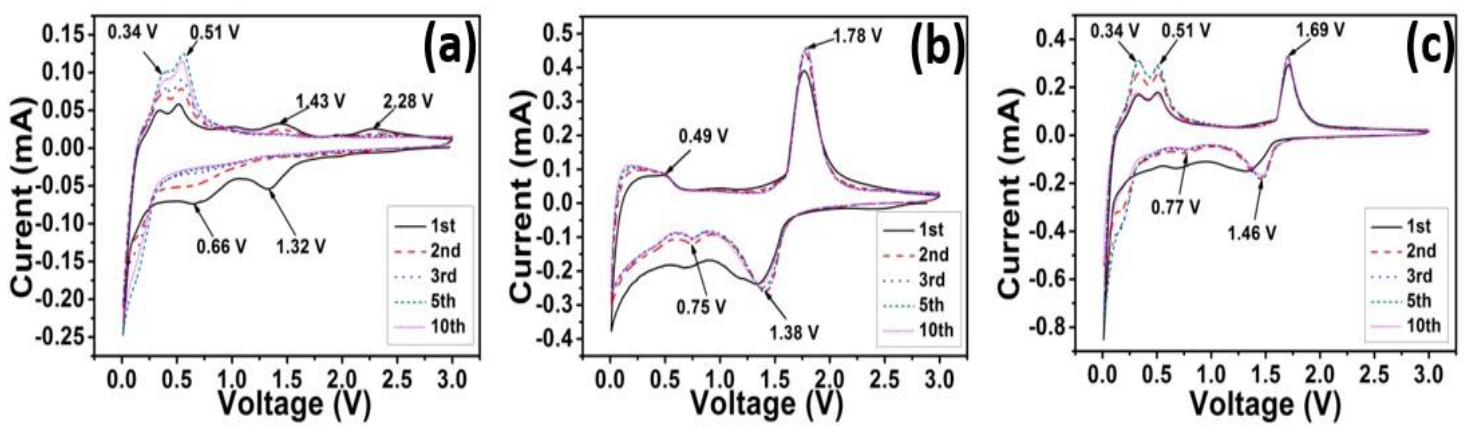

Figure 5. 2 CV curves of electrodes based on (a) pure-Si, (b) pure-LTO and (c) 50LTO20Si at scan rate of $0.2 \mathrm{mV} \mathrm{s}^{-1}$ in the range of $0.02-3 \mathrm{~V}$, respectively.

Figure 5.2b displays the CV curves of pure-LTO electrode: a pair of redox peaks appears at $1.38 \mathrm{~V}$ (reduction) and $1.78 \mathrm{~V}$ (oxidation), which corresponds to the $\mathrm{Li}^{+}$insertion and extraction process of LTO, which is in good agreement with literature [17]. The $0.5 \mathrm{~V}$ separation between the anodic and cathodic peaks is most likely because of the polarization resulting from the sluggish lithium diffusion and relatively low electrical conductivity [1819]. Further $\mathrm{Li}$ intercalation into $\mathrm{Li}_{7} \mathrm{Ti}_{5} \mathrm{O}_{12}$ leads to a broad shoulder from 0.02 to $0.5 \mathrm{~V}$. A small peak at around $0.75 \mathrm{~V}$ can be seen from the first to the 10th cycle, which is also due to the further lithium intercalation into the $\mathrm{Li}_{7} \mathrm{Ti}_{5} \mathrm{O}_{12}$ structure [17]. In the second cathodic cycle the current value dips as compared to the first cycle. This decrease in current is attributed to the SEI formation owing to the low operational voltage [18].

Figure 5.2c displays the CV curves for the 50LTO20Si composite electrode. As compared to Figure 5.2a-b, this electrode has both anodic and cathodic peaks for both Si and LTO as expected and the peak positions remain unchanged, which proves that both Si and LTO can work well with each other without interfering with the activity of the other component. 
In order to further examine the synergy between LTO and silicon, rate capability and cycling behavior, the composites were evaluated for different LTO:Si ratios. Figure 5.3 shows the rate performance of five different samples with different LTO:Si ratios and their corresponding charge/discharge curves. It can be seen from Figure 5.3a that the specific capacities of pure-Si sample at 0.1, 0.2, 0.5 and $1 \mathrm{C}$ are 542, 76, 18 and $8 \mathrm{mAh} \mathrm{g-}$ ${ }^{1}$, respectively. The first cycle discharge capacity is only $377 \mathrm{mAh} \mathrm{g}^{-1}$, which gradually increases to a maximum value of $850 \mathrm{mAh} \mathrm{g}^{-1}$ at the 7th cycle. The low discharge capacity during the first cycle is probably due to partial utilization of the silicon particles and the enhanced capacity in later cycles can be explained by the activation process in silicon $[15,16]$, which is consistent with what has been observed in the CV curve. However, the capacity decreases to $542 \mathrm{mAh} \mathrm{g}^{-1}$ at the 20th cycle, and most of the capacity is delivered between 0.05 and $0.2 \mathrm{~V}$ which can be seen in the corresponding chargedischarge curves. The capacity decreases as the $\mathrm{C}$-rate increases and at $1 \mathrm{C}$, only $8 \mathrm{mAh} \mathrm{g}^{-}$ ${ }^{1}$ was achieved. When charged back to $0.1 \mathrm{C}$, a capacity of $275 \mathrm{mAh} \mathrm{g}^{-1}$ was recovered, which stabilized at 100th cycle. In order to understand the capacity decrease and partial recovery of pure-Si electrode, the coin cell was disassembled after the rate capability tests at 100th cycle and structural changes in the electrode were examined, as shown in Figure 1d. Severe cracks were generated, which led to the isolation of some islands and failure of the electrode. In some areas, peeling was also observed (not shown in Figure 5.1), which is a common problem for pristine Si electrodes. 

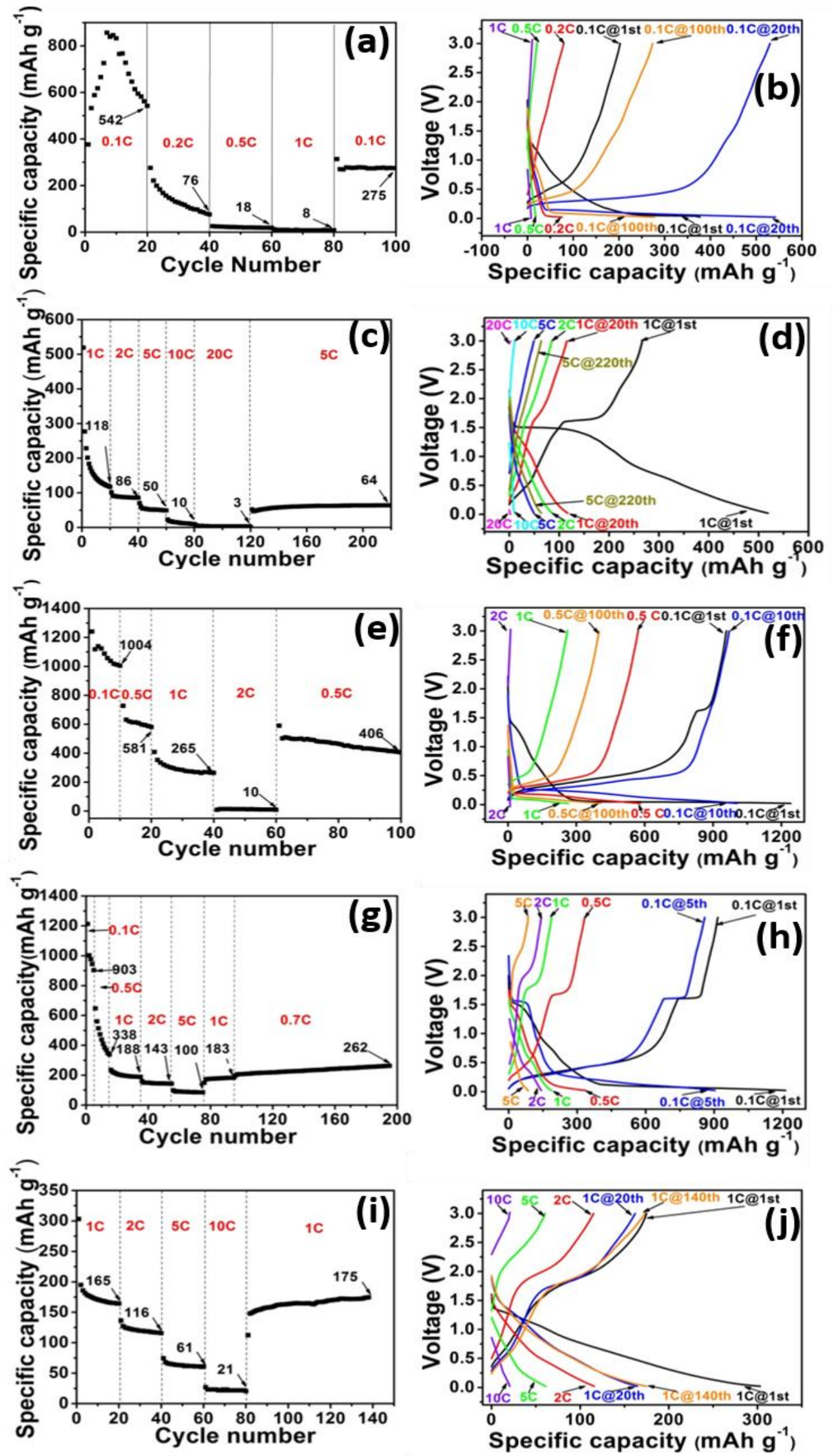
Figure 5. 3 The rate performance and corresponding charge-discharge curves for electrodes based on $(\mathrm{a}, \mathrm{b})$ pure-Si, (c,d) pure-LTO, (e,f) 35LTO35Si, (g,h) 50LTO20Si and (i,j) 65LTO5Si, respectively.

The cyclability of pure LTO electrode is shown in Figure 5.3c-d. For the first discharge and charge cycle at $1 \mathrm{C}$, capacities of 520 and $266 \mathrm{mAh} \mathrm{g}^{-1}$ were achieved, which resulted in a columbic efficiency of $51 \%$. In the discharge curve, a capacity of about $115 \mathrm{mAh} \mathrm{g}^{-1}$ was delivered as a plateau near $1.5 \mathrm{~V}$ and about $390 \mathrm{mAh} \mathrm{g}^{-1}$ was delivered as a long slope between 0.05 and $1.5 \mathrm{~V}$. The plateau at $1.5 \mathrm{~V}$ represents the phase equilibrium between the two end members $\mathrm{Li}_{4} \mathrm{Ti}_{5} \mathrm{O}_{12}$ and $\mathrm{Li}_{7} \mathrm{Ti}_{5} \mathrm{O}_{12}$ [17]. In traditional LTO based electrodes test where the cut off voltage is $1 \mathrm{~V}$, most of the capacity is observed in the plateau region. The capacity in the slope region is mainly due to further intercalation of $\mathrm{Li}_{7} \mathrm{Ti}_{5} \mathrm{O}_{12}$ to $\mathrm{Li}_{8.5} \mathrm{Ti}_{5} \mathrm{O}_{12}$ and the SEI formation process [18]. During the first charging process, capacity delivered in plateau region at around $1.6 \mathrm{~V}$ is around $70 \mathrm{mAh} \mathrm{g}^{-1}$ which is $45 \mathrm{mAh} \mathrm{g}^{-1}$ less than the discharge process. The electrode tends to stabilize at the 20th cycle and the capacity is 118 $\mathrm{mAh} \mathrm{g}^{-1}$. The columbic efficiency is near $100 \%$ at this point. However, when the charge and discharge curves are compared with the first cycle, it could be seen that the $1.5 \mathrm{~V}$ plateaus in both charge and discharge curves diminished and only long slopes were left in the 20th cycle. The capacities decreased when the C-rates increased, however, when the cell was cycled back to $5 \mathrm{C}$, an increased capacity of $64 \mathrm{mAh} \mathrm{g}^{-1}$ was observed as compared to the previous $5 \mathrm{C}$ test. Unlike pure silicon electrode, the disassembled pure LTO electrode at 220th cycle (in Figure 5.1e) had a few smaller cracks but the structural integrity was retained, which can be considered as one of the reasons for the total capacity recovery when the cell was charged back at $5 \mathrm{C}$. 
As shown in Figure 5.3e-f, the first cycle charge and discharge capacities of 35LTO35Si electrode were 955 and $1240 \mathrm{mAh} \mathrm{g}^{-1}$, respectively. In the discharge curve, instead of a plateau, a slope starting from 1.5 to $0.1 \mathrm{~V}$ was observed. A long plateau below $0.1 \mathrm{~V}$ that had a capacity of $970 \mathrm{mAh} \mathrm{g}^{-1}$ was mainly due to the alloying process of silicon. In the following charging processes, the plateau at $1.6 \mathrm{~V}$ still existed, same as pure LTO electrode, and delivered a capacity of $50 \mathrm{mAh} \mathrm{g}^{-1}$. At the 10 th cycle under the same $\mathrm{C}$-rate, the discharge capacity decreased to $1004 \mathrm{mAh} \mathrm{g}^{-1}$ and gave a columbic efficiency of $96.6 \%$. The plateau on the charge curve diminished. The capacity achieved at $0.1 \mathrm{C}$ was excellent as compared to both pure silicon and LTO electrodes and proved the positive effect by using these two materials. When C-rates increased from 0.5 to $1 \mathrm{C}$, the discharge capacity decreased from 581 to $265 \mathrm{mAh} \mathrm{g}^{-1}$, respectively. Although a large amount of the capacity was decreased, $265 \mathrm{mAh} \mathrm{g}^{-1}$ was still comparable to the theoretical capacity of LTO when discharged to $0 \mathrm{~V}$. At an even higher C-rate of $2 \mathrm{C}$, a capacity of only $10 \mathrm{mAh} \mathrm{g}^{-1}$ was retained. When the cell was charged back to $0.5 \mathrm{C}$, a recovery of $70 \%$ was observed, which is attributed to the stable structure of the composite sample. Another reason, which contributed to the decreased capacity at high C-rates could be its sluggish kinetics from the silicon component. The 50LTO20Si electrode showed similar charge-discharge curves and capacities for the first cycle, as shown in Figure 5.3g-h. However, unlike 35LTO35Si, when the $\mathrm{C}$-rate increased, even at $1 \mathrm{C}$, the plateau at $1.6 \mathrm{~V}$ did not diminish in the charging curve. At lower C-rates $(<1 \mathrm{C})$, the electrode with lower LTO contents showed higher capacity whereas, at high C-rates (>1 C), higher LTO concentration was helpful to maintain the performance. As for 50LTO20Si at $5 \mathrm{C}, 100 \mathrm{mAh} \mathrm{g}^{-1}$ capacity was still achievable. For the disassembled electrode image at $195^{\text {th }}$ cycle in Figure 5.1f, no obvious cracks were 
generated in such electrode even after high C-rate testing. The stable capacity at high Crates could be attributed to the structural integrity of the composite. In Figure $5.3 \mathrm{i}-\mathrm{j}$, the 65LTO5Si electrode shows relatively stable capacities under various C-rates, however, the capacities are not comparable to that of 50LTO20Si and 35LTO35Si because of low concentration of $\mathrm{Si}$. It should be noted that there is no capacity decrease when the cell was charged back at $1 \mathrm{C}$ even after $10 \mathrm{C}$ tests for 20 cycles. In its charge-discharge curves, it should be noted that only slopes instead of plateaus existed in the curves from the very first cycle. Comparing our composite electrodes, the plateaus at $1.5 \mathrm{~V}$ in discharge curves and at $1.6 \mathrm{~V}$ in charging curves differed from the first cycles and the following cycles, and also varied from low C-rates to high C-rates. However, it is ambiguous (i) if discharging the cell to $0 \mathrm{~V}$ had an influence on the $1.5 \mathrm{~V}$ plateau region; (ii) if the C-rates had any effect on the plateau and/or (iii) if other active materials affected the plateau. Further studies are required in order to investigate these phenomena.

Since Si and LTO have a huge difference in theoretical capacities, the current densities of the composite samples at the same C-rate of different samples are greatly varied. As shown in Table 5.1, the current density of 35LTO35Si at $1 \mathrm{C}$ is about 4 times that of 65LTO5Si for the same C-rate, which makes current density a useful parameter as opposed to the commonly used C-rate to analyze such composite electrodes. Figure 5.4 shows the relationship between capacity and current density for each sample. The synergism between LTO and silicon is obvious and there is major enhancement in capacities, especially at current densities lower than $3 \mathrm{~A} \mathrm{~g}^{-1}$. The stability of 65LTO5Si is similar to pure-LTO but the capacity of the electrode is limited due to low Si contents. 50LTO20Si and 35LTO35Si show relatively better overall performance since the capacity 
enhancement is realized without sacrificing much rate performance. At lower current densities $\left(<3 \mathrm{~A} \mathrm{~g}^{-1}\right)$, 35LTO35Si performs better than 50LTO20Si due to higher $\mathrm{Si}$ involvement. However, when current density is higher than $3 \mathrm{~A} \mathrm{~g}^{-1}$, 50LTO20Si delivers higher capacity than 35LTO35Si. Even at a high current density of $7 \mathrm{~A} \mathrm{~g}^{-1}$, a capacity of $100 \mathrm{mAh} \mathrm{g}^{-1}$ is still achievable, which is mainly attributed to the contribution of LTO. Compared to the theoretical capacities of graphite $\left(372 \mathrm{mAh} \mathrm{g}^{-1}\right)$ and LTO $\left(175 \mathrm{mAh} \mathrm{g}^{-1}\right.$ when discharged to $1 \mathrm{~V}$ ), the performance of both 50LTO20Si and 35LTO35Si were excellent at the current density of $3 \mathrm{~A} \mathrm{~g}^{-1}$.

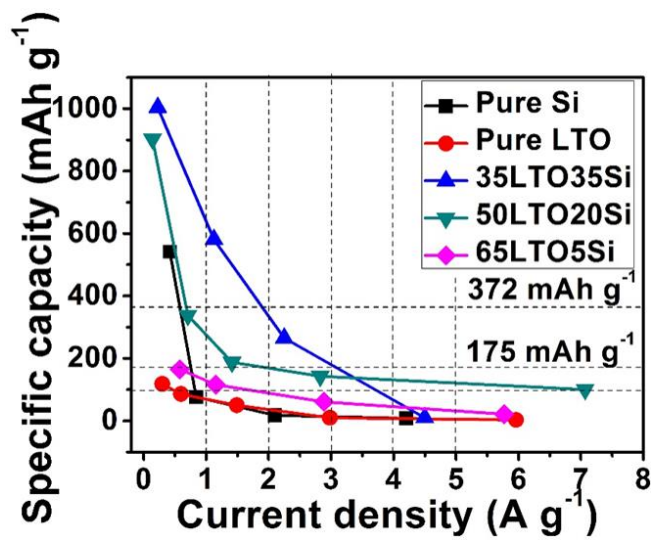

Figure 5. 4 Relationship between capacities and current densities of pure Si, pure LTO, 35LTO35Si, 50LTO20Si and 65LTO5Si electrodes.

From the above results, we have confirmed our strategy to achieve better energy capacity and rate capability by using LTO/Si composites. The addition of Si can enhance the specific capacity of the electrode and at the same time LTO could effectively buffer the volume change of $\mathrm{Si}$, thereby resulting in enhanced C-rate performance. A thin layer of oxide (thickness: $3-5 \mathrm{~nm}$ ) has been observed in our previous work by TEM using same $\mathrm{Si}$ product [12]. The effect of such thin oxide layer on the electrochemical performance could be complicated. At one hand, the oxide layer usually has poor electron conductivity, which could be a limiting factor for the poor rate performance of the Si based battery electrodes 
[20]. At another hand, it is reported that $\mathrm{SiO}_{2}$ and non-stoichiometric silicon oxides are electrochemical active with reasonable $\mathrm{Li}$ ion storage capacity $[10,21]$. We believe that great enhancement in the electrochemical performance of the composites can be realized with careful engineering of each component. Because of that, we synthesized ESD-LTO10Si-5rGO composite electrodes via ESD technique and discussed in the following section.

The electrochemical performance of ESD-LTO-10Si-5rGO electrode will be discussed below. Figure 5.5a shows the CV curves of ESD-LTO-10Si-5rGO electrodes at $0.2 \mathrm{mV} \mathrm{s}^{-1}$ for 10 cycles. An obvious difference compared with ESD-LTO and ESD-LTO$5 \mathrm{rGO}$ electrodes is the appearance of strong de-alloying peaks from $\mathrm{Si}$ at $\sim 0.31 \mathrm{~V}$ and $\sim 0.52$ V. From the insertion it can be seen that the peaks are not strong in the first several cycles but gradually increased in the following cycles. This may be due to the full embedment of Si particles in the composite electrode and a gradual activation happened in the first several cycles [9-10]. Other than Si de-alloying peaks, LTO peaks at $\sim 1.55 \mathrm{~V}$ are strong and stable from $2^{\text {nd }}$ cycle to $10^{\text {th }}$ cycle. $\mathrm{CV}$ at various scan rates were also performed from 0.2 to 10 $\mathrm{mV} \mathrm{s}^{-1}$ as shown in Figure 5.5b. Broad LTO anodic and cathodic peaks can be observed at even high rate of $10 \mathrm{mV} \mathrm{s}^{-1}$. However, no Si peaks can be seen at higher scan rates.
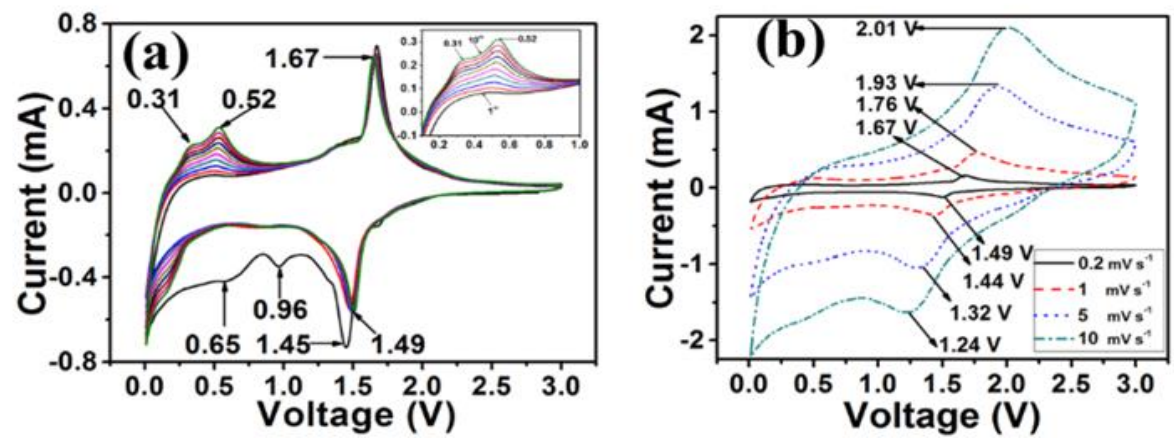

Figure 5. $5 \mathrm{CV}$ curves of ESD-LTO-10Si-5rGO electrodes (a) at fixed scan rate of 0.2 $\mathrm{mV} \mathrm{s}^{-1}$; (b) at various scan rates from 0.2 to $10 \mathrm{mV} \mathrm{s}^{-1}$. 
The rate capability and cycle life tests were performed under various current densities ranging from 0.15 to $150 \mathrm{~A} \mathrm{~g}^{-1}$, as shown in Figure 5.6. At $0.15 \mathrm{~A} \mathrm{~g}^{-1}$. A stable discharge capacity of $624 \mathrm{mAh} \mathrm{g}^{-1}$ was observed, which is much higher than the discharge capacity for pure LTO electrode and LTO-5rGO electrode. It can be attributed to the incorporation of $\mathrm{Si}$ which provides large capacity with small concentration. As the current density increases, the capacity gradually decreases. However, the remaining capacity is still much higher than pure ESD-LTO electrode, which only maintain a capacity of $54 \mathrm{mAh}$ $\mathrm{g}^{-1}$ at $15 \mathrm{~A} \mathrm{~g}^{-1}$. The rate capability test was extended with current density reaching $150 \mathrm{~A}$ $\mathrm{g}^{-1}$. After such harsh test condition, the cell remained undestroyed and delivered a capacity of $290 \mathrm{mAh} \mathrm{g}^{-1}$ at $6 \mathrm{~A} \mathrm{~g}^{-1}$, corresponding to a discharge time of $\sim 3$ mins. The total test cycle number was over 1400. From such rate capability test it can be seen that the involvement of small amount of $\mathrm{Si}$ has great effect on the capacity performance, as compared to ESD-LTO and ESD-LTO/rGO electrodes. In addition, the stability of the composite electrode was not destroyed because of additional Si in it. The stability of the electrode is not only due to the buffer effect from porous ESD generated structure but also due to the zero volume change property of LTO.

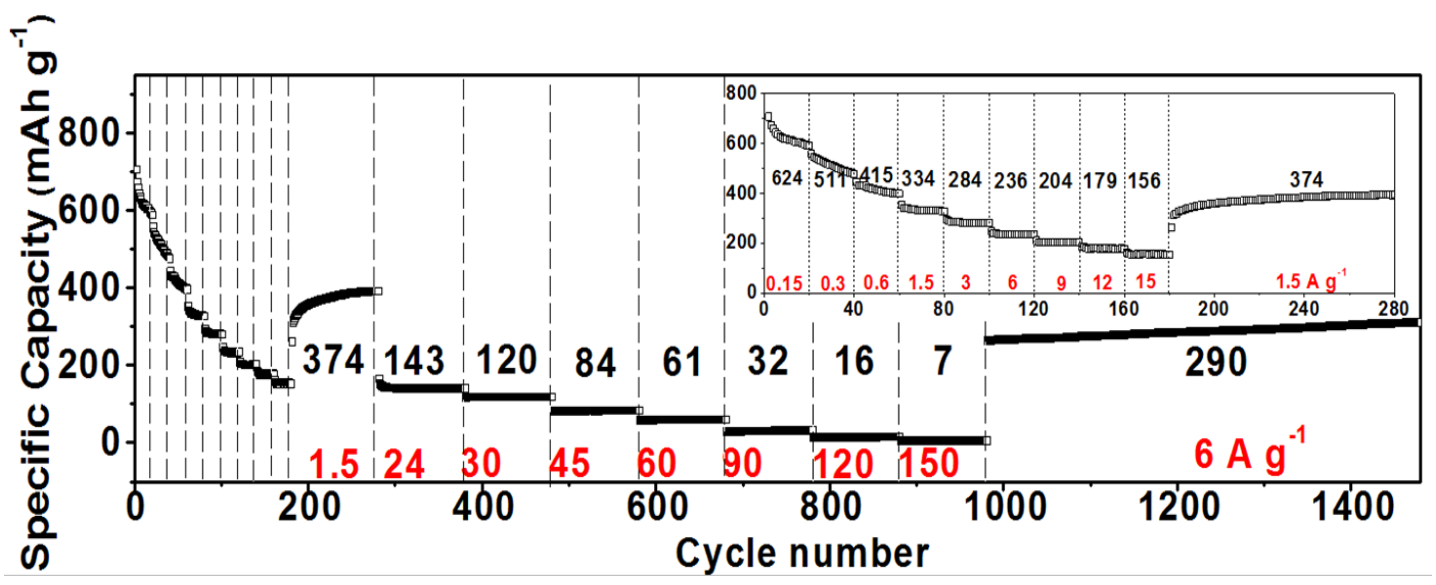


Figure 5. 6 Cyclability and rate capability performance of ESD-LTO-10Si-5rGO electrode at current densities ranging from 0.15 to $150 \mathrm{~A} \mathrm{~g}^{-1}$ for over 1400 cycles.

To better understand the electrochemical reaction of LTO, the charge-discharge curves for the first cycle and the last cycle of each rate are plotted in Figure 5.7. The plateaus from LTO, showed a similar trend as LTO and LTO-rGO electrodes. Also, obvious charge-discharge plateaus from Si can be observed at low current density tests. However, as the current density increase to over $3 \mathrm{~A} \mathrm{~g} \mathrm{~g}^{-1}$, plateaus from $\mathrm{Si}$ almost disappeared. The polarization at LTO plateau $(\sim 1.55 \mathrm{~V})$ were $0.038,0.066$ and $0.104 \mathrm{~V}$ for tests under current densities of $0.15,0.3$ and $0.6 \mathrm{~A} \mathrm{~g} \mathrm{~g}^{-1}$, respectively. Higher polarizations were observed in pure LTO electrode, $0.067,0.098$ and $0.138 \mathrm{~V}$ for $0.15,0.3$ and $0.6 \mathrm{~A} \mathrm{~g}^{-}$ ${ }^{1}$, respectively. This is an indication that $\mathrm{rGO}$ works well in the composite in order to enhance the rate capability.

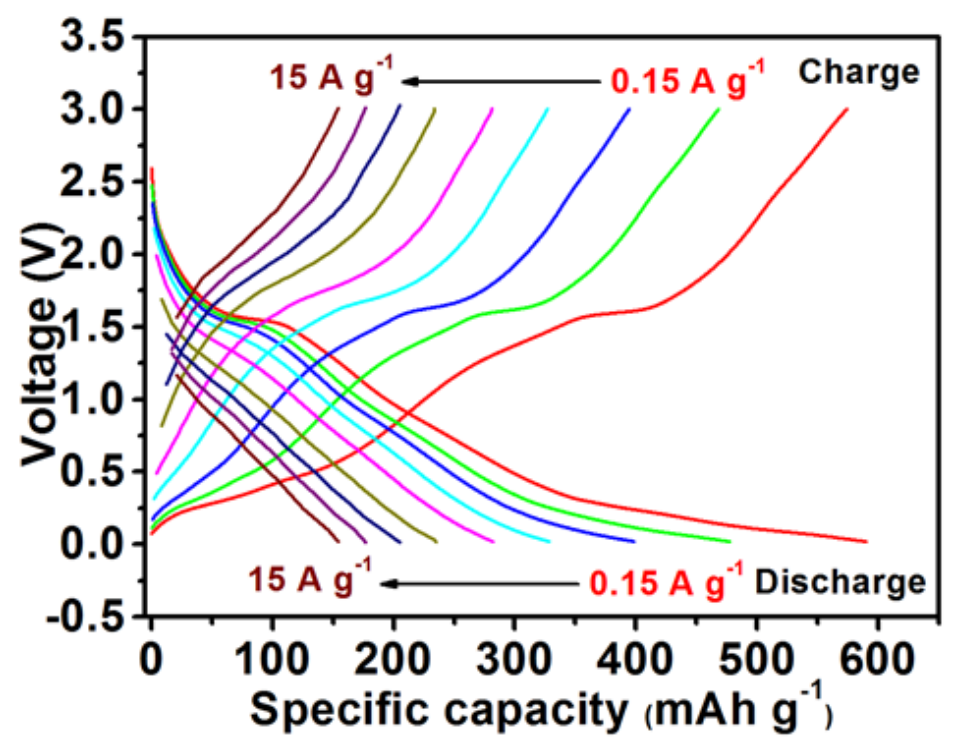

Figure 5. 7 Charge-discharge curves of ESD-LTO-10Si-5rGO electrode at current densities of $0.15,0.3,0.6,1.5,3,6,9,12$ and $15 \mathrm{~A} \mathrm{~g}^{-1}$, respectively.

Asymmetric rate capability tests were performed and the results are shown in Figure 5.8. It was observed that the performance of asymmetric rate tests were all better 
than regular symmetric rate capability tests. A discharge capacity of $150 \mathrm{mAh} \mathrm{g}^{-1}$ at $120 \mathrm{~A}$ $\mathrm{g}^{-1}$ was obtained when the charging current density was $3 \mathrm{~A} \mathrm{~g}^{-1}$. Also, the capacities in the constant discharge process were always higher than that from constant charge process under the same rates, indicating that the discharge process has slower reactions, the same as what has been observed in ESD-LTO and ESD-LTO/rGO electrodes.

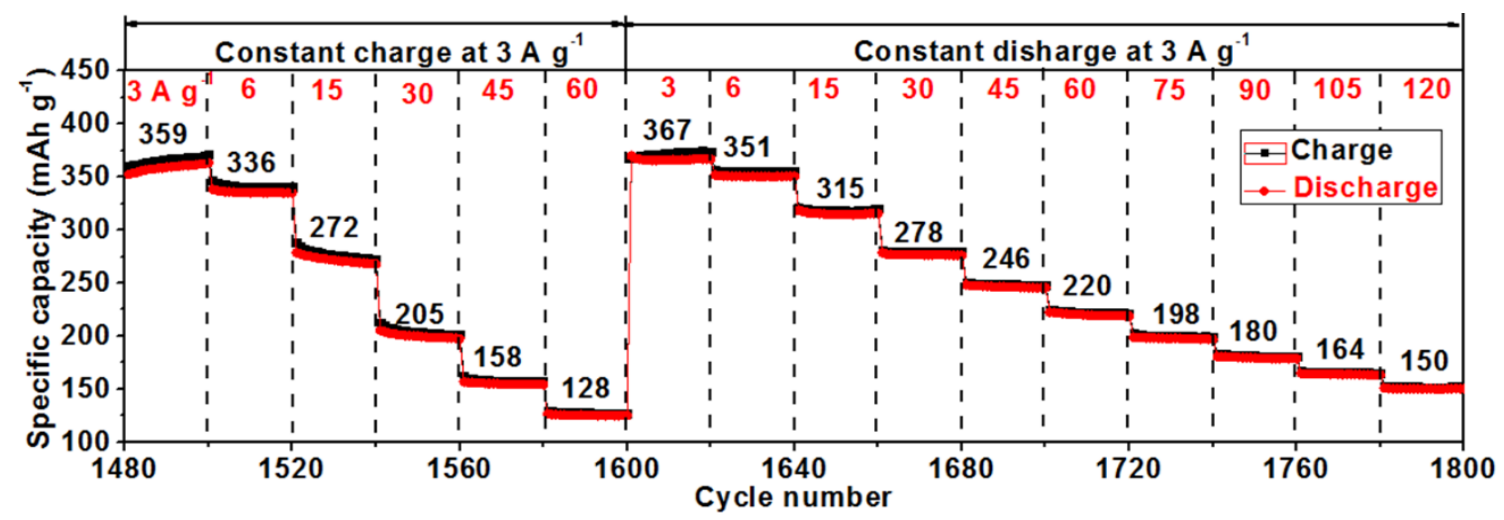

Figure 5. 8 Asymmetric rate capability performance of ESD-LTO-10Si-5rGO electrode Test conditions: constant charge current density: $3 \mathrm{~A} \mathrm{~g}^{-1}$, discharge current density: 3-60 $\mathrm{A} \mathrm{g}^{-1}$; constant discharge current density: $3 \mathrm{~A} \mathrm{~g}^{-1}$, charge current densities: 3-120 $\mathrm{A} \mathrm{g}^{-1}$.
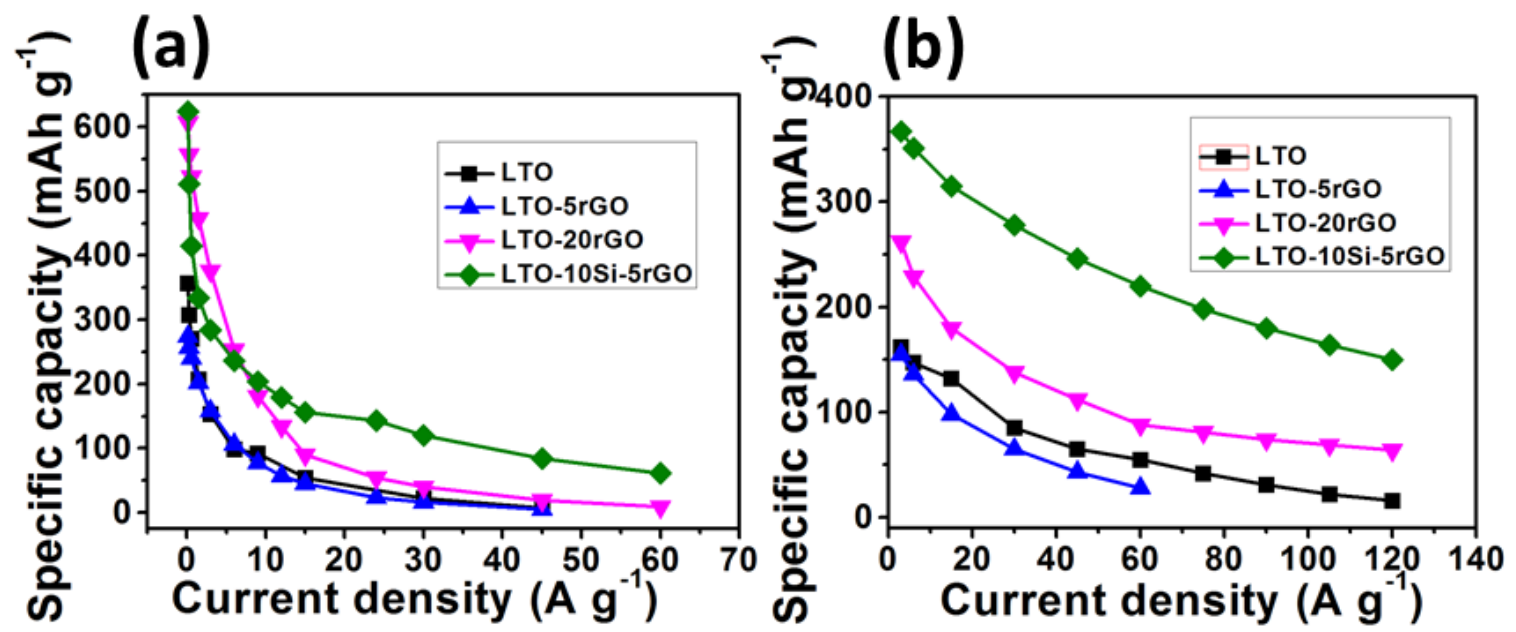

Figure 5.9 (a) Symmetric rate capability performance comparison between ESD-LTO and its composites. (b) Asymmetric rate capability performance (constant discharge current density: $3 \mathrm{~A} \mathrm{~g} \mathrm{~g}^{-1}$, charge current density: 3-120 A g${ }^{-1}$ ) comparison between ESD-LTO and its composites. 
To compare the electrochemical performance of ESD-LTO and its nanocomposites, Figure 5.9 describes both symmetric and asymmetric rate capability tests results. Several changing trends can be summarized as follows: (1) ESD-LTO electrode and ESD-LTO-5rGO composite electrode have similar capacities at both symmetric and asymmetric rate capability tests; (2) LTO-20rGO composite show higher capacities than both pure LTO and LTO-5rGO composite, especially at low current density symmetric rate capability test; (3) LTO-10Si-5rGO composite delivers the highest capacity in both test modes compared with all other electrodes. From the above performance comparison it can be seen that $\mathrm{Si}$ is one of the most important components that can greatly enhance the composite performance even with a small amount. In ESD-LTO/rGO composite, though 5 wt $\%$ rGO in the composite can decrease the polarization as observed in CV peak shift, the capacity enhancement is limited mainly due to the low concentration of rGO in the composite. As the concentration of rGO increased to $20 \mathrm{wt} \%$, obvious capacity enhancement was observed compared to both ESD-LTO and ESD-LTO-5rGO electrodes.

\subsection{Conclusions}

In this chapter, the synergistic effect of LTO and $\mathrm{Si}$ was evaluated by comparing the electrochemical performance of the composite electrodes with Si and LTO electrodes separately, at varying concentrations with different current densities. It was shown that the LTO/Si composite electrodes exhibited both improved energy capacity and rate capability. This indicates that LTO/Si composites, benefited from both high energy capacity of silicon and the good rate capability of LTO. Then ESD-LTO-10Si-5rGO composite thin film electrodes were fabricated through ESD technique. RGO was used to enhance the rate capability and $\mathrm{Si}$ was added to improve the energy density of the composite electrodes. The 
resulting electrode showed extremely high capacity, even at high rates. The main reason for the capacity increase was attributed to the incorporation of $\mathrm{Si}$. However, the electrode stability was not destroyed by Si due to the volume change buffering effect from both LTO and ESD generated structure pores. In addition, the asymmetric rate performance was also observed with charge current density increased to a value as high as $120 \mathrm{~A} \mathrm{~g}^{-1}$. So it concludes that $\mathrm{Si}$ is one of the important component in the ESD-LTO-10Si-5rGO composite that can greatly enhance the composite performance even with a small amount.

\subsection{References}

1. Liu, J., Song, K., van Aken, P.A., Maier, J. and Yu, Y., 2014. Self-supported $\mathrm{Li}_{4} \mathrm{Ti}_{5} \mathrm{O}_{12}-$ $\mathrm{C}$ nanotube arrays as high-rate and long-life anode materials for flexible Li-ion batteries. Nano letters, 14(5), pp.2597-2603.

2. Zhong, Z., Ouyang, C., Shi, S. and Lei M., Ab initio Studies on $\mathrm{Li}_{4+\mathrm{x}} \mathrm{Ti}_{5} \mathrm{O}_{12}$ Compounds as Anode Materials for Lithium-Ion Batteries. ChemPhysChem 9, no. 14 (2008): 21042108.

3. Ge, H., Li, N., Li, D., Dai, C. and Wang, D., 2008. Electrochemical characteristics of spinel $\mathrm{Li}_{4} \mathrm{Ti}_{5} \mathrm{O}_{12}$ discharged to $0.01 \mathrm{~V}$. Electrochemistry communications, 10(5), pp.719-722.

4. Zhu, Y.R., Yin, L.C., Yi, T.F., Liu, H., Xie, Y. and Zhu, R.S., 2013. Electrochemical performance and lithium-ion intercalation kinetics of submicron-sized $\mathrm{Li}_{4} \mathrm{Ti}_{5} \mathrm{O}_{12}$ anode material. Journal of Alloys and Compounds, 547, pp.107-112.

5. Sivashanmugam, A., Gopukumar, S., Thirunakaran, R., Nithya, C. and Prema, S., 2011. Novel $\mathrm{Li}_{4} \mathrm{Ti}_{5} \mathrm{O}_{12} / \mathrm{Sn}$ nano-composites as anode material for lithium ion batteries. Materials Research Bulletin, 46(4), pp.492-500.

6. Wang, Y.Y., Hao, Y.J., Lai, Q.Y., Lu, J.Z., Chen, Y.D. and Ji, X.Y., 2008. A new composite material $\mathrm{Li}_{4} \mathrm{Ti}_{5} \mathrm{O}_{12}-\mathrm{SnO}_{2}$ for lithium-ion batteries. Ionics, 14(1), pp.85-88.

7. Zhu, J.P., Yang, G., Zhao, J.J., Wang, Q.S. and Yang, H.W., 2011, September. Synthesis and electrochemical properties of $\mathrm{Li}_{4} \mathrm{Ti}_{5} \mathrm{O}_{12} / \mathrm{CuO}$ anode material for $\mathrm{Li}$-ion batteries. In Advanced Materials Research (Vol. 279, pp. 77-82). 
8. Chen, M., Li, W., Shen, X. and Diao, G., 2014. Fabrication of core-shell $\alpha-\mathrm{Fe}_{2} \mathrm{O}_{3} @$ $\mathrm{Li}_{4} \mathrm{Ti}_{5} \mathrm{O}_{12}$ composite and its application in the lithium ion batteries. ACS applied materials \& interfaces, 6(6), pp.4514-4523.

9. Chan, C.K., Peng, H., Liu, G., McIlwrath, K., Zhang, X.F., Huggins, R.A. and Cui, Y., 2008. High-performance lithium battery anodes using silicon nanowires. Nature nanotechnology, 3(1), pp.31-35.

10. Lin, Y., Yang, Y., Lin, Y., Zhao, G., Zhou, T. and Huang, Z., 2011. Effects of amorphous silicon film on elevated-temperature cycle performance of $\mathrm{Li}_{4} \mathrm{Ti}_{5} \mathrm{O}_{12}$ for lithium ion battery. Int. J. Electrochem. Sci, 6, pp.5588-5596.

11. Zhang, L., Deng, J., Liu, L., Si, W., Oswald, S., Xi, L., Kundu, M., Ma, G., Gemming, T., Baunack, S. and Ding, F., 2014. Hierarchically designed $\mathrm{SiO}_{\mathrm{x}} / \mathrm{SiO}_{\mathrm{y}}$ bilayer nanomembranes as stable anodes for lithium ion batteries. Advanced Materials, 26(26), pp.4527-4532.

12. Deng, J., Ji, H., Yan, C., Zhang, J., Si, W., Baunack, S., Oswald, S., Mei, Y. and Schmidt, O.G., 2013. Naturally Rolled-Up C/Si/C Trilayer Nanomembranes as Stable Anodes for Lithium-Ion Batteries with Remarkable Cycling Performance. Angewandte Chemie, 125(8), pp.2382-2386.

13. Chen, W., Fan, Z., Dhanabalan, A., Chen, C. and Wang, C., 2011. Mesoporous silicon anodes prepared by magnesiothermic reduction for lithium ion batteries. Journal of The Electrochemical Society, 158(9), pp.A1055-A1059.

14. Chen, W., Jiang, N., Fan, Z., Dhanabalan, A., Chen, C., Li, Y., Yang, M. and Wang, C., 2012. Facile synthesis of silicon films by photosintering as anode materials for lithium-ion batteries. Journal of power sources, 214, pp.21-27.

15. Chan, C.K., Ruffo, R., Hong, S.S., Huggins, R.A. and Cui, Y., 2009. Structural and electrochemical study of the reaction of lithium with silicon nanowires. Journal of Power Sources, 189(1), pp.34-39.

16. Shin, H.C., Corno, J.A., Gole, J.L. and Liu, M., 2005. Porous silicon negative electrodes for rechargeable lithium batteries. Journal of power sources, 139(1), pp.314320.

17. Hsieh, C.T. and Lin, J.Y., 2010. Influence of Li addition on charge/discharge behavior of spinel lithium titanate. Journal of Alloys and Compounds, 506(1), pp.231-236.

18. Liu, J., Li, X., Cai, M., Li, R. and Sun, X., 2013. Ultrathin atomic layer deposited ZrO 2 coating to enhance the electrochemical performance of $\mathrm{Li}_{4} \mathrm{Ti}_{5} \mathrm{O}_{12}$ as an anode material. Electrochimica Acta, 93, pp.195-201. 
19. Meng, X., Liu, J., Li, X., Banis, M.N., Yang, J., Li, R. and Sun, X., 2013. Atomic layer deposited $\mathrm{Li}_{4} \mathrm{Ti}_{5} \mathrm{O}_{12}$ on nitrogen-doped carbon nanotubes. RSC Advances, 3(20), pp.7285-7288.

20. Sun, Q., Zhang, B. and Fu, Z.W., 2008. Lithium electrochemistry of $\mathrm{SiO}_{2}$ thin film electrode for lithium-ion batteries. Applied Surface Science, 254(13), pp.3774-3779.

21. Favors, Z., Wang, W., Bay, H.H., George, A., Ozkan, M. and Ozkan, C.S., 2014. Stable cycling of $\mathrm{SiO}_{2}$ nanotubes as high-performance anodes for lithium-ion batteries. Scientific reports, 4 . 


\section{FABRICATION AND CHARACTERIZATION OF OTHER ELECTRODE}

\section{MATERIALS}

\subsection{Activated Carbon Nanofiber Electrodes}

\subsubsection{Introduction}

Currently, the most commonly used anode material in commercial Li-ion batteries is graphite [1-2]. However, its lower theoretical capacity $\left(372 \mathrm{mAh}^{-1}\right)$ is not enough to satiate the ever increasing energy demands, especially of the automobile sector. Thus, intensive research efforts are being carried out in order to explore alternative electrode materials in alloying mechanism and conversion mechanism, such as silicon [3-5], $\mathrm{SnO}_{2}$ [6], and other transition metal oxides such as $\mathrm{NiO}$ [7], $\mathrm{CuO}$ [8], $\mathrm{Fe}_{2} \mathrm{O}_{3}$ [9], etc. Although there have been improvements in electrochemical performance, large volumetric expansion and poor electrical conductivity are major challenges that need to be addressed in such materials, as a result of which, there is a plethora of issues such as, poor cycle performance, connectivity with the current collectors, poor columbic efficiency in the first cycle, etc. These drawbacks therefore, shift much focus back on developing high performance carbon based anodes for LIBs.

The intercalation and de-intercalation processes of $\mathrm{Li}^{+}$into carbonaceous materials can be expressed as [10-11]:

$$
6 \mathrm{C}+x \mathrm{Li}+x e^{-} \leftrightarrow L_{x} \mathrm{C}_{6}
$$

where $x$ is the stoichiometric factor in $L i_{x} \mathrm{C}_{6}$. It is about 1 for graphitic carbon. Nongraphitic carbon synthesized at low temperatures $\left(500-1000{ }^{\circ} \mathrm{C}\right)$ can be classified into two categories: low specific energy capacity carbon, where $x$ is about $0.5-0.8$; high specific 
energy capacity carbon, where $x$ is about 1.2-3.0. Higher $x$ is the reason why high specific energy capacity carbon can provide more capacity than other kinds of carbon.

Electrospinning is a promising technique to produce continuous nanofibers on a large scale and also it is a relatively easy and fast process. The fiber diameter can be adjusted from nanometers to microns [12-14]. Carbon nanofibers (CNFs) can be obtained by carbonizing electrospun polymer nanofibers at certain temperature. A lot of work has been done based on CNFs as anode materials for Li-ion batteries. Furthermore, precursors of other active materials, such as $\mathrm{Si}$ [15], $\mathrm{SnO}_{2}$ [16], $\mathrm{Fe}_{3} \mathrm{O}_{4}$ [17], $\mathrm{TiO}_{2}$ [18], $\mathrm{NiO}$ [19], etc. have been added to the polymer precursor to synthesize CNF/active material composites. In addition to these additives, the porosity of CNFs has also been tailored in some of the works. For example, Liwen Ji et al. reported the fabrication of porous CNFs by electrospinning a bi-component polymer solution. The resulting porous CNFs had a relatively large surface area of about $235 \mathrm{~m}^{3} \mathrm{~g}^{-1}$ and delivered a capacity of $435 \mathrm{mAh} \mathrm{g}^{-1}$ at the 50th cycle [20]. They also added $\mathrm{SiO}_{2}$ to the polymer precursor followed by $\mathrm{HF}$ treatment to introduce porosity into CNFs [21]. In addition, they also fabricated porous CNFs by in-situ activation with $\mathrm{ZnCl}_{2}$ [22].

Carbon is used extensively as the electrode materials in Electrochemical Double Layer Capacitors (EDLC). With the recent development of Li-ion capacitors (LICs), which combine both the advantages of LIBs and EDLCs, carbon especially activated carbon (AC) is gaining popularity as LIC electrode as well. For example, AC has been mixed with cathode material $\mathrm{LiMn}_{2} \mathrm{O}_{4}$ [23], or anode material $\mathrm{Li}_{4} \mathrm{Ti}_{5} \mathrm{O}_{12}$ [24] to act as cathode or anode in Li-ion capacitors. Because capacitance is a direct consequence of surface area, both CNFs and ACNFs can be employed as LIC electrodes. However, not much work has been 
reported on activated CNFs as electrode candidates for Li-ion batteries. Therefore it is important to look into the performance of ACNFs in LIBs, and as a result, their application can be extended to Li-ion capacitors.

In this section, we have prepared CNFs by electrospinning polyacrylonitrile (PAN) followed by heat treatment. The activation of CNFs was carried out by $\mathrm{KOH}$ chemical activation. Both CNFs and ACNFs have been tested and have shown to be promising candidates for application in Li-ion batteries

\subsubsection{Experimental}

PAN (M.W. 86,000), KOH and solvent $N, N$-dimethyformatide (DMF) were purchased from Sigma-Aldrich. A typical electrospinning method was used to fabricate CNFs. $0.75 \mathrm{~g}$ PAN was dissolved in $10 \mathrm{~mL}$ DMF to form a polymer precursor, which was used for electrospinning. The solution was stirred overnight at $80{ }^{\circ} \mathrm{C}$ before transferring into a syringe. A flat copper foil was put about $15 \mathrm{~cm}$ away from the needle used as a collector of polymer fibers. The flow rate of the syringe pump was $1 \mathrm{~mL} \mathrm{~h}^{-1}$ and a positive direct current (DC) voltage adjusted between 12-14 kV was applied between the needle and the collector to generate a stable and continuous PAN nanofiber network. The collected fibrous mat was transferred to a tube furnace for heat treatment. First, PAN nanofibers were stabilized in an air environment at $280{ }^{\circ} \mathrm{C}$ for $5.5 \mathrm{~h}$ at a heating rate of $5{ }^{\circ} \mathrm{C} \mathrm{min}^{-1}$. Then carbonization was carried out at $800{ }^{\circ} \mathrm{C}$ for $1 \mathrm{~h}$ at a heating rate of $2{ }^{\circ} \mathrm{C} \mathrm{min}-1$ in an argon atmosphere. The as-prepared CNFs were then soaked in aqueous $\mathrm{KOH}$ solution (with a $\mathrm{KOH} / \mathrm{CNFs}$ mass ratio of 5) for $10 \mathrm{~h}$, followed by filtration and drying, to form the $\mathrm{CNFs} / \mathrm{KOH}$ mixture for chemical activation. The $\mathrm{CNFs} / \mathrm{KOH}$ mixture was then put in a tube furnace in an argon atmosphere, and heated at $800{ }^{\circ} \mathrm{C}$ for one hour, at a heating rate 
of $5{ }^{\circ} \mathrm{C} \mathrm{min}^{-1}$. The activated product was then washed using $\mathrm{HCl}(2 \mathrm{~mol} \mathrm{~L}-1)$ and distilled water, filtered and then dried at $105^{\circ} \mathrm{C}$.

The ACNFs electrode was prepared by casting a slurry on copper foil. The slurry was made by mixing $85 \mathrm{wt} \%$ of activated CNFs and $15 \mathrm{wt} \%$ of PAA in ethanol, followed by hand milling for $1 \mathrm{~h}$. Then the electrode was transferred into a vacuum oven and dried at $80{ }^{\circ} \mathrm{C}$ for $12 \mathrm{~h}$. The CNFs electrode was prepared by attaching CNFs mat onto the copper foil directly without any binder. Electrochemical test cells (2032 coin cells) were assembled in an argon-filled glove box.

\subsubsection{Results and Discussion}

Figure 6.1a shows the morphologies of PAN fibers. It can be seen that the diameter of the fiber was around $250 \mathrm{~nm}$ and the surface was smooth. After heat treatment, the PAN fibers were transformed to CNFs. The resulting CNFs had similar morphologies as PAN fibers, but the diameter decreased slightly to $200 \mathrm{~nm}$, as shown in Figure 6.1b. Figure 6.1c exhibits the XRD pattern of CNFs. The large peak near $2 \theta=25^{\circ}$ indicates (002) layers of graphitic structure. Besides, the peak of (100) layers (at $2 \theta=45^{\circ}$ ) is barely seen in the pattern, which indicates the amorphous nature of the fibers with partial graphitic structure [22, 25-26]. In Figure 6.1d, Raman spectra shows two strong peaks centered near $1350 \mathrm{~cm}^{-}$

${ }^{1}$ (D line) and $1600 \mathrm{~cm}^{-1}$ (G line). The D line is a typical feature of carbon with structural defects and disorder, while $G$ line represents the high frequency $E_{2 \mathrm{~g}}$ mode typically found in graphitic carbon. The existence of both $\mathrm{D}$ and $\mathrm{G}$ bands is consistent with XRD results that such CNFs have an amorphous structure with partially graphitized layers [25-26]. 

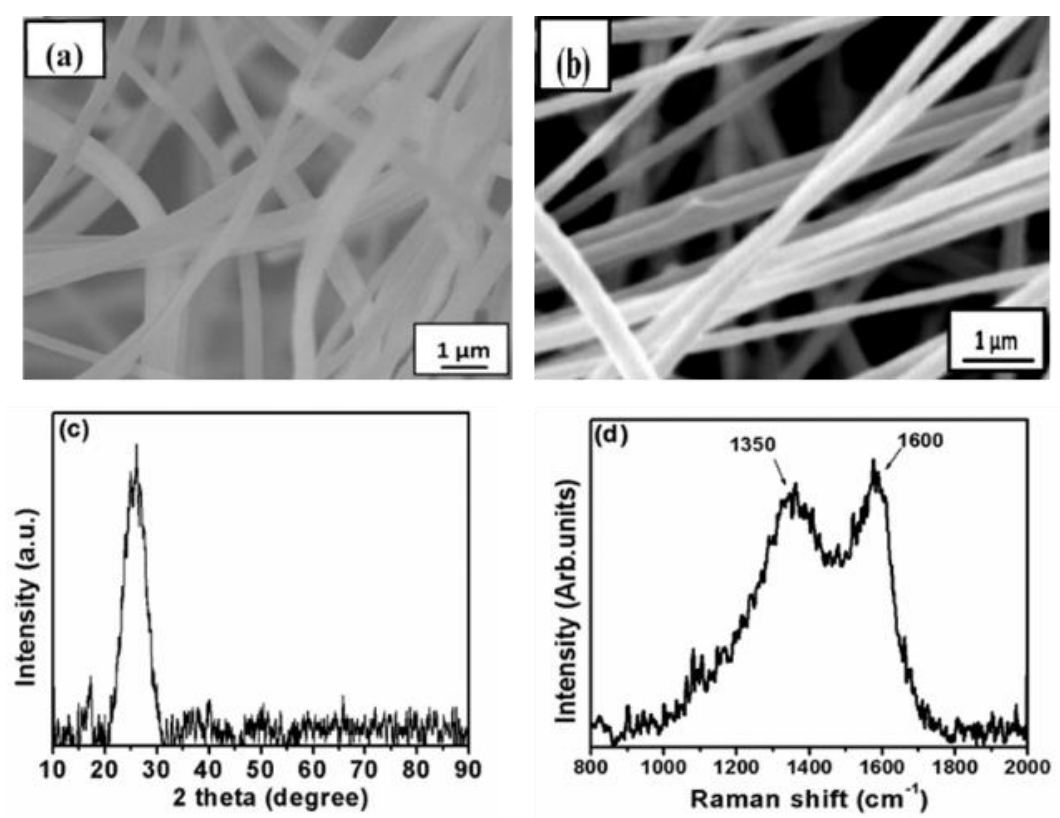

Figure 6. 1 (a)-(b) SEM images of as-electrospun PAN fibers before and after heat treatment. (c) XRD pattern of CNFs and (d) Raman spectra of CNFs.

Table 6.1 shows the BET results of both CNFs and ACNFs. The specific surface area of CNFs increases from 31.6 to $167.9 \mathrm{~m}^{2} \mathrm{~g}^{-1}$ by $\mathrm{KOH}$ activation, and the total pore volume also increased from 0.099 to $0.132 \mathrm{~cm}^{3} \mathrm{~g}^{-1}$. It is obvious that the $\mathrm{KOH}$ activation is effective to introduce porosity into CNFs and subsequently increase the surface area of CNFs.

Table 6. 1 BET test results of CNFs and ACNFs.

\begin{tabular}{lll}
\hline Sample & $\mathrm{SSA}^{\mathrm{a}}\left(\mathrm{m}^{2} \mathrm{~g}^{-1}\right)$ & $\mathrm{TPV}^{\mathrm{b}}\left(\mathrm{cm}^{3} \mathrm{~g}^{-1}\right)$ \\
\hline CNFs & 31.6 & 0.099 \\
ACNFs & 167.9 & 0.132 \\
\hline
\end{tabular}

${ }^{a}$ SSA: Specific surface area

b TPV: Total pore volume.

Figure 6.2a displays the CV curves of the CNFs electrode. There is a broad peak at around $0.45-0.8 \mathrm{~V}$ in cathodic branch of the first cycle, however, this broad peak disappeared from the second cycle. And in the anodic branch, there is no obvious peak corresponding to this reduction process. This peak is related to the solid electrolyte interphase (SEI) formation. The main intercalation of lithium into carbon occurred below 
$0.45 \mathrm{~V}$, and the extraction process is between $0.1-0.5 \mathrm{~V}$, shown as a broad shoulder in anodic branch. The shapes of the CV curves show no discernable changes from the second cycle to the $10^{\text {th }}$ cycle, which indicates that the SEI formation mainly occurred during the first cycle and that the electrochemical performance of the electrode was stable. Figure 6.2c shows the charge-discharge curves of CNFs electrode at different cycles. In the first discharge cycle, only one obvious plateau at around $0.75-0.45 \mathrm{~V}$ can be seen which agrees with the CV curve of the first cycle. The first discharge and charge specific capacity is 988 and $438 \mathrm{mAh} \mathrm{g}^{-1}$ respectively which leads to an irreversible capacity of $550 \mathrm{mAh} \mathrm{g}^{-1}$ during the first cycle. From the second to the $100^{\text {th }}$ cycle, specific capacity decreases only by 28 $\mathrm{mAh} \mathrm{g}^{-1}$, which accounts for an average capacity fade of $0.28 \mathrm{mAh} \mathrm{g}^{-1}$ per cycle. Figure 6.2b shows the $\mathrm{CV}$ curves of the ACNFs electrode. Compared to Figure 6.2a, the SEI formation peak is broader. In Figure 6.2d, the corresponding plateau is also obvious from 1.0 to $0.5 \mathrm{~V}$. The specific capacity of the first discharge and charge cycle is 2242 and 991 $\mathrm{mAh} \mathrm{g}^{-1}$ respectively, which leads to an irreversible capacity of $1251 \mathrm{mAh} \mathrm{g}^{-1}$. In the second cycle, the discharge capacity still remains $786 \mathrm{mAh} \mathrm{g}^{-1}$, which is much higher than that of CNFs electrode. The discharge capacity decreases to $512 \mathrm{mAh} \mathrm{g}^{-1}$ at the $100^{\text {th }}$ cycle. Thus, the ACNFs electrode exhibits extraordinarily high specific capacity and such behavior of carbon has also been observed by other researchers. For example, H. Q. Li et al [27] reported that the discharge and charge capacity of the first cycle of ordered mesoporous carbon was 3083 and $1048 \mathrm{mAh} \mathrm{g}^{-1}$, respectively. Some researchers have demonstrated that the ability of lithium intercalation and deintercalation in non-graphitic carbonaceous materials depends on the properties like crystalline phase, micro structure, hydrogenpresence and micromorphology. For our ACNFs electrode, the reversible capacity is higher 
as compared to CNFs electrode. This is because of its larger surface area which facilitates interfacial/surface Li ion storage. Li ion storage in defective locations such as cavities and nanopores of CNFs could be another reason to explain the higher reversible capacity of the ACNFs electrode than the CNFs electrode [28].
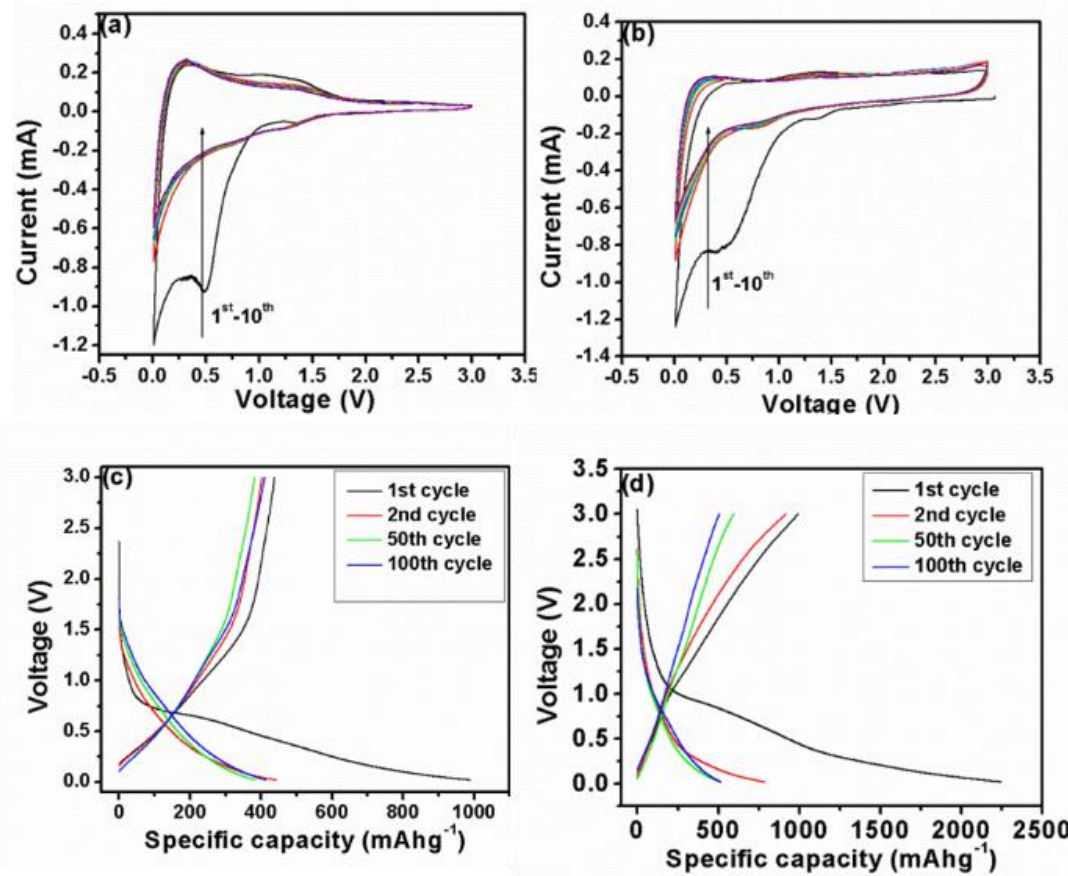

Figure 6. $2 \mathrm{CV}$ curves of (a) CNFs and (b) ACNFs electrodes at a scan rate of $0.2 \mathrm{mV} \mathrm{s}^{-1}$ in the range of 0.02-3 V. Galvanostatic charge-discharge curves of (c) CNFs and (d) ACNFs electrodes between 0.02 and $3 \mathrm{~V}$ at a current density of $100 \mathrm{~mA} \mathrm{~g}^{-1}$.

The cycling performance and columbic efficiency of the CNFs electrode and the ACNFs electrode are shown in Figure 6.3. The reversible capacities of both samples are stabilized after first several cycles. Beyond that there is nearly no reversible capacity decrease in both samples. For the CNFs electrode, reversible capacity slightly increases from the $50^{\text {th }}$ cycle to $100^{\text {th }}$ cycle. The first cycle columbic efficiencies of CNFs electrode and ACNFs electrode are both 44\%. Then it increases dramatically to around $100 \%$ in the following cycles for both the samples. 

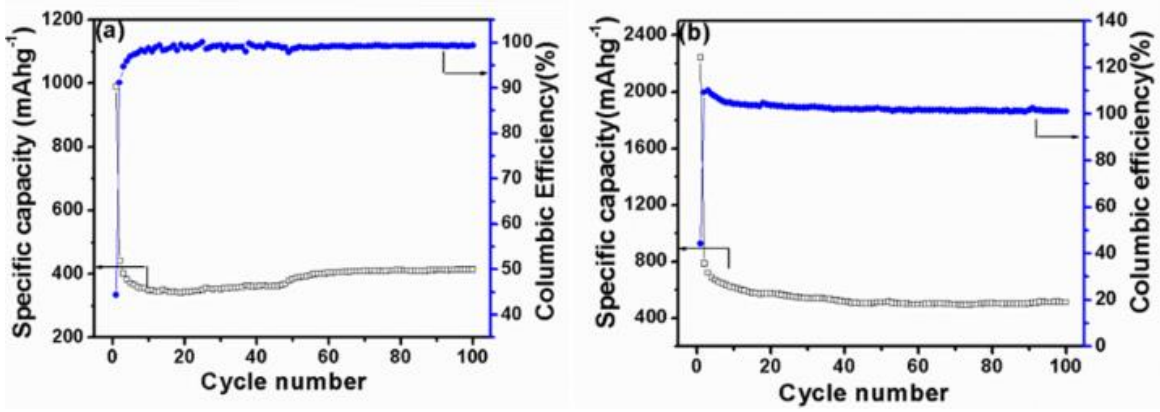

Figure 6. 3 The cycling performance and columbic efficiency of (a) CNFs electrode and (b) ACNFs electrode, respectively.

Figure 6.4 shows the rate performance of both the electrodes at increased current densities. As the current density increases from 100 to $1000 \mathrm{~mA} \mathrm{~g}^{-1}$, the specific capacity decreases from 413 to $139 \mathrm{mAh} \mathrm{g}^{-1}$, and from 512 to $265 \mathrm{mAh} \mathrm{g}^{-1}$ for CNFs and ACNFs electrodes respectively. However, the specific capacity of ACNFs electrode decreases much slower than that of the CNFs electrode, especially when tested at $1000 \mathrm{~mA} \mathrm{~g}^{-1}$. This is because of the large surface area and porous structure of ACNFs, which shorten the diffusion path, making diffusion more facile. After the $1000 \mathrm{~mA} \mathrm{~g}^{-1}$ test, the specific capacity increases to around $600 \mathrm{mAh} \mathrm{g}^{-1}$ for both the electrodes. The possible reason for this increase in specific capacity could be the activation of the electrode material because of the previous high current density testing, creating further sites for $\mathrm{Li}^{+}$ion storage.

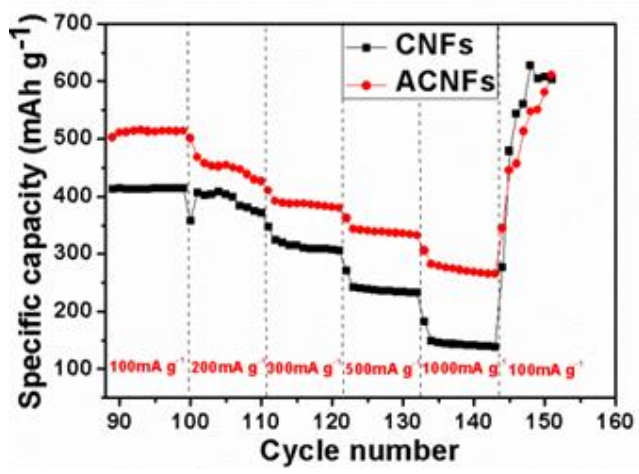

Figure 6. 4 The rate performance of CNFs and ACNFs electrodes at various current densities ranging from $100 \mathrm{~mA} \mathrm{~g}^{-1}$ to $1000 \mathrm{~mA} \mathrm{~g}^{-1}$. 


\subsubsection{Conclusions}

Activated carbon nanofibers (ACNFs) with a surface area of $167.9 \mathrm{~m}^{2} \mathrm{~g}^{-1}$ were prepared by carbonization of PAN fibers by electrospinning, followed by $\mathrm{KOH}$ activation. The electrochemical performance was enhanced due to its special properties, such as high surface area and porous structure. The ACNFs delivered a reversible capacity of $512 \mathrm{mAh}$ $\mathrm{g}^{-1}$ at the $100^{\text {th }}$ cycle for a current density of $100 \mathrm{~mA} \mathrm{~g}^{-1}$. Even at very high current density of $1000 \mathrm{~mA} \mathrm{~g}^{-1}$, the reversible capacity reached $265 \mathrm{mAh} \mathrm{g}^{-1}$. The present results show that the ACNFs are promising anode materials in Li-ion battery application.

\subsubsection{References}

1. Wang, Y. and Cao, G., 2008. Developments in Nanostructured Cathode Materials for High-Performance Lithium-Ion Batteries. Advanced Materials, 20(12), pp.2251-2269.

2. Scrosati, B. and Garche, J., 2010. Lithium batteries: Status, prospects and future. Journal of Power Sources, 195(9), pp.2419-2430.

3. Choi, N.S., Yao, Y., Cui, Y. and Cho, J., 2011. One dimensional Si/Sn-based nanowires and nanotubes for lithium-ion energy storage materials. Journal of Materials Chemistry, 21(27), pp.9825-9840.

4. Chan, C.K., Peng, H., Liu, G., McIlwrath, K., Zhang, X.F., Huggins, R.A. and Cui, Y., 2008. High-performance lithium battery anodes using silicon nanowires. Nature nanotechnology, 3(1), pp.31-35.

5. Chen, W., Fan, Z., Dhanabalan, A., Chen, C. and Wang, C., 2011. Mesoporous silicon anodes prepared by magnesiothermic reduction for lithium ion batteries. Journal of The Electrochemical Society, 158(9), pp.A1055-A1059.

6. Yu, Y., Gu, L., Dhanabalan, A., Chen, C.H. and Wang, C., 2009. Three-dimensional porous amorphous $\mathrm{SnO}_{2}$ thin films as anodes for Li-ion batteries. Electrochimica Acta, 54(28), pp.7227-7230.

7. Li, X., Dhanabalan, A. and Wang, C., 2011. Enhanced electrochemical performance of porous NiO-Ni nanocomposite anode for lithium ion batteries. Journal of Power Sources, 196(22), pp.9625-9630. 
8. Ko, S., Lee, J.I., Yang, H.S., Park, S. and Jeong, U., 2012. Mesoporous CuO Particles Threaded with CNTs for High-Performance Lithium-Ion Battery Anodes. Advanced Materials, 24(32), pp.4451-4456.

9. Zhu, X., Zhu, Y., Murali, S., Stoller, M.D. and Ruoff, R.S., 2011. Nanostructured reduced graphene oxide/ $\mathrm{Fe}_{2} \mathrm{O}_{3}$ composite as a high-performance anode material for lithium ion batteries. Acs Nano, 5(4), pp.3333-3338.

10. Zhou, H., Zhu, S., Hibino, M., Honma, I. and Ichihara, M., 2003. Lithium storage in ordered mesoporous carbon (CMK-3) with high reversible specific energy capacity and good cycling performance. Advanced Materials, 15(24), pp.2107-2111.

11. Winter, M., Besenhard, J.O., Spahr, M.E. and Novak, P., 1998. Insertion electrode materials for rechargeable lithium batteries. Advanced materials, 10(10), pp.725-763.

12. Kaskhedikar, N.A. and Maier, J., 2009. Lithium storage in carbon nanostructures. Advanced Materials, 21(25-26), pp.2664-2680.

13. Frackowiak, E. and Beguin, F., 2002. Electrochemical storage of energy in carbon nanotubes and nanostructured carbons. Carbon, 40(10), pp.1775-1787.

14. Bhardwaj, N. and Kundu, S.C., 2010. Electrospinning: a fascinating fiber fabrication technique. Biotechnology advances, 28(3), pp.325-347.

15. Reneker, D.H. and Yarin, A.L., 2008. Electrospinning jets and polymer nanofibers. Polymer, 49(10), pp.2387-2425.

16. Dong, Z., Kennedy, S.J. and Wu, Y., 2011. Electrospinning materials for energy-related applications and devices. Journal of Power Sources, 196(11), pp.4886-4904.

17. Ji, L. and Zhang, X., 2009. Fabrication of porous carbon/Si composite nanofibers as highcapacity battery electrodes. Electrochemistry Communications, 11(6), pp.1146-1149.

18. Zou, L., Gan, L., Lv, R., Wang, M., Huang, Z.H., Kang, F. and Shen, W., 2011. A film of porous carbon nanofibers that contain $\mathrm{Sn} / \mathrm{SnO}_{\mathrm{x}}$ nanoparticles in the pores and its electrochemical performance as an anode material for lithium ion batteries. Carbon, 49(1), pp.89-95.

19. Wang, L., Yu, Y., Chen, P.C., Zhang, D.W. and Chen, C.H., 2008. Electrospinning synthesis of $\mathrm{C} / \mathrm{Fe}_{3} \mathrm{O}_{4}$ composite nanofibers and their application for high performance lithium-ion batteries. Journal of Power Sources, 183(2), pp.717-723.

20. Chen, J., Yang, L. and Tang, Y., 2010. Electrochemical lithium storage of $\mathrm{TiO}_{2}$ hollow microspheres assembled by nanotubes. Journal of Power Sources, 195(19), pp.68936896. 
21. Qiu, Y., Yu, J., Tan, C. and Yin, J., 2009. Preparation of honeycomb-like NiO with nanogrooves by using electrospun nanofibrous webs as templates. Materials Letters, 63(2), pp.200-202.

22. Ji, L. and Zhang, X., 2009. Fabrication of porous carbon nanofibers and their application as anode materials for rechargeable lithium-ion batteries. Nanotechnology, 20(15), p. 155705 .

23. Ji, L., Lin, Z., Medford, A.J. and Zhang, X., 2009. Porous carbon nanofibers from electrospun polyacrylonitrile $/ \mathrm{SiO}_{2}$ composites as an energy storage material. Carbon, 47(14), pp.3346-3354.

24. Ji, L. and Zhang, X., 2009. Generation of activated carbon nanofibers from electrospun polyacrylonitrile-zinc chloride composites for use as anodes in lithium-ion batteries. Electrochemistry Communications, 11(3), pp.684-687.

25. Hu, X., Deng, Z., Suo, J. and Pan, Z., 2009. A high rate, high capacity and long life $\left(\mathrm{LiMn}_{2} \mathrm{O}_{4}+\mathrm{AC}\right) / \mathrm{Li}_{4} \mathrm{Ti}_{5} \mathrm{O}_{12}$ hybrid battery-supercapacitor. Journal of power Sources, 187(2), pp.635-639.

26. Cericola, D., Novák, P., Wokaun, A. and Kötz, R., 2011. Hybridization of electrochemical capacitors and rechargeable batteries: An experimental analysis of the different possible approaches utilizing activated carbon, $\mathrm{Li}_{4} \mathrm{Ti}_{5} \mathrm{O}_{12}$ and $\mathrm{LiMn}_{2} \mathrm{O}_{4}$. Journal of Power Sources, 196(23), pp.10305-10313.

27. Liu, E., Shen, H., Xiang, X., Huang, Z., Tian, Y., Wu, Y., Wu, Z. and Xie, H., 2012. A novel activated nitrogen-containing carbon anode material for lithium secondary batteries. Materials Letters, 67(1), pp.390-393.

28. Li, C., Yin, X., Chen, L., Li, Q. and Wang, T., 2009. Porous carbon nanofibers derived from conducting polymer: synthesis and application in lithium-ion batteries with highrate capability. The Journal of Physical Chemistry C, 113(30), pp.13438-13442.

29. Li, H.Q., Liu, R.L., Zhao, D.Y. and Xia, Y.Y., 2007. Electrochemical properties of an ordered mesoporous carbon prepared by direct tri-constituent co-assembly. Carbon, 45(13), pp.2628-2635. 


\subsection{Montmorillonite Clay Electrodes}

\subsubsection{Introduction}

Two-dimensional (2D) materials are a group of materials of crystalline solids with sheets of atomic or molecular thicknesses; the sheets are held with strong covalent or ionic intralayer bonding but weaker van der Waals or electrostatic interlayer bonding [1-5]. A great deal of 2D materials have been reported including [6-10], graphene and its derivatives, transition metal dichalcogenides ( $\operatorname{such}$ as $\mathrm{MoS}_{2}, \mathrm{WSe}$ ), layered metal oxides (such as $\mathrm{MnO}_{2}, \mathrm{~V}_{2} \mathrm{O}_{5}$ ), MXenes, clays and so forth. Owing to their ability to intercalate ions into the layered structures, 2D materials have recently attracted much scientific attention for energy storage systems, especially lithium-ion batteries (LIBs) and supercapacitors in recent years [11-12]. Montmorillonite (MMT) is a type of clay mineral that has a 2D layered structure and naturally exists in the earth. Each layer comprises two silica tetrahedral sheets with a central alumina octahedral sheet; the layers are separated with interlayer spaces which contain charge-balancing hydrated cations (shown in Figure 6.5 a) [13-15]. Due to its high surface area, cation intercalation/exchange capability and tunable interlayer distance, MMT is a material of wide interest in applications such as adsorbents, catalysts, sensors, filtration membranes and so on [16-19]. For example, MMT is used for the removal of heavy metal ion pollution due to its cation exchange capability [16]. It has also been used as a reinforcement with polymers because of the very high aspect ratio and high strength [17]. Additionally intercalation of conductive polymer in the MMT interlayers makes it possible to tailor its conductivity over a wide range [18]. In addition, MMT has been used to synthesize polymer-in-ceramic membranes for LIBs [19]. 
The electrochemical performance of $2 \mathrm{D}$ materials depends on several factors including surface area, interlayer distances and the species residing in them, and electronic conductivity. For instance, 2D materials and especially their single or few-layer counterparts, usually have high surface area which enables a large electrode/electrolyte interface, short ion and electron diffusion paths which enable high rate performance [20]. In addition, several other surface related aspects, such as functional groups attached on the surface [21], side reactions [22] and re-stacking of the nanosheets [23] also have a great effect on the electrode performance. In addition, tunable interlayer distance and ion species could affect ion-intercalation, diffusion, kinetics, and energy storage capacity [24-29]. For example, Hao et al. synthesized highly ordered mesoporous $\mathrm{MoS}_{2}$ with expanded d-spacing and achieved high rate capacity of $608 \mathrm{mAh} \mathrm{g}^{-1}$ at $10 \mathrm{~A} \mathrm{~g}^{-1}$ due to the ultra-fast lithium ion intercalation [25]. Zhao et al. reported interlayer expansion through pre-intercalation of appropriate alkali metal ions was a facile and effective method to enhance cycling stability and rate capability by regulating the diffusion channels of intercalation compounds [29].

Due to structural similarity, MMT may react in a similar way as other 2D materials did in some of the properties. Besides, MMT has other advantages like its natural occurrence in the earth, abundance and cost-effectiveness, which make it a potential candidate material for LIBs. However, unlike graphene or other 2D layered materials, to the best of our knowledge, there is no report on the use of clay as an electrochemically active material. Whether or not lithium ions can reversibly intercalate into MMT layers has not been studied. In this work, one of our aims is to explore the feasibility of using MMT as electrodes for LIBs. And the results show that the naturally occurring water containing, "hydrated MMT" (HMMT) is able to reversibly intercalate lithium ions into its structure. 
A reversible capacity of $52 \mathrm{mAh} \mathrm{g}^{-1}$ is maintained for 1000 cycles at current density of 0.5

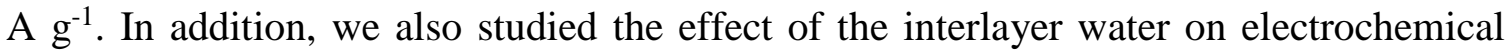
performance of MMT. Removal of interlayer water from MMT (dehydrated MMT, DMMT) will have deteriorative effect on its performance as the interlayer water can serve served as facile ion migration pathways and enabled the fast and reversible ion intercalation.

\subsubsection{Experimental}

MMT powder was used as received. Dehydration of MMT powder was carried out in a Lindberg alumina-tube furnace at $900{ }^{\circ} \mathrm{C}$ for $2 \mathrm{~h}$ in argon atmosphere. The composite electrodes were prepared by casting a slurry on Ti foil. The slurry was prepared by mixing MMT powder, polyvinylidene fluoride (PVDF) and Super $\mathrm{P}$ Li® in N-methyl-2pyrrolidone (NMP) at the weight ratio of 70:15:15. Electrochemical test cells (2032 coin cells) were assembled in an argon filled glove box. The current density and capacity data were calculated using the total mass of the electrode materials.

\subsubsection{Results and Discussion}

SEM and TEM were used to characterize the morphology and structure of HMMT. As shown in Figure $6.5 \mathrm{~b}$, the surface of HMMT clay is flaky and the flakes are in micrometer range which agglomerate to larger sized particles. In HMMT structure, 2D layers are stacked together with water molecules in between. The interlayer spacing varies with the nature of the interlayer cations and amount of water present between the layers [30]. TEM images in Figure $6.5 \mathrm{c}$ displays the 2D layered structure. The average basal spacing at different place varies from $1.46 \mathrm{~nm}$ to $2.71 \mathrm{~nm}$, corresponding to different amounts of water and ions in the interlayers. 

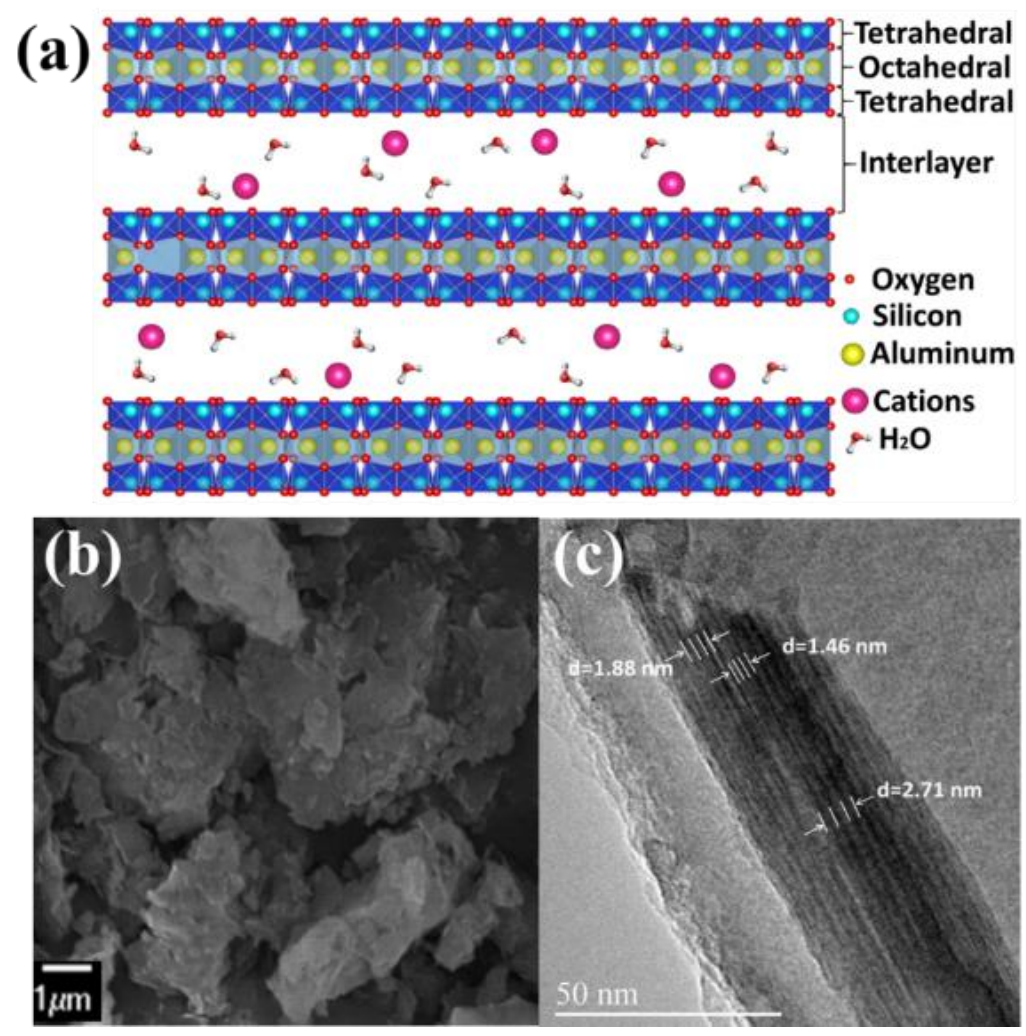

Figure 6. 5 (a) Schematic drawing of HMMT structure. (b) SEM and (c) TEM images of HMMT powders.

To further study the physical properties of MMT clay, various tests were performed and the results are shown in Figure 6.6. The thermogravimetric analysis (TGA) test showed that there was a $10 \%$ weight loss between ambient temperature and $150{ }^{\circ} \mathrm{C}$, which is due to the loss of the water adsorbed at the surface of HMMT powder. Further weight loss is observed at higher temperatures - approximately $8 \%$ weight loss for $\sim 700{ }^{0} \mathrm{C}$. This gradual weight loss may be attributed to the interlayer water loss [31]. BET surface area analysis was performed on both HMMT and DMMT powders. The surface area of DMMT increases from 28.75 to $69.19 \mathrm{~m}^{2} \mathrm{~g}^{-1}$ as compared to the HMMT. The increase in surface area could be a result of partial delamination of clay layers upon the removal of interlayer water. The hysteresis loops of both isotherms seem to be of type H3, corresponding to slit-shaped 
pores in layered materials [32]. Fourier transform infrared spectroscopy (FTIR) test was conducted and the dehydration process was confirmed. The FTIR spectra is illustrated in Figure $6.6 \mathrm{c}$ and peak identifications are summarized in Table 6.2 [33]. X-ray diffraction (XRD) was performed to study the change in the d-spacing after the dehydration process, as shown in Figure 6.6 d. Major peaks of MMT clay have not changed after heat treatment. Instead of one sharp peak, both samples show two broad peaks at lower angle which indicates different d-spacings [32]. Two d-spacings are obtained (HMMT: d=1.07, 1.43 nm; DMMT: $\mathrm{d}=1.07,1.50 \mathrm{~nm})$, as calculated from Bragg's law. The resulting values are smaller than what have been observed in TEM.
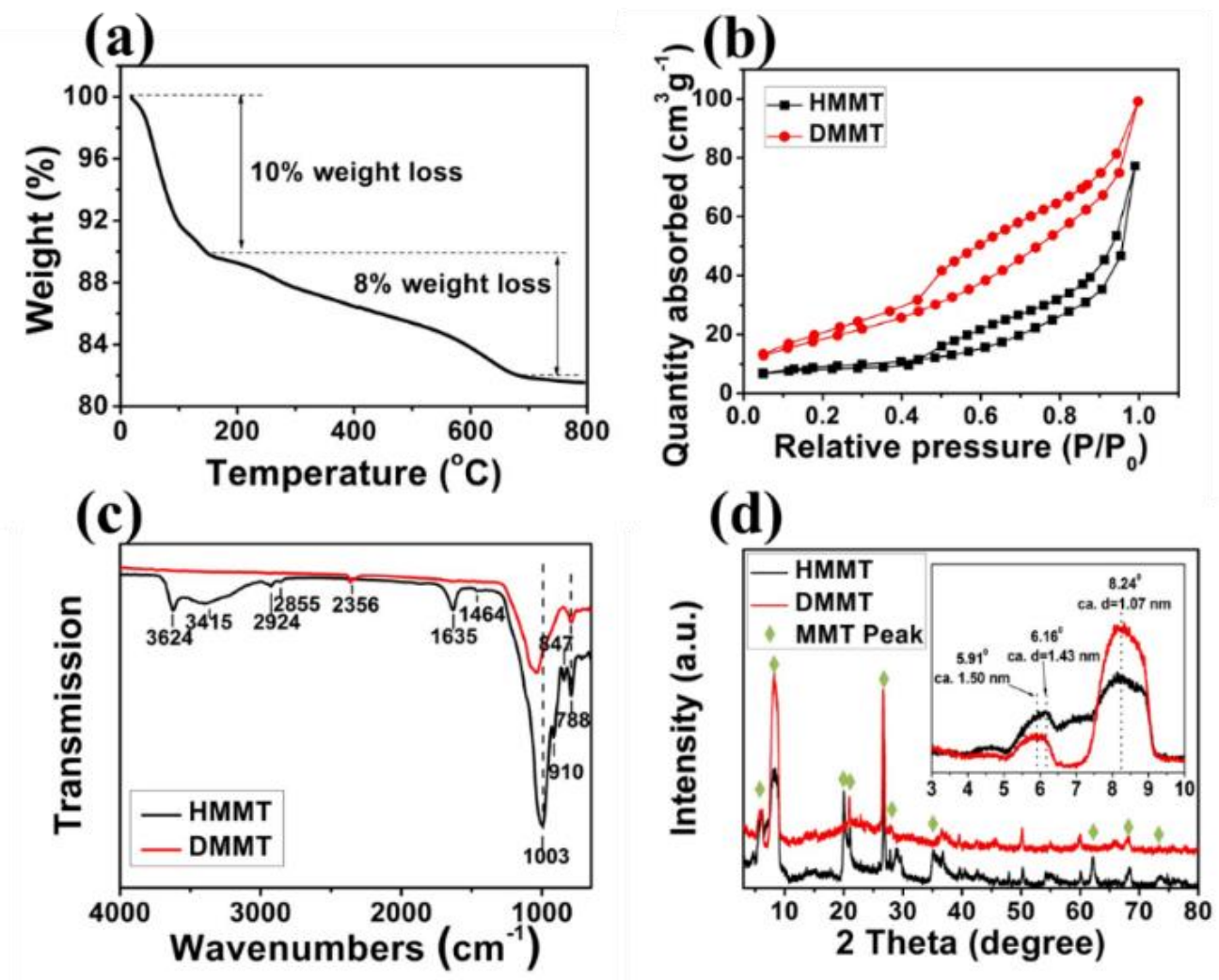

Figure 6. 6 (a) TGA curve of HMMT powder. (b) Nitrogen adsorption-desorption isotherms, (c) FTIR spectra and (d) XRD patterns of both HMMT and DMMT powders. 
Table 6. 2 Summary of FTIR peak identification of MMT clay.

\begin{tabular}{cc}
\hline Wave number $\left(\mathrm{cm}^{-1}\right)$ & Assignment \\
\hline 3624 & O-H stretching, $(\mathrm{Mg}, \mathrm{Al})-\mathrm{OH}$ \\
3415 & H-O-H hydrogen bonded water \\
1635 & H-O-H deformation \\
1003 & Si-O-Si stretching \\
910 & Deformation of OH linked to $2 \mathrm{Al}^{3+}$ \\
847 & Deformation of OH linked to $\mathrm{Al}^{3+}$ and $\mathrm{Mg}^{2+}$ \\
788 & Si-O deformation perpendicular to optical axis \\
\hline
\end{tabular}

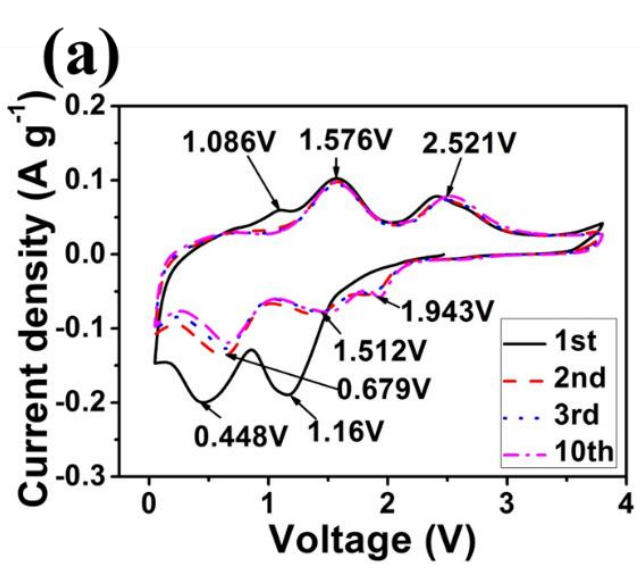

(b)

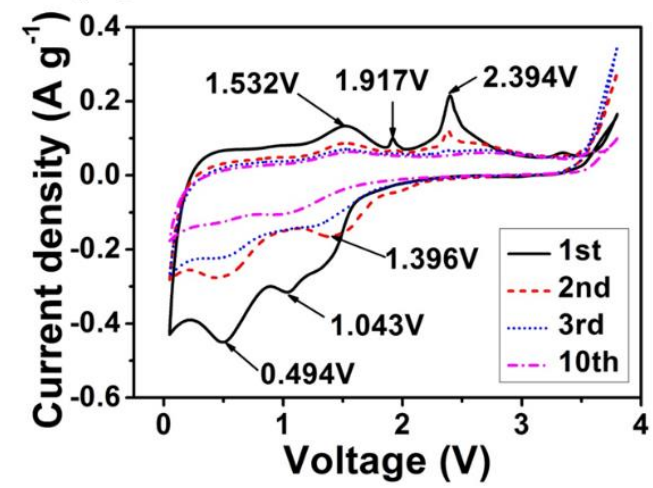

Figure 6. $7 \mathrm{CV}$ curves of (a) HMMT and (b) DMMT at $1 \mathrm{mV} \mathrm{s}^{-1}$, in the voltage window of 0.05-3.8 V.

Figure $6.7 \mathrm{a}$ and $\mathrm{b}$ display the CV curves of HMMT and DMMT electrodes at a scan rate of $1 \mathrm{mV} \mathrm{s}^{-1}$ between a potential of 0.05 and $3.8 \mathrm{~V}\left(\mathrm{vs} \mathrm{Li} / \mathrm{Li}^{+}\right)$. In the first cycle cathodic branch of HMMT, two peaks were observed at 0.448 and $1.16 \mathrm{~V}$, while no obvious peak other than a tiny peak at $1.086 \mathrm{~V}$ was observed for the anodic branch in this range. Due to the fact that solid electrolyte interphase (SEI) formation typically takes place around this potential range, the two cathodic peaks could be partially due to SEI formation [34]. However, stable peaks with smaller current values were observed in the subsequent cycles at approximately 0.679 and $1.512 \mathrm{~V}$ which could correspond to similar reactions as the first cycle. The change in peak shift and current density could be attributed to the combined 
effect of SEI formation and reversible reactions. Other than the aforementioned cathodic peaks, another peak is observed at $1.943 \mathrm{~V}$. Unlike the two peaks in the first cycle, these three peaks were stable and had little change in peak positions and peak currents for the next 9 cycles. In the anodic branch of $\mathrm{CV}$ curves, the two major peaks at 1.576 and 2.512 $\mathrm{V}$ remained stable in the first 10 cycles. The small broad peak at around $1 \mathrm{~V}$ in the first cycle disappears in the following cycles. These repeatable major peaks indicate the reversible lithium ions storage in HMMT electrode. However, conclusive remarks about any possible redox reactions taking place in the major components of $\mathrm{MMT}\left(\mathrm{Al}_{2} \mathrm{O}_{3}, \mathrm{SiO}_{\mathrm{x}}\right)$ cannot be made with these $\mathrm{CV}$ curves. $\mathrm{Al}_{2} \mathrm{O}_{3}$ is usually considered as electrochemically inactive and is often used as coating materials for cathode [35-36]. The observed peaks from the HMMT electrode do not match with the redox peaks for possible reactions between $\mathrm{SiOx}$ and lithium ions from other's researches [37-41]. When compared to the other layered materials, such as graphite, it is possible that the redox peaks could could correspond to the reversible intercalation/deintercalation of lithium ions in the different layers of MMT with charge transfer process at the electrode/electrolyte interface [42]. Therefore, these peaks can be assigned as the characteristic peaks of MMT clay and further investigation is required to understand the mechanism corresponding to the redox peaks. To study the water effect on the electrochemical performance of MMT, same CV test were also performed for DMMT electrode (Figure 6.7b). Four major peaks at similar voltages as in HMMT electrode are observed in the first cycle. However, these peaks diminished quickly in the following cycles. At the $10^{\text {th }}$ cycle, no obvious peaks could be observed. By comparing the $\mathrm{CV}$ curves of both samples, it can be seen that DMMT electrode has larger current density than HMMT electrode which indicates that DMMT stores more charge than 
HMMT in the first several cycles. This could be explained by higher surface area and more effective mass than HMMT considering $18 \%$ water removal. The decreasing trend of current density of DMMT was more obvious than HMMT because the structure integrity was destroyed by removing the interlayer water.
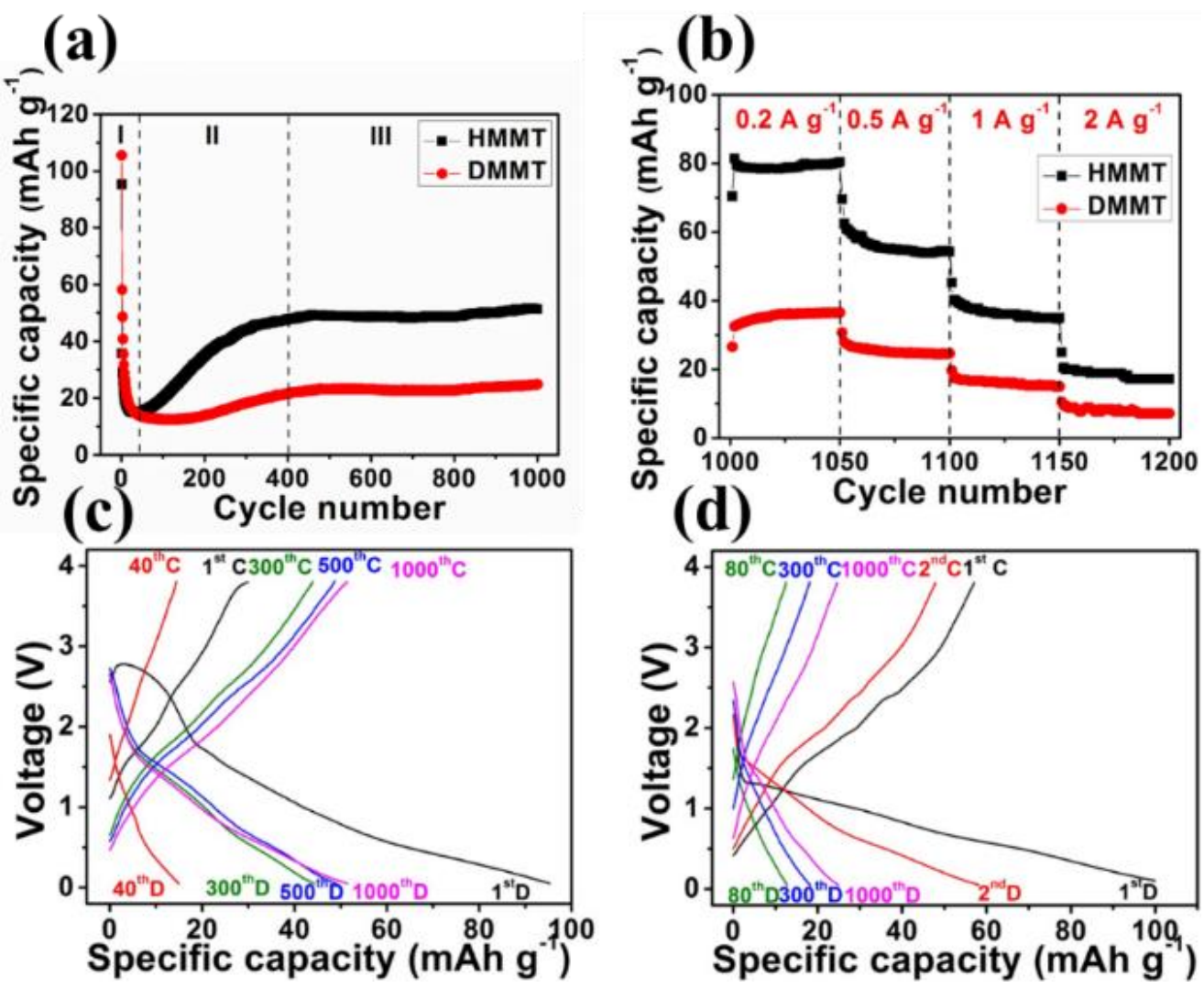

Figure 6. 8 (a) Cycliability performance of both HMMT and DMMT electrodes at current density of $0.5 \mathrm{~A} \mathrm{~g} \mathrm{~g}^{-1}, 0.05 \mathrm{~V}-3.8 \mathrm{~V}$. (b) Rate capability performance of both HMMT and DMMT electrodes at current density of $0.2,0.5,1$ and $2 \mathrm{~A} \mathrm{~g} \mathrm{~g}^{-1}$. Corresponding chargedischarge curves of (c) HMMT and (d) DMMT at different cycles.

In order to determine the long term cyclability, both the electrodes were charged and discharged for 1000 cycles, as shown in Figure 6.8a. For HMMT electrode, the whole process can be divided into three zones from the trend in capacity change. In zone I, the capacity gradually decreased from $95 \mathrm{mAh} \mathrm{g}^{-1}$ at the first cycle to $15 \mathrm{mAh} \mathrm{g}^{-1}$ in the $40^{\text {th }}$ cycle. After 40 cycles, the capacity kept increasing until around the $300^{\text {th }}$ cycle which forms 
zone II. In this zone, the capacity increased by $180 \%$ reaching $42 \mathrm{mAh} \mathrm{g}^{-1}$. After $400^{\text {th }}$ cycle, the electrode stabilized and at $1000^{\text {th }}$ cycle, a capacity of $52 \mathrm{mAh} \mathrm{g}^{-1}$ capacity was achieved. The capacity loss in the first cycle can be attributed to an SEI layer formation, as well as to the irreversible reduction of electrochemically active surface groups such as possibly hydroxyls [43]. The columbic efficiency for the first cycle was around 30\%, which is typical for high surface area electrode materials [44]. But from the second cycle, it increased to almost $100 \%$ around the $10^{\text {th }}$ cycle and was maintained at the same level for the prolonged cycles. The DMMT electrode displayed similar trend as the HMMT electrode, especially in zone I and III, but with lower specific capacities. This is a good indication that the removal of the interlayer water deteriorates the $\mathrm{Li}^{+}$intercalation performance, as a result of the shrinkage of the interlayer distance resulting in destruction of the facile ion migration pathways. Similar phenomena have been observed for vanadium oxide xerogel $[27,29]$. In the first 10 cycles in Zone I, DMMT shows higher specific capacity than HMMT which is consistent with what has been observed in CV curves. In zone II of DMMT, although an increasing trend was maintained but the capacity increase in this zone was much less than of HMMT. Notably, this increased capacity has been observed for many materials. This phenomenon may be attributed to the growth of an electrochemically active gel-like polymer layer, which can enhance lithium ion storage [45]. For another reason, it may due to the gradual activation process of electrode materials [46]. In addition, recent results showed that for $\mathrm{RuO}_{2} \cdot \mathrm{yH}_{2} \mathrm{O}$, besides the traditional conversion reaction, formation of $\mathrm{LiOH}$ by surface reaction between - $\mathrm{OH}$ group and lithium ions can provide additional capacity through reversible conversion of $\mathrm{LiOH}$ to form $\mathrm{Li}_{2} \mathrm{O}$ and $\mathrm{LiH}$ [47]. So for HMMT electrode, similar reaction could be responsible for the 
increased capacity in zone II. But for DMMT electrode, due to the reduced amount of -OH group, the increase in capacity is limited. The charge-discharge curves for both electrodes are compared in Figure 6.8c. For HMMT, it shows some slight curvatures at $\sim 1.5 \mathrm{~V}$ in discharge and $\sim 2.5 \mathrm{~V}$ in charge curves, which are consistent with the above $\mathrm{CV}$ results. The other part of the charge-discharge curves are most straight lines with different slopes, implying the different amount of surface charging contribution. As compare to HMMT, the curvatures in the curves for DMMT are not obvious, especially after the second cycle, which is also consistent with the CV curves that no strong peaks after the second scan.

To test the high rate performance of MMT electrode, further charge-discharge measurements under various current densities from 0.2 to $2 \mathrm{~A} \mathrm{~g}^{-1}$ were carried out after the 1000 cycles test, and the results were shown in Figure $6.8 \mathrm{~b}$ and d. The highest capacity was obtained at a current density of $0.2 \mathrm{~A} \mathrm{~g}^{-1}$ for both samples. As the current density increases, the capacity decreases remained stable for each rate, which indicates that the MMT structure was stable even under such high current density. At the current density of $2 \mathrm{~A} \mathrm{~g}^{-1}$, a stable capacity of $19 \mathrm{mAh} \mathrm{g}^{-1}$ is obtained for 50 cycles for the HMMT electrode. It should be noted that the current densities selected for this study are much larger than that are used for traditional tests. For example, $2 \mathrm{~A} \mathrm{~g}^{-1}$ equals up to $11 \mathrm{C}$ for $\mathrm{Li}_{4} \mathrm{Ti}_{5} \mathrm{O}_{12}$ and $7 \mathrm{C}$ for graphite (based on the theoretical capacity). Such rate performance is mainly due to the 2D layered structure of MMT clay which makes it easy for the electrolyte ions to access the entire surface and do not require the lithium ions to diffuse into a 3D lattice structure. The DMMT electrode showed lower capacity than the untreated sample under all current densities, which could be due to the lack of lithium ion traveling channel-inter layer water. 

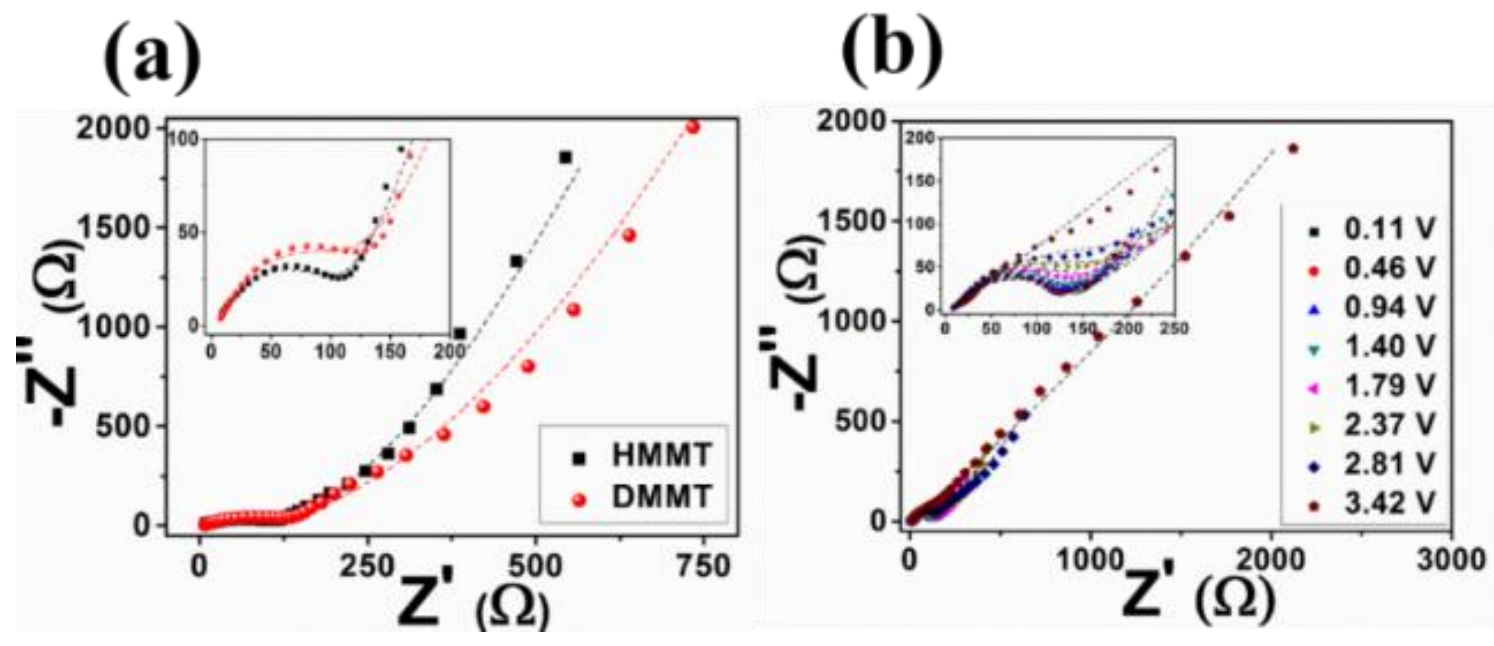

Figure 6. 9 (a) Nyquist plots of both HMMT and DMMT electrodes at freshly assembled state (b) Nyquist plots of HMMT electrode at different voltages.

The Electrochemical Impedance Spectroscopy (EIS) tests were performed for both MMT electrodes as fresh cells and are shown in Figure 6.9a. The Nyquist plots were similar in shape, comprising a depressed semicircle in the high frequency region, followed by a relative straight slopping line in the low frequency region. The semicircle in the highfrequency range is usually associated with the surface properties of the electrode, and the diameter of the semicircle corresponds to the charge-transfer resistance of the electrode, also known as Faraday resistance [48]. It can be easily observed that the diameters of the semicircles clearly larger for DMMT compared with HMMT which indicates larger charge transfer resistance. DMMT electrode displays higher values of the contact resistance, charge transfer resistance, solid electrolyte interphase resistance and $\mathrm{Li}^{+}$diffusion resistance than the HMMT electrode. Figure $6.9 \mathrm{~b}$ exhibits the Nyquist plots for HMMT electrode at different voltages in charging process. From magnified figure it can be seen that the intercepts with real part are almost the same, which means that at all voltages exhibit the same combination resistance of the intrinsic resistance of the HMMT, the ionic resistance of the electrolyte and the contact resistance. And the number is pretty small, 
which indicates that by casting with $15 \%$ super $\mathrm{P} \mathrm{Li}^{\circledR}$, the conductivity of the whole electrode has improved dramatically as compared to the low conductivity nature of MMT clay. The diameters of the semicircles in the high-frequency range clearly decrease as the voltage increases, especially from $0.11 \mathrm{~V}$ to $0.46 \mathrm{~V}$, which indicates the decrease of electrical conductivity. At lower frequencies, the straight lines represent the diffusive resistance of lithium ions in the electrode. The slope angles gradually decrease from ca. $75.6^{\circ}$ at $0.11 \mathrm{~V}$ to ca. $39.7^{\circ}$ at $3.42 \mathrm{~V}$. The steeper low-frequency tail (more close to vertical) indicates higher lithium ion conductivity in the electrode materials [49]. At higher voltage, as more lithium ions are intercalated into the MMT structure, it turns harder for additional ions to intercalate into the structure. The Columbic repulsion from intercalated $\mathrm{Li}^{+}$is responsible for this increased diffusive resistance.

\subsubsection{Conclusions}

In this work, we have demonstrated MMT clay is possible choice as a new green electrode materials for lithium ion batteries. With layered structures and water in between, a capacity of $52 \mathrm{mAh} \mathrm{g}^{-1}$ was achieved at 1000 cycle at the current density of $0.5 \mathrm{~A} \mathrm{~g}^{-1}$ for HMMT electrode. Rate capability test exhibits that at lower current density of $0.2 \mathrm{~A} \mathrm{~g}^{-1}$, higher capacity of $80 \mathrm{mAh} \mathrm{g}^{-1}$ could be achieved for HMMT electrode. A key feature of this study is that we demonstrated importance of water in the structure for the lithium ion migration through comparison with DMMT electrode. Our finding provides lots of options to use other nature materials that have similar 2D structures as MMT as electrode materials for lithium ion batteries. 


\subsubsection{References}

1. Nicolosi, V., Chhowalla, M., Kanatzidis, M.G., Strano, M.S. and Coleman, J.N., 2013. Liquid exfoliation of layered materials. Science, 340(6139), p.1226419.

2. Chhowalla, M., Shin, H.S., Eda, G., Li, L.J., Loh, K.P. and Zhang, H., 2013. The chemistry of two-dimensional layered transition metal dichalcogenide nanosheets. Nature chemistry, 5(4), pp.263-275.

3. Wang, Q.H., Kalantar-Zadeh, K., Kis, A., Coleman, J.N. and Strano, M.S., 2012. Electronics and optoelectronics of two-dimensional transition metal dichalcogenides. Nature nanotechnology, 7(11), pp.699-712.

4. Ma, R. and Sasaki, T., 2010. Nanosheets of Oxides and Hydroxides: Ultimate 2D ChargeBearing Functional Crystallites. Advanced materials, 22(45), pp.5082-5104.

5. Wang, Q. and O'Hare, D., 2012. Recent advances in the synthesis and application of layered double hydroxide (LDH) nanosheets. Chemical reviews, 112(7), pp.4124-4155.

6. Yazyev, O.V. and Chen, Y.P., 2014. Polycrystalline graphene and other two-dimensional materials. Nature nanotechnology, 9(10), pp.755-767.

7. Hwang, H., Kim, H. and Cho, J., 2011. $\mathrm{MoS}_{2}$ nanoplates consisting of disordered graphene-like layers for high rate lithium battery anode materials. Nano letters, 11(11), pp.4826-4830.

8. Lukatskaya, M.R., Mashtalir, O., Ren, C.E., Dall'Agnese, Y., Rozier, P., Taberna, P.L., Naguib, M., Simon, P., Barsoum, M.W. and Gogotsi, Y., 2013. Cation intercalation and high volumetric capacitance of two-dimensional titanium carbide. Science, 341(6153), pp.1502-1505.

9. Zhao, M.Q., Ren, C.E., Ling, Z., Lukatskaya, M.R., Zhang, C., Van Aken, K.L., Barsoum, M.W. and Gogotsi, Y., 2015. Flexible MXene/carbon nanotube composite paper with high volumetric capacitance. Advanced Materials, 27(2), pp.339-345.

10. Pinnavaia, T.J., 1983. Intercalated clay catalysts. Science, 220(4595), pp.365-371.

11. Ling, Z., Ren, C.E., Zhao, M.Q., Yang, J., Giammarco, J.M., Qiu, J., Barsoum, M.W. and Gogotsi, Y., 2014. Flexible and conductive MXene films and nanocomposites with high capacitance. Proceedings of the National Academy of Sciences, 111(47), pp.1667616681.

12. Muller, G.A., Cook, J.B., Kim, H.S., Tolbert, S.H. and Dunn, B., 2015. High performance pseudocapacitor based on 2D layered metal chalcogenide nanocrystals. Nano letters, 15(3), pp.1911-1917. 
13. Chin, I.J., Thurn-Albrecht, T., Kim, H.C., Russell, T.P. and Wang, J., 2001. On exfoliation of montmorillonite in epoxy. Polymer, 42(13), pp.5947-5952.

14. Lopes, A.C., Martins, P. and Lanceros-Mendez, S., 2014. Aluminosilicate and aluminosilicate based polymer composites: Present status, applications and future trends. Progress in Surface Science, 89(3), pp.239-277.

15. Suter, J.L., Groen, D. and Coveney, P.V., 2015. Chemically Specific Multiscale Modeling of Clay-Polymer Nanocomposites Reveals Intercalation Dynamics, Tactoid Self-Assembly and Emergent Materials Properties. Advanced Materials, 27(6), pp.966984.

16. Bhattacharyya, K.G. and Gupta, S.S., 2008. Adsorption of a few heavy metals on natural and modified kaolinite and montmorillonite: a review. Advances in colloid and interface science, 140(2), pp.114-131.

17. Podsiadlo, P., Kaushik, A.K., Arruda, E.M., Waas, A.M., Shim, B.S., Xu, J., Nandivada, H., Pumplin, B.G., Lahann, J., Ramamoorthy, A. and Kotov, N.A., 2007. Ultrastrong and stiff layered polymer nanocomposites. Science, 318(5847), pp.80-83.

18. Boukerma, K., Piquemal, J.Y., Chehimi, M.M., Mravčáková, M., Omastová, M. and Beaunier, P., 2006. Synthesis and interfacial properties of montmorillonite/polypyrrole nanocomposites. Polymer, 47(2), pp.569-576.

19. Raja, M., Kumar, T.P., Sanjeev, G., Zolin, L., Gerbaldi, C. and Stephan, A.M., 2014. Montmorillonite-based ceramic membranes as novel lithium-ion battery separators. Ionics, 20(7), pp.943-948.

20. Arico, A.S., Bruce, P., Scrosati, B., Tarascon, J.M. and Van Schalkwijk, W., 2005. Nanostructured materials for advanced energy conversion and storage devices. Nature materials, 4(5), pp.366-377.

21. Hulicova-Jurcakova, D., Seredych, M., Lu, G.Q. and Bandosz, T.J., 2009. Combined Effect of Nitrogen-and Oxygen-Containing Functional Groups of Microporous Activated Carbon on its Electrochemical Performance in Supercapacitors. Advanced functional materials, 19(3), pp.438-447.

22. Zhang, S.S., 2006. A review on electrolyte additives for lithium-ion batteries. Journal of Power Sources, 162(2), pp.1379-1394.

23. Du, G., Guo, Z., Wang, S., Zeng, R., Chen, Z. and Liu, H., 2010. Superior stability and high capacity of restacked molybdenum disulfide as anode material for lithium ion batteries. Chemical Communications, 46(7), pp.1106-1108. 
24. Hu, Z., Wang, L., Zhang, K., Wang, J., Cheng, F., Tao, Z. and Chen, J., 2014. MoS 2 Nanoflowers with Expanded Interlayers as High-Performance Anodes for Sodium-Ion Batteries. Angewandte Chemie, 126(47), pp.13008-13012.

25. Liu, H., Su, D., Zhou, R., Sun, B., Wang, G. and Qiao, S.Z., 2012. Highly ordered mesoporous $\mathrm{MoS}_{2}$ with expanded spacing of the (002) crystal plane for ultrafast lithium ion storage. Advanced Energy Materials, 2(8), pp.970-975.

26. Liang, Y., Yoo, H.D., Li, Y., Shuai, J., Calderon, H.A., Robles Hernandez, F.C., Grabow, L.C. and Yao, Y., 2015. Interlayer-expanded molybdenum disulfide nanocomposites for electrochemical magnesium storage. Nano letters, 15(3), pp.21942202.

27. Wang, Y., Shang, H., Chou, T. and Cao, G., 2005. Effects of Thermal Annealing on the $\mathrm{Li}+$ Intercalation Properties of $\mathrm{V}_{2} \mathrm{O}_{5} \odot \mathrm{nH}_{2} \mathrm{O}$ Xerogel Films. The Journal of Physical Chemistry B, 109(22), pp.11361-11366.

28. Wang, J., Curtis, C.J., Schulz, D.L. and Zhang, J.G., 2004. Influences of treatment temperature and water content on capacity and rechargeability of $\mathrm{V}_{2} \mathrm{O}_{5}$ xerogel films. Journal of The Electrochemical Society, 151(1), pp.A1-A7.

29. Zhao, Y., Han, C., Yang, J., Su, J., Xu, X., Li, S., Xu, L., Fang, R., Jiang, H., Zou, X. and Song, B., 2015. Stable alkali metal ion intercalation compounds as optimized metal oxide nanowire cathodes for lithium batteries. Nano letters, 15(3), pp.2180-2185.

30. Norrish, K., 1954. Crystalline swelling of montmorillonite: manner of swelling of montmorillonite.

31. Pérez-Santano, A., Trujillano, R., Belver, C., Gil, A. and Vicente, M.A., 2005. Effect of the intercalation conditions of a montmorillonite with octadecylamine. Journal of colloid and interface science, 284(1), pp.239-244.

32. Yuan, P., He, H., Bergaya, F., Wu, D., Zhou, Q. and Zhu, J., 2006. Synthesis and characterization of delaminated iron-pillared clay with meso-microporous structure. Microporous and Mesoporous Materials, 88(1), pp.8-15.

33. Angaji, M.T., Zinali, A.Z. and Qazvini, N.T., 2013. Study of physical, chemical and morphological alterations of smectite clay upon activation and functionalization via the acid treatment. World Journal of Nano Science and Engineering, 2013.

34. Chen, W., Fan, Z., Dhanabalan, A., Chen, C. and Wang, C., 2011. Mesoporous silicon anodes prepared by magnesiothermic reduction for lithium ion batteries. Journal of The Electrochemical Society, 158(9), pp.A1055-A1059.

35. Myung, S.T., Izumi, K., Komaba, S., Sun, Y.K., Yashiro, H. and Kumagai, N., 2005. 
Role of alumina coating on $\mathrm{Li}-\mathrm{Ni}-\mathrm{Co}-\mathrm{Mn}-\mathrm{O}$ particles as positive electrode material for lithium-ion batteries. Chemistry of Materials, 17(14), pp.3695-3704.

36. Cheng, H.M., Wang, F.M., Chu, J.P., Santhanam, R., Rick, J. and Lo, S.C., 2012. Enhanced cycleabity in lithium ion batteries: Resulting from atomic layer deposition of $\mathrm{Al}_{2} \mathrm{O}_{3}$ or $\mathrm{TiO}_{2}$ on $\mathrm{LiCoO}_{2}$ electrodes. The Journal of Physical Chemistry C, 116(14), pp.7629-7637.

37. Sun, Q., Zhang, B. and Fu, Z.W., 2008. Lithium electrochemistry of $\mathrm{SiO}_{2}$ thin film electrode for lithium-ion batteries. Applied Surface Science, 254(13), pp.3774-3779.

38. Tu, J., Yuan, Y., Zhan, P., Jiao, H., Wang, X., Zhu, H. and Jiao, S., 2014. Straightforward approach toward $\mathrm{SiO}_{2}$ nanospheres and their superior lithium storage performance. The Journal of Physical Chemistry C, 118(14), pp.7357-7362.

39. Favors, Z., Wang, W., Bay, H.H., George, A., Ozkan, M. and Ozkan, C.S., 2014. Stable cycling of $\mathrm{SiO}_{2}$ nanotubes as high-performance anodes for lithium-ion batteries. Scientific reports, 4.

40. Kim, J.H., Park, C.M., Kim, H., Kim, Y.J. and Sohn, H.J., 2011. Electrochemical behavior of $\mathrm{SiO}$ anode for Li secondary batteries. Journal of electroanalytical chemistry, 661(1), pp.245-249.

41. Yan, N., Wang, F., Zhong, H., Li, Y., Wang, Y., Hu, L. and Chen, Q., 2013. Hollow porous $\mathrm{SiO}_{2}$ nanocubes towards high-performance anodes for lithium-ion batteries. Scientific reports, 3 .

42. Winter, M., Besenhard, J.O., Spahr, M.E. and Novak, P., 1998. Insertion electrode materials for rechargeable lithium batteries. Advanced materials, 10(10), pp.725-763.

43. Verma, P., Maire, P. and Novák, P., 2010. A review of the features and analyses of the solid electrolyte interphase in Li-ion batteries. Electrochimica Acta, 55(22), pp.63326341.

44. Guo, Y.G., Hu, J.S. and Wan, L.J., 2008. Nanostructured materials for electrochemical energy conversion and storage devices. Advanced Materials, 20(15), pp.2878-2887.

45. Grugeon, S., Laruelle, S., Dupont, L. and Tarascon, J.M., 2003. An update on the reactivity of nanoparticles Co-based compounds towards Li. Solid State Sciences, 5(6), pp.895-904.

46. Sun, H., Xin, G., Hu, T., Yu, M., Shao, D., Sun, X. and Lian, J., 2014. High-rate lithiation-induced reactivation of mesoporous hollow spheres for long-lived lithium-ion batteries. Nature communications, 5 . 
47. Hu, Y.Y., Liu, Z., Nam, K.W., Borkiewicz, O.J., Cheng, J., Hua, X., Dunstan, M.T., Yu, X., Wiaderek, K.M., Du, L.S. and Chapman, K.W., 2013. Origin of additional capacities in metal oxide lithium-ion battery electrodes. Nature materials, 12(12), pp.1130-1136.

48. Zhang, S.S., Xu, K. and Jow, T.R., 2006. EIS study on the formation of solid electrolyte interface in Li-ion battery. Electrochimica acta, 51(8), pp.1636-1640.

49. Andre, D., Meiler, M., Steiner, K., Wimmer, C., Soczka-Guth, T. and Sauer, D.U., 2011. Characterization of high-power lithium-ion batteries by electrochemical impedance spectroscopy. I. Experimental investigation. Journal of Power Sources, 196(12), pp.5334-5341. 


\section{SUMMARY AND FUTURE WORK}

\subsection{Summary}

This dissertation presents fabrication, characterization and evaluation of electrostatic spray deposition derived high performance electrode materials for lithium ion batteries. Lithium titanate $\left(\mathrm{Li}_{4} \mathrm{Ti}_{5} \mathrm{O}_{12}\right)$ is one of the most promising candidate anode materials due to its excellent cyclability, good rate capability, structure stability and SEI free nature (when cutoff voltage $=1 \mathrm{~V}$ ). However, its energy density is relatively low due to low theoretical capacity and high working voltage. One of the objectives of this study is to increase the energy density by two strategies: i) fabrication of ESD derived porous thin film LTO electrode and evaluation of its electrochemical property when cutoff voltage is around $0 \mathrm{~V}$; ii) developing LTO based nanocomposites by adding rate capability enhancement component rGO and energy density enhancement component Si. Besides LTO based electrode materials, activated CNFs as well as MMT clay based electrode have also been studied.

Firstly, ESD was used to synthesize porous LTO thin film electrode. Electrochemical studies showed that it can deliver $357 \mathrm{mAh} \mathrm{g}^{-1}$ capacity at $0.15 \mathrm{~A} \mathrm{~g}^{-1}$, which doubled the theoretical capacity of LTO when cutoff voltage window is 1V. At high current density test of $6 \mathrm{~A} \mathrm{~g}^{-1}$, corresponding to an actual charge/discharge time of $60 \mathrm{~s}$, a capacity of $98 \mathrm{mAh} \mathrm{g}^{-1}$ was still achievable. From reaction kinetics study it was observed that the capacitive Li storage contribution was not negligible compared to diffusion controlled Li storage contribution in such porous thin structures. At even higher rate, $\mathrm{Li}^{+}$ is predominantly stored by capacitive charge because bulk ion transport is not able to keep up with the applied galvanostatic current due to the sluggish kinetics. In addition, 
asymmetric rate tests were performed and it was revealed that the charging process was much faster than discharging process. Furthermore, the cell lasted for more than 1400 cycles even after harsh condition tests. Then rGO and Si were introduced into LTO separately to form $\mathrm{LTO} / \mathrm{rGO}$ and $\mathrm{LTO} / \mathrm{Si}$ composites, respectively. The rate capability enhancement from rGO was studied by evaluating LTO/rGO composites. The synergic effect between LTO and Si was proved by preparing various LTO/Si composites. It was demonstrated that the addition of $\mathrm{Si}$ and concentration optimization was an easy and effective way to produce high energy density LTO-based electrodes for LIBs. Finally, both rGO and $\mathrm{Si}$ were added in ESD-LTO-10Si-5rGO composite thin film electrode by ESD technique. It turns out that the resulting composite exhibited both high energy and high power densities. More importantly, the cycle life can be over 1000 cycles which is promising than most of silicon involving composite electrode. In summary, it was concluded that ESD is a versatile technique that can not only be used to synthesize electrode materials with designed structures and morphologies, but also can easily be employed in fabricating nanocomposite materials. The resulting ESD derived LTO and its nanocomposites electrodes exhibit promising electrochemical performance.

In the last part of this thesis, it presents studies of other electrode materials, such as CNFs \& ACNFs, and MMT clay. The effect of chemical activation process on the electrochemical performance of CNFs from electrospinning have been studied. For MMT clay electrode, we demonstrated for the first time the feasibility of lithium ions to reversibly intercalate/de-intercalate into MMT clay. The importance of interlayer water has also been proved in the study. The advantages of using these materials as anode for LIBS was discussed. 


\subsection{Future Work}

The present dissertation has introduced the application of ESD technique to fabricate various electrode materials with controlled structures and morphologies. The work has been focused on LTO and its nanocomposites to exemplify the merits of using ESD in terms of improving energy density and power density of LTO. Additionally, other different types of materials have also been studied.

In the studies of LTO based electrodes, the success of two proposed strategies to increase its energy density has been illustrated through formation of porous structures and fabrication of nanocomposites. For porous LTO thin film electrode, though the origin of extra capacity compared to theoretical number and the excellent kinetics have been observed and discussed, deeper understanding and direct evidence will be needed to further confirm the mechanism. Additionally, we have proved the energy and power enhancement effect from Si and rGO in ESD-LTO-10Si-5rGO composite, however the composition for each component were not optimized. One of the future research directions could focus on this aspect. For ESD derived electrode materials, though very promising electrochemical performance have been achieved, much effort is still needed to meet the requirements of practical commercial application. For example, issues on how to scale up the fabrication process, how they will perform in a large cell with more active material loading, what their real performance in a practical full cell paring with commercial cathode materials will be, as well as other problems may not be obvious in the coin cell, such as the gassing problem.

In this dissertation, MMT clay as a 2D electrode material has also been studied for the first time. Preliminary results about the influence of interlayer water to electrochemical performance of MMT have been provided. By applying various modification strategies, 
such as delamination/exfoliation of bulk MMT clay, insertion of interlayer spacer (OD nanoparticles, 1D nanotubes/wires and 2D nanosheets), compositing with other electrode materials, the electrochemical performance of MMT could be improved. 


\section{APPENDIX}

\section{Charge Storage Distribution Calculation Based on}

\section{Scan Rate Dependent Cyclic Voltammograms Analysis}

In a battery, although the diffusion controlled charge storage processes are usually of primary interest to be investigated, the effects of the non-diffusion controlled processes need to be taken into account for some cases, such as the study for nanomaterial based electrodes which have unneglectable non-diffusion controlled charge storage contribution. Cyclic voltammetry is one of the most widely used techniques for evaluating electrochemical reactions, proving information on thermodynamics and kinetics of electron transfer reactions, chemical reactions and adsorption processes. In CV curves, there are several important parameters that need to be considered in evaluating a given curve, such as peak current, peak position, half-wave potential, scan rate, voltage window, etc. In this appendix, we will focus on the relationship between current and scan rate for various type of reactions. In an electrochemical cell, diffusion controlled reaction is one of the main reactions that will happen. Based on the reversibility, diffusion controlled reactions can be divided into three categories: (i) reversible, (ii) totally irreversible and (iii) quasi-reversible processes. Besides diffusion controlled reactions, there may exist some other reactions that not controlled by diffusion, including (iv) double layer capacitance and (v) pseudocapacitance. For each different type of charge storage process, the conclusive mathematical equations will be presented. We have more interest and will focus on the assumptions and conditions applied during equation development which may leads to the application limitations of this charge storage distribution calculation. 
Equation A1 represents a chemically reversible system with the forward and reverse electron transfer rate constant $k_{f}$ and $k_{b}$, respectively. $O_{x}$ and $R$ represent oxidant and reductant, respectively [2].

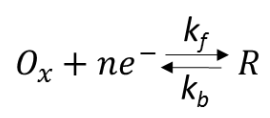

At equilibrium, the $k_{f}$ and $k_{b}$ have same value when the applied potential is equal to the $E^{0}$ (standard potential) of the redox couple. At such case, $k_{f}$ and $k_{b}$ value can also be called the standard rate constant $k_{s}$ with the units of $\mathrm{cm} \mathrm{s}^{-1} . k_{s}$ is a measure of kinetic facility of a redox couple. Large $k_{s}$ value represents that following the application of an applied potential, equilibrium between $O_{x}$ and $R$ can be re-established quickly. The reactions with large $k_{s}$ value is considered as a reversible system. Small $k_{s}$ value represents the slow kinetics and longer time requirement to establish equilibrium. When the $k_{s}$ value is very small or the electrode kinetics are very sluggish, the reactions is considered as totally irreversible systems. Though the reversibility of a system can be determined by the above mentioned $k_{s}$ value, experimentally, the reversibility is also depends on the scan rate employed. In another way, the appearance of reversibility depends on the time window of the experiment. For certain reaction, it would be a reversible system at low scan rate but would change to irreversible system when scan rate increases. Experimentally, the zone boundaries are defined as:

$$
\begin{array}{cr}
\Lambda \geq 15 ; k^{0} \geq 0.3 v^{\frac{1}{2}} \mathrm{~cm} \mathrm{~s}^{-1} & \text { Reversible } \\
15 \geq \Lambda \geq 10^{-2(1+a)} ; 0.3 v^{\frac{1}{2}} \geq k^{0} \geq 2 \times 10^{-5} v^{\frac{1}{2}} \mathrm{~cm} \mathrm{~s}^{-1} & \text { Quasi-reversible } \\
\Lambda \leq 10^{-2(1+a)} ; k^{0} \leq 2 \times 10^{-5} v^{\frac{1}{2}} \mathrm{~cm} \mathrm{~s}^{-1} & \text { Totally irreversible }
\end{array}
$$


The relationships between current and scan rate of various reaction processes have been summarized in Table A1.

Table A 1 Summary of relationships between current and scan rate of various reaction processes.

\begin{tabular}{|c|c|c|c|}
\hline Reaction & $\begin{array}{c}\text { Relationship between Current } \\
\text { and Scan rate } \\
\text { (a) }\end{array}$ & $\begin{array}{c}\text { Assumptions and Boundary } \\
\text { Conditions } \\
\end{array}$ & Ref. \\
\hline $\begin{array}{l}\text { Diffusion } \\
\text { Controlled } \\
\text { Reversible Reaction }\end{array}$ & $\begin{array}{c}i=n F A C_{O}^{*}\left(\pi D_{O} \sigma\right)^{\frac{1}{2}} \chi(\sigma t)^{(\mathrm{b})} \\
i_{p}=0.4463\left(\frac{F^{3}}{R T}\right)^{1 / 2} n^{3 / 2} A D_{O}^{1 / 2} C_{O}^{*} v^{1 / 2}\end{array}$ & $\begin{array}{l}\text { Semi-infinite liner diffusion; } \\
\text { Planar electrode; Solution } \\
\text { initially containing only } \\
\text { species O; Rate of electron } \\
\text { transfer is rapid at the } \\
\text { electrode surface; flux } \\
\text { balance; }\end{array}$ & [2] \\
\hline $\begin{array}{l}\text { Diffusion } \\
\text { Controlled Totally } \\
\text { Irreversible } \\
\text { Reaction }\end{array}$ & $\begin{aligned} i & =F A C_{O}^{*} D_{O} \frac{1}{2} v^{\frac{1}{2}}\left(\frac{a F}{R T}\right)^{\frac{1}{2}} \pi^{\frac{1}{2}} \chi(b t)^{(c)} \\
i_{p} & =\left(2.99 \times 10^{5}\right) a^{1 / 2} A D_{O}^{1 / 2} C_{O}^{*} v^{1 / 2}\end{aligned}$ & $\begin{array}{l}\text { One step, one electron } \\
\text { reaction; Planar electrode; } \\
\text { Semi-infinite liner diffusion; } \\
\text { Solution initially containing } \\
\text { only species } \mathrm{O} \\
k_{f} / k_{b} \approx 0\end{array}$ & [2] \\
\hline $\begin{array}{l}\text { Diffusion } \\
\text { Controlled Quasi- } \\
\text { reversible Reaction }\end{array}$ & $\begin{array}{c}i=F A C_{O}^{*} D_{O}^{\frac{1}{2}} f^{\frac{1}{2}} v^{\frac{1}{2}} \Psi(E)^{(\mathrm{d})} \\
i_{p}=i_{p}(r e v) K(\Lambda, a)^{(\mathrm{e})}\end{array}$ & $\begin{array}{l}\text { One step, one electron } \\
\text { reaction; Planar electrode; } \\
\text { Semi-infinite liner diffusion; } \\
\text { Solution initially containing } \\
\text { only species O; }\end{array}$ & [2] \\
\hline $\begin{array}{l}\text { Double Layer } \\
\text { Capacitance }\end{array}$ & $i_{d l}=v C_{d l} A$ & $\begin{array}{l}\text { The interphasial region } \\
\text { between electrode and ionic } \\
\text { solution is ideally polarizable; } \\
\text { the electrode is in a state of } \\
\text { electrostatic equilibrium; }\end{array}$ & [3] \\
\hline Pseudocapacitance & $i_{p}=\frac{n^{2} F^{2} \Gamma_{0} v}{4 R T}$ & $\begin{array}{l}\text { Planar electrode; kinetics of } \\
\text { the process is sufficiently } \\
\text { facile; monolayer deposition; }\end{array}$ & [3] \\
\hline
\end{tabular}


(a) $i$ is current at any point on $\mathrm{CV}$ curves, $i_{p}$ is the peak current on $\mathrm{CV}$ curves, $v$ is scan rate, $F$ is Faraday constant, $A$ is electrode area, $C_{O}^{*}$ is surface concentration, $D_{O}$ is chemical diffusion coefficient, $n$ is number of electrons transferred in the redox event, $a$ is the transfer coefficient, $C_{d l}$ is double layer capacitance, $\Gamma_{0}$ is surface coverage.

(b) The general results of solving $\chi(\sigma t)$ is a set of values as a function of $\sigma t$ or $n\left(E-E_{1 / 2}\right)$.

(c) $\chi(b t)$ can also be solved as a set of values but different from $\chi(\sigma t)$.

(d) $\Psi(E)=\frac{i}{F A C_{O}^{*} D_{O} \frac{1}{2}}\left(\frac{n F}{R T}\right)^{\frac{1}{2}} v^{\frac{1}{2}}$ and $\Lambda=\frac{k_{S}}{\left(D_{O}^{1-a} D_{R}^{a} f v\right)^{1 / 2}}$

(e) $i_{p}(r e v)$ is the reversible $i_{p}$ value.

From the table it can be seen that for reversible and totally irreversible reactions, the peak current and the current at any other points on the curve are proportional to the square root of the scan rate. But for quasi-reversible reactions, they are not strictly proportional to the square root of the scan rate. However, for both double layer capacitance and pseudocapacitance, the current is proportional to scan rate $v$.

In general, the current in CV curve obeys a power law relationship with scan rate $v$, which can be expressed as in Equation A2 [4]:

$$
i=a v^{b}
$$

Both $a$ and $b$ are adjustable parameters that may vary at different voltages, and $i$ represents the current value of any point on CV curve. There are two well-defined conditions: $b=0.5$ (diffusion controlled current contribution) and $b=1.0$ (non-diffusion controlled current contribution or capacitive contribution). By performing CV analysis at various scan rates, $a$ and $b$ values can be obtained. The $b$ values at different voltage give basic information about whether the current is from diffusion controlled process or non-diffusion controlled 
process. However, it is hard to quantify the contribution from each component based on this equation.
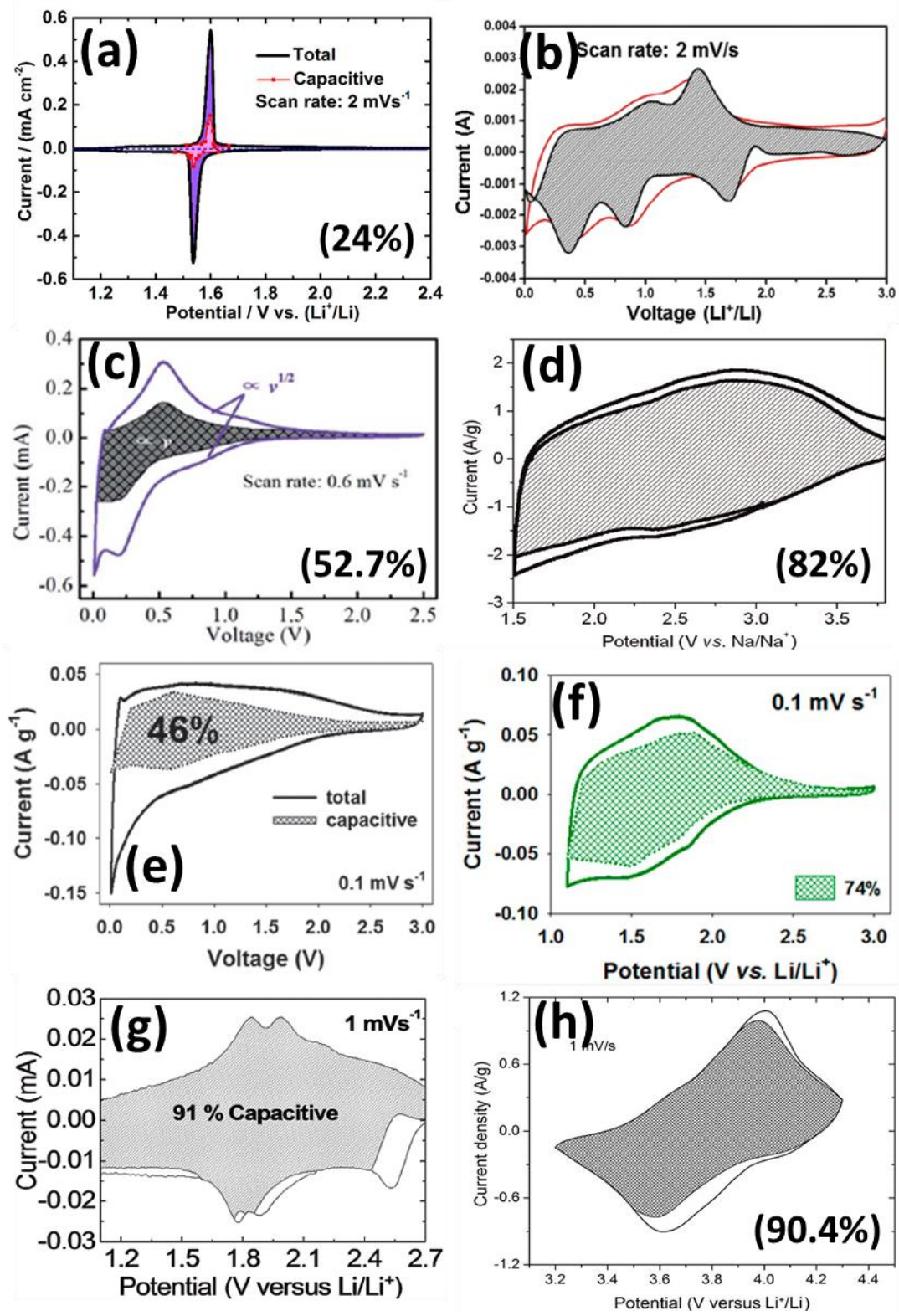

Figure A 1. Capacitive charge storage contribution of different materials at various scan rates. (a) LTO thin film $\left(35 \mathrm{~nm}\right.$ ) electrode at $2 \mathrm{mV} \mathrm{s}^{-1}$ [5]. (b) Graphene oxide wrapped amorphous copper vanadium oxide electrode at $2 \mathrm{mV} \mathrm{s}^{-1}$ [6]. (c) $\mathrm{Na}_{2} \mathrm{Ti}_{3} \mathrm{O}_{7} @ \mathrm{CNTcoaxial}$ nanocables electrode at $0.6 \mathrm{mV} \mathrm{s}^{-1}$ [7]. (d) $\mathrm{V}_{2} \mathrm{O}_{5} / \mathrm{CNT}$ electrode at $10 \mathrm{mV} \mathrm{s}^{-1}$ [8]. (e) In $\mathrm{Nb}_{2} \mathrm{O}_{5} @$ Carbon core-shell nanoparticles and reduced graphene oxide nanocomposites electrode at $0.1 \mathrm{mV} \mathrm{s}^{-1}$ [9]. (f) $\mathrm{Nb}_{2} \mathrm{O}_{5} @ \mathrm{C}$ electrode at $0.1 \mathrm{mV} \mathrm{s}^{-1}$ [10]. (g) Mesoporous $\mathrm{MoS}_{2}$ electrode at $1 \mathrm{mV} \mathrm{s}^{-1}$ [11]. (h) $\mathrm{VOPO}_{4}$ nanosheets electrode at $1 \mathrm{mV} \mathrm{s}^{-1}$ [12]. 
In another way, Equation A2 can also be written as Equation A3 and by applying this equation, it is possible to separate these two types of current contributions in the CV curves [4].

$$
i(V)=k_{1} v+k_{2} v^{1 / 2}
$$

where $k_{1} v$ represents the non-diffusion controlled charge storage and $k_{2} v^{1 / 2}$ represents the diffusion controlled charge storage and and $i$ represents the current value of any point on $\mathrm{CV}$ curve. $k_{1}$ and $k_{2}$ values can be solved by applying various $v$ and $i$ values to equation A3.

The above mentioned method has been widely used for various types of materials in recent research works and the conclusions obtained from such analysis were supported by their other electrochemical analysis, see Figure A1 [5-12].

\section{References}

1. Bandaru, P.R., Yamada, H., Narayanan, R. and Hoefer, M., 2015. Charge transfer and storage in nanostructures. Materials Science and Engineering: R: Reports, 96, pp.1-69.

2. Bard, A.J., Faulkner, L.R., 2001. Electrochemical Methods: Fundamentals and Applications, second edition. John Wiley \& Sons.

3. Conway, B.E., 2013. Electrochemical supercapacitors: scientific fundamentals and technological applications. Springer Science \& Business Media.

4. Augustyn, V., Simon, P. and Dunn, B., 2014. Pseudocapacitive oxide materials for highrate electrochemical energy storage. Energy \& Environmental Science, 7(5), pp.15971614.

5. Yu, P., Li, C. and Guo, X., 2014. Sodium storage and pseudocapacitive charge in textured $\mathrm{Li}_{4} \mathrm{Ti}_{5} \mathrm{O}_{12}$ thin films. The Journal of Physical Chemistry C, 118(20), pp.1061610624.

6. Zhao, K., Liu, F., Niu, C., Xu, W., Dong, Y., Zhang, L., Xie, S., Yan, M., Wei, Q., Zhao, D. and Mai, L., 2015. Graphene Oxide Wrapped Amorphous Copper Vanadium Oxide 
with Enhanced Capacitive Behavior for High-Rate and Long-Life Lithium-Ion Battery Anodes. Advanced Science, 2(12).

7. Dong, S., Shen, L., Li, H., Nie, P., Zhu, Y., Sheng, Q. and Zhang, X., 2015. Pseudocapacitive behaviours of $\mathrm{Na}_{2} \mathrm{Ti}_{3} \mathrm{O}_{7} @$ CNT coaxial nanocables for highperformance sodium-ion capacitors. Journal of Materials Chemistry A, 3(42), pp.2127721283.

8. Chen, Z., Augustyn, V., Jia, X., Xiao, Q., Dunn, B. and Lu, Y., 2012. High-performance sodium-ion pseudocapacitors based on hierarchically porous nanowire composites. ACS nano, 6(5), pp.4319-4327.

9. Lim, E., Jo, C., Kim, M.S., Kim, M.H., Chun, J., Kim, H., Park, J., Roh, K.C., Kang, K., Yoon, S. and Lee, J., 2016. High-Performance Sodium-Ion Hybrid Supercapacitor Based on $\mathrm{Nb}_{2} \mathrm{O}_{5} @$ Carbon Core-Shell Nanoparticles and Reduced Graphene Oxide Nanocomposites. Advanced Functional Materials, 26(21), pp.3711-3719.

10. Lim, E., Jo, C., Kim, H., Kim, M.H., Mun, Y., Chun, J., Ye, Y., Hwang, J., Ha, K.S., Roh, K.C. and Kang, K., 2015. Facile Synthesis of $\mathrm{Nb}_{2} \mathrm{O}_{5} @$ Carbon Core-Shell Nanocrystals with Controlled Crystalline Structure for High-Power Anodes in Hybrid Supercapacitors. ACS nano, 9(7), pp.7497-7505.

11. Cook, J.B., Kim, H.S., Yan, Y., Ko, J.S., Robbennolt, S., Dunn, B. and Tolbert, S.H., 2016. Mesoporous $\mathrm{MoS}_{2}$ as a Transition Metal Dichalcogenide Exhibiting Pseudocapacitive Li and Na-Ion Charge Storage. Advanced Energy Materials.

12. Zhu, Y., Peng, L., Chen, D. and Yu, G., 2015. Intercalation Pseudocapacitance in Ultrathin $\mathrm{VOPO}_{4}$ Nanosheets: Toward High-Rate Alkali-Ion-Based Electrochemical Energy Storage. Nano letters, 16(1), pp.742-747. 
VITA

\section{CHUNHUI CHEN}

2004-2008

B.A., Material Chemistry

Central South University (CSU), Changsha, China

2008-2009

Research Assistant

State Key Laboratory for Powder Metallurgy, CSU

2009-2013

M.S., Materials Science and Engineering

Florida International University, Miami, FL, USA

2013-2016

Doctoral Candidate (PhD)

Florida International University, Miami, FL, USA

PUBLICATIONS AND PRESENTATIONS

1. Chunhui Chen, Richa Agrawal and Chunlei Wang (2015). Nanomaterials 2015(5):14691480. DOI: 10.3390/nano5031469.

2. Richa Agrawal, Yong Hao, Yin Song, Chunhui Chen, Chunlei Wang (2015). Proc. SPIE 9493, Energy Harvesting and Storage: Materials, Devices, and Applications VI, 94930B; DOI:10.1117/12.2180124;

3. D. S. Gardner, C. W. Holzwarth III, Y. Liu, S. B. Clendenning, W. Jin, B. K. Moon, C. Pint, Z. Chen, E. Hannah, R. Chen, C. P. Wang, Chunhui Chen, Ermei Mäkilä, and J.L. Gustafson (2015). Devices Meeting (IEDM), 2014 IEEE International, Page(s): 8.2.18.2.4. DOI: 10.1109/IEDM.2014.7047009.

4. Yin Song, Chunhui Chen and Chunlei Wang (2015). Nanoscale 7.16 (2015): 7084-7090. DOI: 10.1039/C4NR06856D.

5. Jun Wu, Chunhui Chen, Yong Hao and Chunlei Wang (2015). Colloids and Surfaces A: Physicochem. Eng. Aspects 468 (2015) 17-21. DOI:10.1016/j.colsurfa.2014.12.009.

6. Chunhui Chen, R. Agrawal, T. K. Kim, X. Li, W. Chen, Y. Yan, M. Beidaghi, V. Penmatsa and C. Wang (2014). ECS Trans. 2014 61(27): 155-163. DOI:10.1149/06127.0155ecst

7. Yin Song, Richa Agrawal, Yong Hao, Chunhui Chen, and Chunlei Wang (2014). ECS Transactions, 61(2014) 55-64. DOI:10.1149/06107.0055ecst.

8. Abirami Dhanabalan, Xifei Li, Richa Agrawal, Chunhui Chen and Chunlei Wang (2013). Nanomaterials 2013, 3(4), 606-614. DOI: 10.3390/nano3040606.

9. Chunhui Chen, Richa Agrawal, Yong Hao and Chunlei Wang (2013). ECS Journal of Solid State Science and Technology, 2 (10), (2013), M3074-M3077. DOI:10.1149/2.011310jss.

10. Wei Chen; Nan Jiang; Zhongli Fan; Abirami Dhanabalan; Chunhui Chen; Yunjun Li; Mohshi Yang; Chunlei Wang (2012). J. Power Source, 214(2012)21-27. DOI: 10.1016/j.jpowsour.2012.04.047. 
11. Wei Chen, Zhongli Fan, Abirami Dhanabalan, Chunhui Chen, Chunlei Wang (2011). Journal of Electrochemical Society. 158 (9) (2011) A1055-A1059. DOI: 10.1149/1.3611433.

12. Tae Kwon Kim, Chunhui Chen, Abirami Dhanabalan and Chunlei Wang (2011). ECS transactions, vol 35(34) (2011) 159-165. DOI: 10.1149/1.3654214.

13. Taekwon Kim, Wei Chen, Chunhui Chen, Chunlei Wang (2011). MRS Proceedings, 1333, mrss11-1333-m06-23. DOI:10.1557/opl.2011.1066.

14. D. S. Gardner, C. W. Holzwarth III, Y. Liu, S. B. Clendenning, W. Jin, B. K. Moon, C. Pint, Z. Chen, E. Hannah, R. Chen, C. P. Wang, Chunhui Chen, Ermei Mäkilä, and J.L. Gustafson, Nano Energy 25 (2016) 68-79. DOI:10.1016/j.nanoen.2016.04.016.

15. Chunhui Chen, Perdomo Pedro J., Melisa Fernandez, Andres Barbeito and Chunlei Wang, Porous $\mathrm{NiO} /$ graphene composite thin films as high performance anodes for lithium-ion batteries. Submitted to Journal of energy storage, under revision.

16. Yong Hao, Chunhui Chen, Xinyi Yang, Guanjun Xiao, Bo Zou, Jianwen Yang and Chunlei Wang. Studies on intrinsic phase-dependent electrochemical properties of MnS nanocrystals as anodes for lithium-ion batteries. Submitted to Journal of Power Sources.

17. Jujun Yuan, Chunhui Chen, Yong Hao, Xianke Zhang, Richa Agrawal, Chunlei Wang, Huanjun Yu, Xiurong Zhu, Yi Yu, Zuzhou Xiong, Ying Luo, Yingmao Xie. Synthesis of three-dimensionally porous $\mathrm{ZnMn}_{2} \mathrm{O}_{4}$ thin films for lithium-ion battery anodes by electrostatic spray deposition technique. Submitted to Electrochimica Acta.

18. Jujun Yuan, Chunhui Chen, Yong Hao, Xianke Zhang, Bo Zou, Richa Agrawal, Chunlei Wang, Huanjun Yu, Xiurong Zhu, Yi Yu, Zuzhou Xiong, Yingmao Xie. $\mathrm{SnO}_{2}$ /polypyrrole hollow spheres with improved cycle stability as lithium-ion battery anodes. Submitted to Journal of Alloys and Compounds, under revision.

19. Xifei Li, Wei Chen, Abirami Dhanabalan, Chunhui Chen, and Chunlei Wang. Editors: Ramesh S. Chaughule and R.V. Ramanujan, 2012 by American Scientific Publishers, ISBN: 1-58883-181-7.

20. Richa Agrawal, Chunhui Chen, Yong Hao, Yin Song, and Chunlei Wang. Editor: Rashid bin Mohd Yusoff, John Wiley \& Sons, Inc., 2015. DOI: 10.1002/9783527690312.ch6. ISBN: 978-3-527-33806-1.

21. Chunhui Chen and Chunlei Wang. High performance $\mathrm{Li}_{4} \mathrm{Ti}_{5} \mathrm{O}_{12}$ based composite electrodes for Li-ion batteries. March 2014.

22. Chunhui Chen, Yanzhang Ma and Chunlei Wang. Green electrode materials based on montmorillonite clay for energy storage applications. December 2014.

23. Chunhui Chen and Chunlei Wang. 2015 SPIE defense Security and Sensing (DDS) meeting, Baltimore, Maryland, USA, April 17-21, 2016 (talk).

24. Chunhui Chen, Perdomo, Pedro J., Melisa Fernandez, Andres Barbeito, Richa Agrawal, Yong Hao and Chunlei Wang. 227th ECS Meeting, Chicago May 24-28, 2015 (talk).

25. Chunhui Chen, Gautam Shah and Chunlei Wang. 227th ECS Meeting, Chicago May 24-28, 2015 (talk).

26. Chunhui Chen and Chunlei Wang. 225th ECS meeting, Orlando, May 11-15, 2014 (talk).

27. Chunhui Chen, Xifei Li, Wei Chen, and Chunlei Wang. $219^{\text {th }}$ ECS meeting, Montreal, Canada, May 1-6, 2011(talk).

(In total 39 presentations at International Conferences) 